\title{
EFFECT OF STARTER CULTURES ON LACTOBACILLUS ACIDOPHILUS SURVIVAL AND GENE EXPRESSION IN YOGURT
}

\author{
A Thesis \\ presented to \\ the Faculty of California Polytechnic State University, \\ San Luis Obispo
}

\begin{abstract}
In Partial Fulfillment
of the Requirements for the Degree

Master of Science in Agriculture, with Specialization in Dairy Products Technology
\end{abstract}

By

Elizabeth Wei-Yin Ng

May 2009 
(c)2009

Elizabeth Wei-Yin Ng

ALL RIGHT RESERVED 


\section{COMMITTEE MEMBERSHIP}

TITLE:

EFEECT OF STARTER CULTURE ON

LACTOBACILLUS ACIDOPHILUS SURVIVAL AND

GENE EXPRESSION IN YOGURT

AUTHOR:

ELIZABETH WEI-YIN NG

DATE SUBMITTED: $\quad$ May, 2009

COMMITTEE CHAIR: Phillip S. Tong, Ph. D., Professor

COMMITTEE MEMBER: Po Sai Marie Yeung, Ph. D., Assistant Professor

COMMITTEE MEMBER: Anya Goodman, Ph. D., Assistant Professor 


\begin{abstract}
The Effect of Starter Culture on Lactobacillus acidophilus Survival and Gene

Expression in Yogurt

Elizabeth Wei-Yin Ng
\end{abstract}

Probiotics, especially Lactobacillus acidophilus, strains have increasingly been incorporated into food products as dietary adjuncts due to their purported health benefits. Dairy products, especially yogurt, are frequently used as probiotic delivery systems. To realize therapeutic effects, it is important to consume a high amount of probiotics. However, maintaining a sufficient amount of viable probiotics in yogurt throughout the shelf life has been a challenge as starter cultures have shown to possess some deleterious effects on probiotic survival. The main objective of this thesis project was to determine the extent of antagonistic effects imposed by yogurt starter cultures (Lactobacillus delbrueckii ssp. bulgaricus and Streptococcus thermophilus) and their metabolic products on the survival of five different $L$. acidophilus strains designated as ATCC700396, LA-5, NCFM, PIM703 and SBT2062. These probiotic strains were incorporated as adjuncts in yogurts, which were made with and without starter cultures. To simulate $\mathrm{pH}$ reduction in regular yogurt, yogurt without starter cultures was manufactured by adding an acidulant (glucono-delta-lactone). The $\mathrm{pH}$ of both yogurts was approximately 4.6 throughout the 28-day storage period at $4^{\circ} \mathrm{C}$. Viable cell counts of the probiotic strains were enumerated weekly on a selective medium (MRS-maltose agar). While cell count of L. acidophilus PIM703 and SBT2062 remained steady ( $\left.\sim 6 \times 10^{7} \mathrm{CFU} / \mathrm{g}\right)$ in yogurt with starter cultures during storage period, the survival of ATCC700396 and NCFM was reduced significantly $(p<0.05)$ by 3 log and 4.6 log, respectively. In contrast, in yogurt without starter cultures, all L. acidophilus strains survived well with a 
maximum of 1-log reduction. Our results indicated that while the presence of starter cultures (especially L. delbrueckii ssp. bulgaricus) had a negative effect on the survival of some probiotic strains, low $\mathrm{pH}$ was not an important factor impairing their viable cell counts.

In addition to survival studies, gene expression of selected stress genes (dnaK and $g r o E L$ ) was determined using semi-quantitative reverse-transcription polymerase chain reaction (RT-PCR) method. This preliminary study demonstrated the important of dnaK in L. acidophilus NCFM to maintain its viability under various stress in yogurt during refrigerated storage period. These studies underscore the selection criteria of probiotic strains in fermented food should include their abilities to coexist with the starter cultures. Our future work is to provide a better understanding of strain differences in survival of probiotics in yogurt.

Keywords: Survival, probiotic, Lactobacillus acidophilus, yogurt, starter cultures 


\section{ACKNOWLEDGEMENTS}

I would like to thank Dr. Phillip Tong and Dr. Marie Yeung for their great support and guidance from the beginning through the research now completed. You have taught me so much to grow as a better scientist. Also, thank you to Dr. Anya Goodman for her great advice.

I would like to thank all staff and students at the Dairy Products Technology Center for their help and support.

I also want to thank my grandmother, parents and aunts for the great encouragement while completing this research. 
TABLE OF CONTENTS

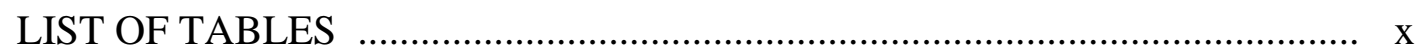

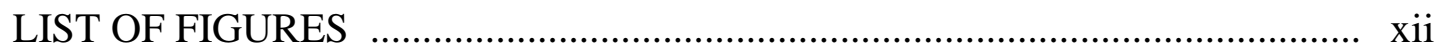

\section{CHAPTER}

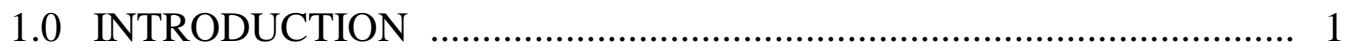

2.0 LITERATURE REVIEW ......................................................... 3

2.1 History and Definition of Probiotics ........................................ 3

2.2 Probiotic Selection Criteria and Their Potential Health Benefits .. 6

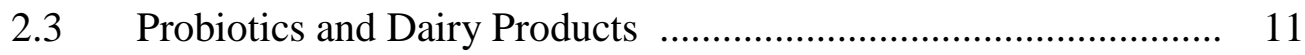

2.4 Factors Affecting the Survival of Probiotics f.............................. 12

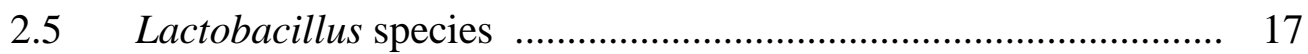

2.6 Molecular Aspects of Probiotics ............................................. 20

2.6.1 Genome of Lactobacillus acidophilus ........................... 20

2.6.2 Stress Reponses ...................................................... 21

2.6.3 Gene Expression Analysis with RT-PCR ........................ 24

$2.7 \quad$ Hypotheses and Objectives f...................................................... 26

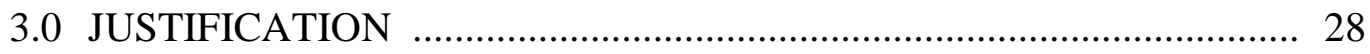

4.0 MATERIALS AND METHODS …..................................................... 31

4.1 Bacterial Strains, Propagation and Storage ................................ 31

4.2 Bacterial Species Identification ….............................................. 33

4.3 Selective Media for Lactobacillus acidophilus ............................ 33

4.4 Enumeration of L. acidophilus _............................................... 34

4.5 Agar Diffusion Assay .............................................................. 35 
4.6 Survival Assays of L. acidophilus ............................................. 36

4.6.1 Effect of Yogurt Starter Cultures ................................... 36

4.6.2 Effect of Yogurt Filtrate …............................................ 38

4.6.3 Effect of Killed Starter Cultures ....................................... 39

4.6.4 Effect of Individual Starter Culture Species ...................... 39

4.6.5 Survival of Probiotics in Soy Milk and Milk ..................... 41

4.6.6 $\mathrm{pH}$ Measurement ......................................................... 41

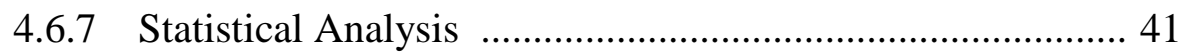

4.7 Gene Expression Study in L. acidophilus .................................. 42

4.7.1 Stress Genes and Primer Design .................................... 42

4.7.2 Total RNA Extraction ..................................................... 43

4.7.3 Reverse Transcription-Polymerase Chain Reaction ......... 46

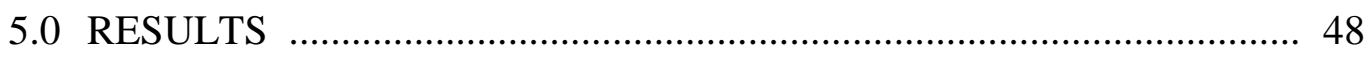

5.1 Identification of Bacterial Species …........................................ 48

$5.2 \quad$ Selective Media for $L$. acidophilus ............................................. 49

5.3 Determination of Survival of L. acidophilus .............................. 49

5.3.1 Effect of Yogurt Starter Cultures ................................... 49

5.3.2 Effect of Yogurt Filtrate .............................................. 53

5.3.3 Effect of Killed Starter Cultures ....................................... 55

5.3.4 Effect of Individual Starter Culture Species ..................... 57

5.3.5 Probiotics of L. acidophilus in Soy Milk and Milk ........... 59

5.4 Agar Diffusion Assay ............................................................ 61

5.5 Expression of Stress Genes in L. acidophilus ............................ 62

5.5.1 Species-Specific Primers ................................................. 62

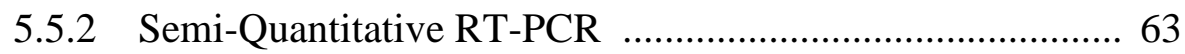




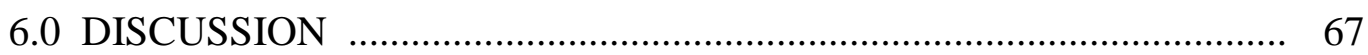

6.1 Bacterial Identification ........................................................... 67

6.2 Survival of L. acidophilus _................................................. 68

6.3 Expression of stress genes in L. acidophilus .............................. 73

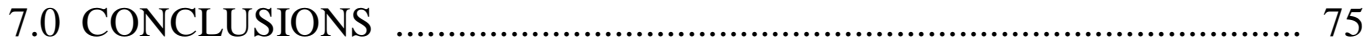

8.0 FUTURE RESEARCH DIRECTIONS .............................................. 77

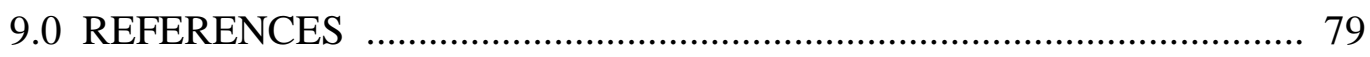

\section{APPENDICES}

A Carbohydrate Fermentation Profile after $24 \mathrm{~h}$ using API $50 \mathrm{CH} \quad$.............. 94

B Carbohydrate Fermentation Profile after $48 \mathrm{~h}$ using API $50 \mathrm{CH}$.............. 96

C Carbohydrate Fermentation Profile after 72 h using API $50 \mathrm{CH}$.............. 97

D Statistical Results of Survival of L. acidophilus Using Minitab Software

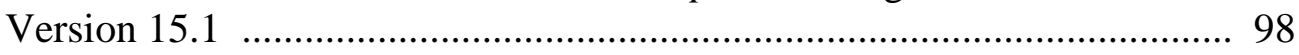




\section{LIST OF TABLES}

Table Page

2.1 Cited definitions and descriptions of probiotics over the past 50 years $\quad \ldots . .5$

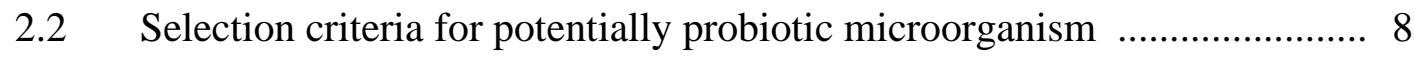

2.3 Probiotic strains with peer review published evidence from clinical studies

2.4 Summary of different factors affecting the viability of probiotics 14

2.5 Examples of some Lactobacillus strains used in commercial applications 18

2.6 Selective media for the enumeration of L. acidophilus, S. thermophilus and L. delbrueckii ssp. bulgaricus from yogurts 20

4.1 Ingredients of MRS agar without dextrose per 1 liter 34

4.2 Experimental design (effect of starter culture) factor and response variables

4.3 Amount of yogurt filtrate added into L. acidophilus NCFM 38

4.4 Experimental design (effect of individual starter culture species) factor and response variables

4.5 Experimental design (gene expression) factor and response variables ...... 42

4.6 Sequences of primer sets for L. acidophilus ......................................... 43

5.1 Speciation results obtained from carbohydrate fermentation tests ........... 48

5.2 Viable cell count of L. acidophilus strains in yogurt made with GDL during 28 days of storage period at $4^{\circ} \mathrm{C}$

5.3 Viable cell count of L. acidophilus strains in yogurt made with starter cultures during 28 days of storage period at $4{ }^{\circ} \mathrm{C}$

5.4 Viable cell count of L. acidophilus NCFM in MRS broth containing various amounts of yogurt filtrate during 15 days of storage period at $4^{\circ} \mathrm{C} 54$

5.5 Viable cell count (CFU/g) of L. acidophilus strains (NCFM and SBT2062) in pasteurized yogurt during 15 days of storage period at $4^{\circ} \mathrm{C}$

5.6 Viable cell count (CFU/g) of L. acidophilus strains (NCFM and SBT2062) in yogurt with $L$. delbrueckii ssp. bulgaricus or S. thermophilus during 28 days of storage period at $4^{\circ} \mathrm{C}$ 
5.7 Viable cell count (CFU/mL) of L. acidophilus strains in milk during 28 days of storage period at $4^{\circ} \mathrm{C}$

5.8 Viable cell count (CFU/mL) of L. acidophilus strains in soymilk during 28 days of storage period at $4^{\circ} \mathrm{C}$

5.9 Average adjusted volume comparison of dnaK gene from Lactobacillus acidophilus NCFM and SBT2062 in yogurt after 14 days of refrigerated storage period at $4^{\circ} \mathrm{C}$ 


\section{LIST OF FIGURES}

Figure Page

4.1 Agar diffusion assay using MRS agar spotted with overnight starter cultures

4.2 Outline of yogurt production with and without starter culture fermentation 37

4.3 Outline of yogurt production with individual starter culture species 40

5.1 Relative survival of five different L. acidophilus strains in yogurt made with GDL during 28 days of storage period at $4^{\circ} \mathrm{C}$ 52

5.2 Relative Survival of five different L. acidophilus strains in yogurt made with starter cultures during 28 days of storage period at $4^{\circ} \mathrm{C}$ 53

5.3 Relative survival of L. acidophilus NCFM in MRS broth containing various amounts of yogurt filtrate during 15 days of storage period at $4^{\circ} \mathrm{C} 55$

5.4 Relative survival of L. acidophilus NCFM and SBT2062 in pasteurized yogurts made with GDL or starter cultures during15 days of storage period at $4^{\circ} \mathrm{C}$

5.5 Relative survival of L. acidophilus NCFM and SBT2062 in yogurt made with individual starter culture species (S. thermophilus or L. delbrueckii ssp. bulgaricus) during 28 days of storage period at $4^{\circ} \mathrm{C}$

5.6 Relative survival of L. acidophilus strains in milk during 28 days of storage period at $4^{\circ} \mathrm{C}$

5.7 Relative survival of L. acidophilus strains in soymilk during 28 days of storage period at $4^{\circ} \mathrm{C}$

5.8 Agar diffusion assay on MRS agar spotted with starter cultures using L. acidophilus NCFM as an indicator

5.9 A 1.5\% agarose gel of PCR products using species-specific primers to stress genes (dnakK, dnaJ, grpE and groES, hrcA, gadC and groEL)

5.10 A 1.5\% agarose gel of PCR products of dnaK, groEL and 16S rRNA genes

5.11 Average adjusted volume (intensity* $\mathrm{mm}^{2}$ ) comparison of dnaK gene from Lactobacillus acidophilus NCFM and SBT2062 in yogurt during 14 days of storage period at $4^{\circ} \mathrm{C}$ 


\section{0}

\section{INTRODUCTION}

In recent years foods that can be shown to provide health benefits have attracted consumer interest. These foods should also fit into current lifestyles, such as good flavor and convenience with an acceptable price. Such products are commonly referred to probiotic-containing products, especially yogurt. The worldwide consumption of yogurt has been increasing, and this is predominantly due to the unique flavor, great nutritional sources, and health benefits (from probiotics) (Chandan, 1999; Sanders, 1998). Probiotics are defined as "live microorganisms which when administered in adequate amounts confer a health benefit on the host" (FAO/WHO, 2001). The health benefits of consuming probiotics have been demonstrated in the number of scientific publications, including antimicrobial production (Olivares et al., 2005; Shah, 1999), immune system modulation (Schlee, et al., 2008), inhibition of Helicobacter pylori (Aiba et al., 1998; Gotteland and Cruchet, 2003), improvement of lactose intolerance (de Vrese et al., 2001; Montes et al., 1995), cholesterol assimilation (Liong and Shah, 2005; Walker and Gilliland, 1993), prevention of autoimmunity (Bolton et al., 2008), and antimutagenic properties (Choi et al., 2005; Lankaputhra and Shah, 1998). However, these therapeutic effects are believed to be strain specific. Thus, clinical experiments studied from one strain should not be expected in other strains even from the same genus or species.

One of the most important characteristics of a probiotic strain is that it must be non-pathogenic. Also, they should exhibit some desirable properties, such as maintaining its viability during the manufacture and storage, and resistance to the physico-chemical processing of the food product. Because efficacy of probiotics is directly related to the 
number of live and active culture cells ingested, it is important to perpetuate high numbers of the microorganisms during processing, storage and host ingestion. A minimum dose of greater than $10^{8}$ viable probiotic cells has often been suggested for daily ingestion to realize the desired health benefits (Parvez et al., 2006). To date, maintaining a sufficient amount of probiotics during processing and shelf-life of the product is a primary challenge for industries and scientists. Regardless of the viability of probiotics, molecular analysis, such as gene expression, has also become a key tool in probiotic research by identifying the beneficial microorganisms in the gastrointestinal tract and unraveling their specific characteristics. Taken all together, we will propose shelf-life studies and gene expression studies based upon survival of L. acidophilus in yogurt. This may provide a better understanding of the relationship between survival of L. acidophilus and any possible negative impacts from yogurt starter cultures. 


\section{0}

\section{LITERATURE REVIEW}

Consumption of fermented dairy products, especially yogurt, is rapidly growing. In addition to the nutritional value of these products, health benefits associated from the probiotics that are commonly used in these products, drive consumers' demand. Typical yogurt in the US is mainly fermented by two different species of bacteria (Lactobacillus delbrueckii ssp. bulgaricus and Streptococcus thermophilus), and sometimes probiotics (L. acidophilus in particular) are added as adjuncts due to their potential therapeutic effects on human. This chapter will provide background information regarding probiotics, their purported health benefits and their physiological characteristics (such as survivability) in dairy foods. Some perspectives on the molecular responses to stress will also be discussed near the end of this chapter.

\subsection{History and Definition of Probiotics}

The concept of “probiotics” was first realized in the early 1900s by a Nobel Prize winning scientist, Elie Metchnikoff, who observed that Bulgarian peasants' average life expectancy greatly exceeded that of the general population. He associated their longevity to the frequent consumption of fermented milks, and he hypothesized that fermented milks contained beneficial bacteria, which could potentially replace harmful microorganisms in human bodies (Heller, 2001; Del Piano et al., 2006). Thereafter, Metchnikoff developed Bulgarian yogurt, which was fermented by the bacterium that he called "Bulgarian bacillus” or "Lactobacillus bulgaricus” (Vasiljevic and Shah, 2008). In fact, this microorganism was previously isolated from "podkvassa" (a starter for the 
production of Bulgarian sour milk) by a Bulgarian physician named Stamen Grigoroff. During this time, Grigoroff also identified Streptococcus thermophilus. However, this microorganismdid not receive much attention because it was considered a pathogen. Therefore, Metchnikoff's work was based on L. bulgaricus, and many of his experiments convinced his belief that this microorganism improved immune system and digestion. (Anukam and Reid, 2007). L. bulgaricus is now commonly used as one of the starter cultures for commercial yogurt in the US. After conducting many experiments, Metchnikoff proposed that proliferation of enteric pathogens and their toxins had deleterious effects on human health. However, these impacts could be prevented or reduced by lactic acid-producing bacteria, mainly lactobacilli, commonly found in fermented milk. Since then, his discovery and assertion have stimulated scientific discussion on the association between human health and microorganisms. More recently, the food and dairy industries have shown great interest in adding probiotics to a variety of products and marketing them as functional foods. High consumer demand has also driven the increased production of these foods.

The word "probiotics" comes from two Greek words ( $\pi \rho 0$ and $\beta 10 \tau \circ \sigma)$ meaning "for life" (Hamilton-Miller et al., 2003), and was initially used as an antonym of the word "antibiotic". The first description of probiotics was proposed by Kollath in 1953. He defined "probiotics are common in vegetable food as vitamins, aromatic substances, enzymes and possibly other substances connected with vital process”. Later, many other definitions had been proposed over time (Table 2.1), and the most recent one was proposed by the Food and Agriculture Organization of the United Nations/the World Health Organization (FAO/WHO) working group (2001), which defined "probiotics" as 
"live microorganisms which when administered in adequate amounts confer a health benefit on the host”. This definition implies that sufficient amounts of viable probiotic cells should be ingested at the time of consumption to exert the desirable effects.

Table 2.1. Cited definitions and descriptions of probiotics over the past 50 years

\begin{tabular}{|c|c|}
\hline Definition and Description & Reference \\
\hline $\begin{array}{l}\text { Probiotics are common in vegetable food as vitamins, aromatic substances, enzymes and } \\
\text { possibly other substances connected with vital process }\end{array}$ & Kollath, 1953 \\
\hline Probiotics are opposite of antibiotics & Vergin, 1954 \\
\hline Deleterious effects of antibiotics can be prevented by probiotic therapy & Kolb, 1955 \\
\hline $\begin{array}{l}\text { Substances produced by microorganisms (this is interesting...the "substances" refer to } \\
\text { metabolites instead of actual cells) which promote the growth of other microorganisms }\end{array}$ & $\begin{array}{l}\text { Lilly and Stillwell } \\
1965\end{array}$ \\
\hline $\begin{array}{l}\text { Compounds that build resistance to infection in the host but do not inhibit the growth of } \\
\text { microorganisms in vitro }\end{array}$ & $\begin{array}{l}\text { Fujii and Cook, } \\
1973\end{array}$ \\
\hline Organisms and substances which contribute to intestinal microbial balance & Parker, 1974 \\
\hline $\begin{array}{l}\text { A live microbial feed supplement which beneficially affects the host animal by improving } \\
\text { its intestinal microbial balance }\end{array}$ & Fuller, 1989 \\
\hline $\begin{array}{l}\text { A viable mono- or mixed-culture of microorganisms which applied to animal or man, } \\
\text { beneficially affects the host by improving the properties of the indigenous microflora }\end{array}$ & $\begin{array}{l}\text { Havenaar and } \\
\text { Huis in't Veld, } \\
1992\end{array}$ \\
\hline $\begin{array}{l}\text { Live microbial culture or cultured dairy product which beneficially influences the health and } \\
\text { nutrition of the host }\end{array}$ & Salminen, 1996 \\
\hline $\begin{array}{l}\text { Living microorganisms, which upon ingestion in certain numbers, exert health benefits } \\
\text { beyond inherent basic nutrition }\end{array}$ & Schaafsma, 1996 \\
\hline $\begin{array}{l}\text { A microbial dietary adjuvant that beneficially affects the host physiology by modulating } \\
\text { mucosal and systemic immunity, as well as improving nutritional and microbial balance in } \\
\text { the intestinal tract }\end{array}$ & Naidu et al. 1999 \\
\hline $\begin{array}{l}\text { Microbial cell preparations or compounds of microbial cells that have a beneficial effect of } \\
\text { the health and well-being of the host }\end{array}$ & $\begin{array}{l}\text { Salminen et al., } \\
1999\end{array}$ \\
\hline $\begin{array}{l}\text { A preparation of or a product containing viable, defined microorganisms in sufficient } \\
\text { numbers, which alter the microflora (by implantation or colonization) in a compartment of } \\
\text { the host and by that exert beneficial health effects in this host }\end{array}$ & $\begin{array}{l}\text { Schrezenmeir and } \\
\text { de Vrese, } 2001\end{array}$ \\
\hline $\begin{array}{l}\text { Live microorganisms which when administered in adequate amounts confer a health benefit } \\
\text { on the host }\end{array}$ & $\begin{array}{l}\text { FAO/WHO report, } \\
2001\end{array}$ \\
\hline
\end{tabular}

Source: Adapted from Sanders, 2008;Vasiljevic and Shah, 2008 


\subsection{Probiotic Selection Criteria and Their Potential Health Benefits}

In order to capitalize most desired health benefits, which require their activities, probiotics should survive and grow in sufficient numbers when reached the gastrointestinal tract. Numerous selection criteria have been recommended (Reid, 1999); among them several key criteria (Table 2.2), including safety, origin of isolation, survival and stability of probiotics in the product during storage, resistance to gastric juice and bile toxicity, adhesion to gut epithelial cells, specifically pertain probiotic food applications (Charteris et al. 1998; Chandan, 2006; Vasiljevic and Shah, 2008). One of the most important characteristics of a probiotic strains is that it must be non-pathogenic to the host. Members of the genera Lactobacillus and Bifidobacterium are mainly used as probiotics.This is due to their long and safe history, and their ubiquitous nature in many mammalian gastrointestinal environments(Adams and Marteau, 1995; Kailasapathy and Chin, 2000; Percival, 1997; Salminen et al., 1998). On very rare occasions, there have been reports of infections linked to the consumption of commercial probiotics fermented products by individuals who are immunocompromised or have underlying medical conditions such as patients with HIV infection, bacteremia or endocarditis (Borriello et al., 2003). These immunocompromised patients generally are more vulnerable to infection with pathogens and have higher incidence of opportunistic infections. Moreover, there is no evidence that consumption of probiotics alone increases the risk of opportunistic infections in these patients. Therefore,the probiotic used are not necessarily related (Cannon et al., 2005; Mackey et al., 1999; Rautio et al., 1999).

It is suggested that probiotics should be of human origin if humans are the host because some health benefits might be host-specific (Lee and Salminen, 1995; Chandan, 
1999). Thus, taxonomic classification of probiotic is thought to be an important criterion. The taxonomic analyses should provide information on the origin and normal habitat of the probiotic strain. However, the idea of human origin has recently been challenged by two arguments: 1) Human infants are born with virtually sterile gastrointestinal tract (FAO/WHO, 2001). The development of microflora varies among individuals and therefore there is no clear consensus on the origin of human microflora; 2) Increasing number of studies support the notion that the beneficial effects are strain-dependent. Therefore, species thought to be originated from human origin do not necessary confer the same effect to the host (FAO/WHO, 2001; Morelli, 2007; Playne,et al., 2003; Sanders et al., 1996).

Some probiotic characteristics such as the ability to attach and interact with the intestinal epithelial cells are considered essential for probiotic selection. It is generally believed that adhesion of probiotic strains to mucosal surfaces contributes to their efficacies, since adherent strains likely have a competitive advantage against normal microflora community in the gastrointestinal tract (Parvez et al., 2006). When probiotics block the microbial attachment sites in human guts, they may prevent infections caused by intestinal pathogens from daily food consumption (Tamime, 2005). Probiotics may render the intestinal milieu unfavorable to pathogens through the production of lactic acid and volatile short-chain fatty acids (acetates, propionates and butyrates) upon fermentation, which subsequently leads to a decrease in colonic pH. Probiotics may also produce other substances (such as hydrogen peroxide and bacteriocins) that are inhibitory to potential enteric pathogens. 
Table 2.2.Selection criteria for potentially probiotic microorganism

\begin{tabular}{|c|c|}
\hline Group & Criterion $^{1}$ \\
\hline Technology & $\begin{array}{l}\text { Inexpensive cultivation } \\
\text { Ease of concentration to high cell density } \\
\text { Freeze drying stability (with cryoprotection) } \\
\text { Process application robustness } \\
\text { Product application robustness } \\
\text { Genetically stable strains } \\
\text { Phage resistance } \\
\text { Good sensory properties (food application) } \\
\text { Large scale production }\end{array}$ \\
\hline $\begin{array}{l}\text { Medical - scientific } \\
\text { (in vitro selectable) }\end{array}$ & $\begin{array}{l}\text { Genera of human origin } \\
\text { Nontoxic and nonpathogenic } \\
\text { Viability at high populations, preferably at least } 10^{6} \\
-10^{8} \text { cfu/g or mL } \\
\text { Demonstrable efficacy } \\
\text { Ability to withstand technological processes } \\
\text { Ability to remain viable throughout the shelf life } \\
\text { Antagonistic toward pathogenic bacteria } \\
\text { Gastric transit tolerance } \\
\text { Small intestinal transit tolerance } \\
\text { Bile salt tolerance } \\
\text { Epithelial adhesion and growth } \\
\text { Antimicrobial production and susceptibility }\end{array}$ \\
\hline $\begin{array}{l}\text { Medical - scientific } \\
\text { (in vivo selectable) }\end{array}$ & $\begin{array}{l}\text { Amelioration of lactose maldigestion } \\
\text { Stimulation of the immune system } \\
\text { Diminution of cardiovascular disease risk }\end{array}$ \\
\hline
\end{tabular}

${ }^{1}$ Adapted from Charteris et al. 1998; Chandan, 2006; Vasiljevic and Shah, 2008

When the epithelial cells or normal microflora of the intestines become damaged or disturbed as a results of infection or irritation, altered gut permeability and inflammation may occur (Vaughan and Mollet, 1999). As mentioned above, probiotics have the potential to prevent and/or reduce infection associated with enteric pathogens. Nevertheless, in order to attach to and colonize on epithelial cells, probiotics must survive through gastrointestinal tract after ingestion. Two main challenging factors for probiotics during transit are an extremely low $\mathrm{pH}$ in the stomach and high concentration 
of bile salt in the intestine. Therefore, acid tolerance and bile salt resistance are desirable probiotic characteristics (Sanders et al., 1996; Chandan, 1999).

Rational selection and validation of promising probiotic candidates should be based on experimental evidence in well-designed experiments. A comprehensive evaluation should include in vitro data (Reid, 2005) and in vivo determination using animal models such as mice or pigs, and eventually in clinical studies (Holzapfel et al., 1998). As mentioned previously, a desirable probiotic strain that survive acid and bile must possess a variety of other properties, including the ability to adhere to intestinal epithelial cells, colonize the gastrointestinal tract, produce antimicrobial factors, and inhibit the growth and attachment of enteric pathogens. Additional desirable traits include stimulating and modulating immunity, inactivating procarcinogens, preventing or reducing cancer, and lowering cholesterol (Agerholm-Larsen et al., 2000; Gibson and Fuller, 2000; Holzapfel et al., 1998; Reid, 1999). Numerous studies have documented probiotics effectively mitigate a variety of gastrointestinal and extra-intestinal disorders including inflammatory bowel disease (IBD), irritable syndrome (IBS), vaginal infections, and boost immune response. Some probiotics have also been investigated in relation to atopic eczema, rheumatoid arthritis, and liver cirrhosis. Scarpellini et al. (2008) reviewed that ingestion of yogurt containing Lactobacillus acidophilus and Bifidobacterium bifidum induce the production of cytokines by enhancing the nonspecific phagocytic activity of circulating granulocytes (a category of white blood cells). Besides the immunomodulation, some clinical studies demonstrated the role of some probiotics (such as L. acidophilus and L. reuteri) in lowering cholesterol (Sanders and Klaenhammer, 2001; Taranto et al., 1998). However, the results of some proposed health 
benefits are conflicting. In general, the strongest clinical evidence for probiotics is related to their use in improving gut health and stimulating immune function.

Many commercially available probiotics may provide one or several proposed health benefits according to clinical studies (Parvez et al., 2006). Table 2.3 summarizes the therapeutic effects of some probiotic strains based on clinical trials (Shah, 2006). It was reported that probiotic effects do not tie to specific genus or species, but instead are strain-specific (Gorbach, 2000). Therefore, not all the strains of the same species possess beneficial activities. More importantly, each health benefit is often associated with a few groups of probiotic bacteria, implying that there is no single strain that would provide all the potential health benefits. Due to this specificity, probiotics must be identified at the strain level, and experiments should be carried out with multiple strains (Shortt, 1999).

Table2.3. Probiotic strains with peer review published evidence from clinical studies

\begin{tabular}{|c|c|c|}
\hline Strain & Health Benefits in Clinical Studies & Scientifically Established Effects \\
\hline L. johnsonii LA1 & $\begin{array}{l}\text { Adherence to human intestinal cells, } \\
\text { balances intestinal flora }\end{array}$ & Mucosal adherence, immune enhancement \\
\hline L. acidophilus NCFM & $\begin{array}{l}\text { Lowering of fecal enzyme activity, } \\
\text { improvement in lactose absorption, } \\
\text { production of bacteriocin }\end{array}$ & Alleviation of lactose malabsorption \\
\hline L. rhamnosus GG & $\begin{array}{l}\text { Prevention of antibiotic associated, diarrhea } \\
\text { and rotavirus diarrhea }\end{array}$ & $\begin{array}{l}\text { Management of Clostridium difficile } \\
\text { diarrhea, prevention of acute diarrhea, } \\
\text { prevention of antibiotic diarrhea, reduction } \\
\text { in fecal enzyme associated diarrhea }\end{array}$ \\
\hline L. casei Shirota & $\begin{array}{l}\text { Prevention of intestinal disturbance, } \\
\text { balancing intestinal flora, lowering of fecal } \\
\text { enzyme activity }\end{array}$ & \\
\hline L. reuteri & $\begin{array}{l}\text { Colonizing the intestinal tract in animal } \\
\text { studies, shortening of duration rotavirus } \\
\text { diarrhea, immune enhancement }\end{array}$ & Shortening of duration of rotavirus \\
\hline B. animalis BB12 & $\begin{array}{l}\text { Treatment of rotavirus diarrhea, balancing } \\
\text { intestinal flora }\end{array}$ & Shortening of duration of rotavirus \\
\hline S. cerevisiae Boulardii & $\begin{array}{l}\text { Prevention of antibiotic associated diarrhea, } \\
\text { treatment of } C \text {. difficile colitis }\end{array}$ & Prevention of antibiotic associated diarrhea \\
\hline E. faecium (Gaio) & Reduction in cholesterol & Reduction in cholesterol \\
\hline
\end{tabular}

Adapted from Shah (2006) 


\subsection{Probiotics and Dairy Products}

Probiotic cultures have been exploited extensively by the dairy industry as a tool for the development of novel functional products. Today, more than 100 probioticcontaining products, including pasteurized milk, ice-cream, fermented milk, cheese, infant formula, fruit juices, single shots and oat-based products, are available worldwide (Lourens-Hattingh and Viljoen, 2001; Stanton et al., 2002; Shah, 2004). Probiotics are also exclusively available in the form of powders, tablets or capsules as dietary supplements, which are frequently produced by freeze drying method. The exposure of probiotics to freezing and dehydration may lead to cell injury and decreased viability during processing and storage. During processing, the temperature/phase changes and dehydration can lead to the damage of cell membranes, cell walls, ribosomes and DNA (Stanton et al., 2005). Moreover, membrane lipid oxidation may occur during storage. Therefore, by the time the product is consumed, viability of probiotics may be depleted to a level where the desirable health benefits cannot be provided.

As capsules or tablets frequently contain low number of viable probiotic cells, incorporation of probiotics in foods, especially in dairy products, is more common. In fact, commercial dairy products fermented by probiotic cultures have had a history of safety. Among dairy products normally sold in the US, the most familiar is yogurt. According to the standards of identity listed in the United States Code of Federal Regulations (CFR), yogurt (in section 21 CFR part 131.200) is produced by culturing with the lactic-acid producing bacteria Lactobacillus delbrueckii ssp. bulgaricus and Streptococcus thermophilius (Chandan, 2006). Additional cultures known as "probiotics" may be added for the purpose of conferring their presumptive health benefits. Whether $L$. 
delbrueckii ssp. bulgaricus and S. thermophilus are considered probiotics, this is still debatable to their use because they have no promising demonstrable probiotic effects (Kailasapathy and Chin, 2000). Regardless of their non-human origins, they (especially $S$. thermophilus)have low resistance to gastric acidic conditions (Conway et al., 1987). Accordingly, they may not survive and reach the attachment sites of the intestines in great numbers. Moreover, they lack capability of adhesion in the gut (Chandan, 1999). Thus, L. delbrueckii ssp. bulgaricus and S. thermophilus are used as the main yogurt starters, and probiotics are added as supplements. Probiotics used in commercial products today are mainly members of the genera Lactobacillus and Bifidobacterium.

As mentioned previously, probiotics should survive during transit through the gastrointestinal tract. This implies they should withstand the extreme low $\mathrm{pH}$ of gastric juice ( $\mathrm{pH} 1-3)$ in the stomach, and tolerate bile salts in the small intestine. Yogurt is an effective delivery system for probiotics due to the buffering action of the milk proteins that protect probiotics from those harsh environments.

\subsection{Factors Affecting the Survival of Probiotics}

Some probiotics (especially bifidobacteria) are fastidious microorganisms, and are susceptible to environmental conditions, such as organic acid accumulation, high temperature, hyperosmotic pressure, low water activity, high redox potential (presence of oxygen) and the presence of inhibitory substances (Lourens-Hattingh and Viljoen, 2002). Consequently, survivability and stability of probiotics has become a marketing and technological challenge for the industry. The viability and activity of probiotics in the

products have been frequently cited as a prerequisite for achieving numerous beneficial 
health benefits (Galdeano and Perdigón, 2004). Therefore, in order to obtain their desirable functional properties, probiotics need to be delivered in sufficient numbers with high viable rate (Godward et al., 2000; Talwalker and Kailasapathy, 2004). A general agreement is that high dose is required, which range from $1 \times 10^{6} \mathrm{cfu} / \mathrm{mL}$ (Kurmann and Rasic, 1991; Tamime et al., 2005) to over $1 \times 10^{8} \mathrm{cfu} / \mathrm{mL}$ (Laurens-Hattingh and Viljoen, 2001). Kailasapathy and Chin (2000) suggested that, in general, the minimum therapeutic dose should be $1 \times 10^{8}$ to $1 \times 10^{10} \mathrm{cfu} / \mathrm{day}$. High dosage is likely required to compensate for the possible decline on the amount of the viable probiotic cells during processing and storage of probiotic product as well as passage through the upper and lower parts of the gastrointestinal tract.

Numerous studies were conducted in Asia, Australia, Europe and the US to determine the presence or viability of Lactobacillus and Bifidobacterium species (Vinderola et al., 2001; Lourens-Hattingh and Viljoen, 2002; Tamime, 2002; Weese, 2002; La Torre et al., 2003; Tharmaraj and Shah, 2003; Varga et al., 2003; Huys et al., 2006; Lin et al., 2006), and most showed the probiotic species were either misidentified or had low viability.

Many factors affect the viability of probiotics in a delivery system (Table 2.4), and most are dependent on particular strains. These factors include their interactions with other bacterial species, the final acidity of the product, the availability of nutrients, the presence of growth promoters (such as small peptides or free amino acids) and inhibitors (chemical or biological), osmotic pressure (concentration of sugar), oxygen content and concentration of inoculums (Shah, 2000). All microorganisms interact with their environment by utilizing components in the medium and secrete metabolic products. 
Thus, the composition of the dairy product is a significance factor influencing the metabolic activities of probiotics (Heller, 2001). Addition of casein or whey protein isolates and yeast extract can enhance the growth of probiotics in milk due to their lack of the capability to synthesize most amino acids, cofactors and vitamins (Claesson et al., 2007; Desai et al., 2004; Lucas et al., 2004). Furthermore, the addition of milk protein also increases the buffering capacity of fermented milks and allows better survival of probiotics.

Table 2.4. Summary of different factors affecting the viability of probiotics

\begin{tabular}{ll}
\hline Step & Stress Factor \\
\hline $\begin{array}{l}\text { Preparation of } \\
\text { probiotic cultures }\end{array}$ & $\begin{array}{l}\text { Presence of organic acids during cultivation } \\
\text { Concentration - high osmotic pressure, low water activity, } \\
\text { higher concentration of particular ions } \\
\text { Temperature - freezing, vacuum and spray drying } \\
\text { Drying }\end{array}$ \\
$\begin{array}{ll}\text { Prolong storage - oxygen exposure, temperature fluctuation } \\
\text { Production, storage } \\
\text { and transportation of } \\
\text { probiotic-containing } \\
\text { products }\end{array}$ & $\begin{array}{l}\text { Nutrient depletion } \\
\text { Strain antagonism }\end{array}$ \\
& $\begin{array}{l}\text { Increased acidity } \\
\text { Positive redox potential (presence of oxygen) }\end{array}$ \\
& bacteriocins) \\
& Storage temperature \\
Gastrointestinal & Gastric acid and juices \\
transit & Bile salt \\
& Microbial antagonism
\end{tabular}

Source: Adapted from Vasiljevic and Shah, 2008

Since lactobacilli and bifidobacteria in general are microaerophilic and obligate anaerobic microorganisms, respectively, oxygen toxicity is an important factor affecting 
their viability. Several studies have focused on the prevention of detrimental effects of oxygen on probiotics strains, including the use of anti-oxidants or oxygen scavengers (Dave and Shah, 1997b; Talwalkar and Kailasapathy, 2003; Talwalkar et al., 2004). Unlike aerobic microorganisms, which can completely reduce oxygen to water, the oxygen-scavenging system in probiotics is either reduced or completely absent due to the lack of a functional electron-transport system. This results in the incomplete reduction of oxygen to hydrogen peroxide $\left(\mathrm{H}_{2} \mathrm{O}_{2}\right)$. Probiotics do not possess catalase, an enzyme needed for the decomposition of hydrogen peroxide. The intracellular accumulation of toxic oxygenic metabolites, such as superoxide anion $\left(\mathrm{O}_{2}{ }^{-}\right)$, hydroxyl radical $\left(\mathrm{OH}^{-}\right)$, and hydrogen $\mathrm{H}_{2} \mathrm{O}_{2}$ can eventually lead to cell death (Talwalkar and Kailasapathy, 2003; Villegas and Gilliland, 1998). In the production of yogurt, L. delbrueckii ssp. bulgaricus is known to produce a high amount of $\mathrm{H}_{2} \mathrm{O}_{2}$, and this appears to decreased viability of probiotics in the product (Tamime, 2005).

In addition to the oxygen toxicity, another well-studied factor affecting the viability of probiotics is organic acid (primarily lactic acid) production during fermentation. When lactic acid content increases, $\mathrm{pH}$ level correspondingly decreases, and this may inhibit the survival of probiotics. Below $\mathrm{pH} 4.4$, most probiotics encounter cellular damage and substantial decrease in the number of viable probiotic bacteria is usually observed. Extended refrigeration storage and transportation is also critical in maintaining the viability of probiotics. Yogurt starter cultures, particularly L. delbrueckii ssp. bulgaricus, possess $\beta$-galactosidase that is active at low $\mathrm{pH}$ and low temperature, which eventually increases the accumulation of lactic acids during refrigerated storage (Donkora et al., 2006). Some studies reported that the low pH is the most important factor 
affecting the viability of $L$. acidophilus (most common Lactobacillus species incorporated in commercial yogurts in the US) and Bifidobacterium species (Laroia and Martin, 1991; Shah and Ravula, 2000) post-fermentation. On the other hand, Ruis et al. (1994) pointed that $L$. acidophilus has a high cytoplasmic buffering capacity (pH 3.72-7.74), which allows it to resist changes in intracellular $\mathrm{pH}$ and therefore gain stability under acidic conditions. However, this effect has not been documented universally for all strains.

On the contrary, yogurt starter cultures may enhance the growth and survival of probiotics by producing growth-promoting substrates or by reducing the oxygen content in milk (Kailasapathy and Rybka, 1997; Dave and Shah, 1997a; Saarela et al., 2000; Vinderola et al., 2002). S. thermophilus is a facultative anaerobic microorganism, which reduces the redox potential in milk by the consumption of oxygen by NADH oxidase (an enzyme catalyzed $\mathrm{NADH}+\mathrm{H}^{+}$with the presence of $\mathrm{O}_{2}$ to $\mathrm{NAD}$ and hydrogen peroxide) and pyruvate oxidase (an enzyme catalyzed pyruvate with the presence of $\mathrm{O}_{2}$ to acetate and $\mathrm{CO}_{2}$ ) (Teraguchi et al., 1987). Accordingly, this can create an anaerobic condition stimulating the growth of $L$. delbrueckii ssp. bulgaricus and probiotics in yogurt (Lankaputhra and Shah, 1996). In addition, L. delbrueckii ssp. bulgaricus possess proteolytic enzymes that liberate amino acids such as valine, glycine, and histidine that are essential to some probiotics (Bifidobacteria species) (Tamime, 2005).

Since the efficacy of probiotics is related to the viable number at the time of consumption, they must survive during the processing, storage and transit through the gastrointestinal tract. Although yogurt starters possess some benefits during fermentation, some inhibitory substances may affect the loss of viability of probiotics. However, these synergistic and antagonistic effects are still the subject of further research before a 
consensus can be reached as many previous studies used different probiotic strains or yogurt cultures

\subsection{Lactobacillus species}

Lactobacilli are ubiquitous in nature, and are found in carbohydrate rich environments. They are gram-positive, non-spore forming rods or coccobacilli, catalase negative (Charteris, et al., 1997). They are fermentative, microaerophilic and chemoorganotrophic. The G+C content of their DNA is usually between 32 and 53 mol\%. They occur naturally in the gastrointestinal tract (primarily small intestine) of humans and animals, in the human mouth and vagina (Felis and Dellaglio, 2007). L. acidophilus, L. salivarius, L. casei, L. plantarum, L. fermentum, L. reuteri and $L$. brevis have been the most common Lactobacillus species isolated from the human intestine (Mitsuoka, 1992). A few particular strains of L. acidophilus, L. casei, L. paracasei, L. johnsonii, L. reuterui, $L$. salivarius and $L$. rhamnosus have been extensively studied as candidates of probiotics and their functional properties and safety have been well-documented. Examples of lactobacilli used as commercial probiotic cultures are shown in Table 2.5. 
Table 2.5.Examples of some Lactobacillus strains used in commercial applications

\begin{tabular}{|c|c|}
\hline Species and strain & Source \\
\hline $\begin{array}{l}\text { L. acidophilus NCFB } 1748 \\
\text { L. paracasei F19 }\end{array}$ & Arla (Stockholm, Sweden) \\
\hline L. reuteri SD2112 (MM2) & Biogaia (North Carolina, USA) \\
\hline $\begin{array}{l}\text { L. acidophilus LA-1/LA-5 } \\
\text { L. paracasei CRL } 431\end{array}$ & Chr. Hansen, Inc. (Horsholm, Denmark) \\
\hline L. acidophilus La-14 & Danisco (Brabrand, Denmark) \\
\hline L. paracasei Immunitas (DN014001) & Danone (Paris, France) \\
\hline $\begin{array}{l}\text { L. acidophilus } \mathrm{LAFTI}^{\circledR} \mathrm{L} 10 \\
\text { L. paracasei } \mathrm{LAFTI}^{\circledR}{ }^{\mathrm{L}} \mathrm{L} 26\end{array}$ & DSM Food Specialties (New South Wales, Australia) \\
\hline L. rhamnosus LB21 & Essum AB (Umeå, Sweden) \\
\hline L. rhamnosus DR20 (HN001) & Fonterra Cooperative Group Ltd (Auckland, New Zealand) \\
\hline $\begin{array}{l}\text { L. acidophilus R0011 } \\
\text { L. rhamnosus R0052 }\end{array}$ & Institute Rosell (Quebec, Canada) \\
\hline L. acidophilus LB & Lacteol Laboratory (Houdan, France) \\
\hline L. paracasei F19 & Medipharm AB (Kågeröd, Sweden) \\
\hline L. acidophilus DDS-1 & Nebraska Cultures, Inc. (Lincoln, NE) \\
\hline L. johnsonii La-1 & Nestlé (Lausanne, Switzerland) \\
\hline $\begin{array}{l}\text { L. plantarum } 299 \mathrm{~V} \\
\text { L. rhamnosus } 271\end{array}$ & Probi AB (Lund, Sweden) \\
\hline L. acidophilu $\mathrm{NCFM}^{\circledR}$ & Rhodia (Wisconsin, USA) \\
\hline L. acidophilus SBT-2062 & Snow Brand Milk Products Co., Ltd. (Tokyo, Japan) \\
\hline L. salivarius UCC118 & University College (Cork, Ireland) \\
\hline $\begin{array}{l}\text { L. rhamnosus GR-1 } \\
\text { L. reuteri } \mathrm{RC}-14\end{array}$ & Urex Biotech, Inc. (Ontario, Canada) \\
\hline L. rhamnosus GG(ATCC53103) & Valio Dairy (Helsinki, Finland) \\
\hline L. casei Shirota (YIT 9018) & Yakult (Tokyo, Japan) \\
\hline
\end{tabular}

Adapted from Holm, 2003; Playne, et al., 2003; Sanders, 2003; Shah, 2004.

Lactobacillus acidophilus

Among many Lactobacillus species, L. acidophilus is likely the most common probiotics for dietary use. This microorganism is classified by the Food and Drug Administration (FDA) as Generally Regarded As Safe (GRAS) (Parvez, 2006). 
Approximately $80 \%$ of the yogurt manufactured in the US contains L. acidophilus (Sanders, 2003). In addition to its gram positive rod shape with rounded ends, the typical size of L. acidophilus is $0.6-0.9 \mu \mathrm{m}$ in width and $1.5-6.0 \mu \mathrm{m}$ in length. Its growth condition is generally enhanced under a microaerophilic environment of $5 \% \mathrm{O}_{2}, 85 \% \mathrm{~N}_{2}$, and $10 \% \mathrm{CO}_{2}$ (Shah, 2006). The optimum growth temperature is between $35^{\circ} \mathrm{C}$ and $40^{\circ} \mathrm{C}$; it can grow at as high as $45^{\circ} \mathrm{C}$.

The name "L. acidophilus" was derived from "acidus" meaning "acid" and “philus” meaning "loving” (Shah, 2006). This microorganism possesses the characteristics necessary to survive the harsh environmental conditions in the gut, namely, high acid content and the surface-reducing effect caused by bile salts. Although L. acidophilus grows slowly in milk, which is partly related to low concentration of small peptides and free amino acids, it produces high amounts of lactic acid (Vedamuthu, 2006). This may be based upon its homofermentative nature. Due to its wide range of acid tolerance (0.3-1.9\% lactic acid), L. acidophilus can grow in slightly acidic media at $\mathrm{pH}$ of 4.5-6.4 (optimum growth at $\mathrm{pH}$ 5.5-6,0), but its growth ceases at $\mathrm{pH}$ 3.6-4.0.Another desirable characteristic for them to be effective probiotics is tolerance to bile salts. Though Walker and Gilliland (1993) reported that L. acidophilus ATCC4356 could withstand bile toxicity, it is perceived that not all strains have this ability. Hence, in vitro determination of bile salt tolerance should be conducted (Sanders et al., 1996).

In order to study its viability, an appropriate medium is necessary to selectively enumerate L. acidophilus from the products amongst other closely related species. deManRogasa-Sharpe (MRS) agar is usually used as a weak selective medium for the isolation of lactic acid bacteria from most fermented food products. Many selective media for $L$. 
acidophilus were therefore based on MRS (Table 2.6) (Coeuret et al., 2003; Van de Casteele et al., 2006). The list of these selective media is extensive, and selection often reflects the preference of the user.

Table 2.6. Selective media for the enumeration of L. acidophilus, S. thermophilus and $L$. delbrueckii ssp. bulgaricus from yogurts

\begin{tabular}{|c|c|c|c|}
\hline Bacteria & Agar & Incubation conditions & Reference \\
\hline L. acidophilus & $\begin{array}{l}\text { NA-salicin agar } \\
\text { MRS-clindamycin agar } \\
\text { MRS-sorbitol agar } \\
\text { MRS-ribose agar } \\
\text { MRS-gluconate agar } \\
\text { MRS-arabinose agar } \\
\text { MRS-maltose agar } \\
\text { MRS-trahalose agar } \\
\text { MRS-bile agar } \\
\text { TMVC agar } \\
\text { X-Glu agar } \\
\text { RCABC agar } \\
\text { CLBS agar }\end{array}$ & Anaerobic, $37^{\circ} \mathrm{C}, 48-72 \mathrm{~h}$ & $\begin{array}{l}\text { Dave and Shah, } 1996 \\
\text { Van de Casteele et al., } 2006 \\
\text { Tharmaraj and Shah, } 2003 \\
\text { Lankaphuthra and Shah, } 1996 \\
\text { Lankaphuthra et al., } 1996 \\
\text { IDF, } 1995\end{array}$ \\
\hline $\begin{array}{l}\text { L. delbrueckii } \\
\text { ssp. bulgaricus }\end{array}$ & $\begin{array}{l}\text { Acidified MRS agar (pH } \\
4.58) \\
\text { RCA agar (pH 5.3) } \\
\text { RCPB agar (pH 5) }\end{array}$ & Anaerobic, $45^{\circ} \mathrm{C}, 48-72 \mathrm{~h}$ & $\begin{array}{l}\text { Tharmaraj and Shah, } 2003 \\
\text { Lankaphuthra and Shah, } 1996 \\
\text { Rybka and Kaisalapathy, } 1996\end{array}$ \\
\hline S. thermophilus & $\begin{array}{l}\text { S. thermophilus agar } \\
\text { M17 agar }\end{array}$ & Aerobic, $37^{\circ} \mathrm{C}, 48-72 \mathrm{~h}$ & $\begin{array}{l}\text { Tharmaraj and Shah, } 2003 \\
\text { Ravula and Shah, } 1998\end{array}$ \\
\hline
\end{tabular}

Adapted from Coeuret et al., 2003; Van de Casteele et al., 2006

\subsection{Molecular Aspects of Probiotics}

\subsubsection{Genome of Lactobacillus acidophilus}

The complete genome sequence of $L$. acidophilus NCFM was determined (Altermann et al. 2005). Based on sequence analysis, this microorganism encodes 20 putative peptidases, homologs of PrtP and PrtM (cell-envelope protease and membrane- 
bound lipoprotein, respectively), and two complete oligopeptide transport systems (Altermann et al., 2005). Nine two-component regulatory systems were predicted; some associated with determinants implicated in bacteriocins production. L. acidophilus NCFM contains genes (and therefore expresses the predicted proteins) including those: involved in the digestion of fructo-oligosaccharides (Barrangou et al., 2003); tolerate acidic conditions (Azcarate-Peril et al., 2004); and affect the cell surface, cell division, and adhesion to epithelial cells (Altermann et al., 2005). It is also predicted to produce a number of stress-related proteins, including most of the highly conserved SOS regulon genes (Altermann, et al., 2005). The $\mathrm{F}_{1} \mathrm{~F}_{0}$-ATPase system, which is encoded by the atp operon, has been well characterized in L. acidophilus (Kullen and Klaenhammer, 1999). Additionally, a gene relA is identified to encode an enzyme putatively involved in osmotolerance by synthesis and hydrolysis of (p)ppGpp (Altermann et al., 2005). All this information help understand the physiology of L. acidophilus, elucidate potential mechanisms on their survival during transit through gastrointestinal tract and their interaction with the intestinal mucosa and microbiota.

\subsubsection{Stress Responses}

For probiotic bacteria destined to be delivered to the human host, they are subjected to a variety of stresses beginning from the production of the culture, incorporation into milk products or dietary supplements, transport and storage, transit along the human GI tract, to finally at the location such as colon where they are transiently colonized (Delcour et al., 2000). When the probiotic cells are exposed to environmental stress, these stress factors (acid, hyperosmotic pressure and oxidation) 
may cause protein denaturation, which may affect their survival and eventually lead to cell death (Vorob’eva, 2004).To overcome these challenges, several survival mechanisms exhibited by bacteria are normally referred to as the stress response (Kim et al., 2001), and this response is usually associated with genes encoding a group of protein called heat shock proteins (HSPs) (De Angelis and Gobbetti, 2004). These proteins are called "heat shock" because the concentration of these proteins were found to be increased shortly after the microorganism was exposed to a higher temperature; a process called heat shock response (Ang et al., 1991). In fact, the expression of HSPs can also be induced by other stress conditions, such as high salinity, alcohol and organic acids (Sugimoto et al., 2008). The HSPs are capable of re-folding nascent polypeptides or heat-denatured proteins from denaturation, assembling protein complexes and translocating proteins during cellular stress (Bukau and Horwich, 1998). During normal growth of the cell, HSPs are expressed at low concentration. When the cell is exposed to a heat shock or other stresses, the synthesis rate of HSPs markedly increases and then slowly decreases to normal levels. Among different types of HSPs, DnaK, DnaJ, GrpE, GroEL and GroES are molecular chaperones expressed in significant amounts (Craig et al., 1994). The two major subgroups of molecular chaperones consist of the complex DnaK/DnaJ/GrpE and the complex GroEL/GroES (Zink et al., 2000). Denatured proteins are first bound to the complex DnaK/DnaJ/GrpE. The re-folding mechanism by this complex is widely reviewed (Foster and Hall, 1990; de Angelis and Gobbetti, 2004). It is known that binding and release of substrate proteins are regulated by the ATPase activity of DnaK, which is under tight control by DnaJ and GrpE (Szabo et al., 1994; McCarty et al., 1995). DnaJ accelerates the rate of ATP hydrolysis of DnaK, whereas GrpE promotes the 
nucleotide exchange of ATP and ADP (Liberek et al., 1991). DnaJ and GrpE have the utmost importance for the chaperone activity of DnaK in vivo and in vitro (Bukau and Horwich, 1998; Rosen and Ron, 2002).The partially folded polypeptide (protein) released from the complex DnaK/DnaJ/GrpE is passed to the complex GroEL/GroES for further folding within its cage structure (Vorob’eva, 2004).

It has been generally assumed that any stress, which triggers protein denaturation, will greatly induce the synthesis of the DnaK, DnaJ, GrpE, GroEL and GroES (Broadbent et al., 1998).In several lactic acid bacteria, such as L. johnsonii, L. delbruckii ssp. bulgaricus, L. plantarum and L. acidophilus, heat-shock chaperones were found to be consistently upregulated presumably due to the need to repair acid-induced damaged proteins and/or to facilitate the folding of nascent proteins (Vaughan and Mollet, 1999; Somkuti and Steinberg, 1999; Van de Guchte et al., 2002). Although Lorca et al. (2002) hypothesized that DnaK, DnaJ, GrpE, GroES and GroEL are important heat shock proteins found in L. acidophilus, little experimental evidence of the HSPs mechanism in this microorganismis established. Most reviews on heat shock response use Escherichia coli, Bacillus subtilis, Lactococcus lactis ssp. lactis and Lactobacillus plantarum as model organisms (Henderson et al., 2006; Sugimoto et al., 2008; Vorob’eva, 2004). Because of the difference in HSPs possession among lactic acid bacteria, a subset of acidinduced heat-shock proteins may vary between species (Champomier-Verges et al., 2002).Accordingly, molecular analyses are required to understand the expression of these genes/proteins in L. acidophilus. These analyses may include northern blots, cDNA microarrays reverse-transcription polymerase chain reaction (RT-PCR), proteomics, etc. 


\subsubsection{Gene Expression Analysis with RT-PCR}

Precise regulation of gene expression allows an organism to respond suitably to environmental conditions. For bacteria, gene expression is regulated by specific noncoding DNA sequences called promoters, which are genetic sequences that determines when and to what extend the associated genes are transcribed. An understanding of gene regulation in probiotics may lead to better improvement of probiotic cells for food applications.

Several methods are commonly used for the quantification of transcription level; these methods include northern blotting (Boot et al., 1996), in situ hybridization (Parker and Barnes, 1999), RNAse protection assays (Hod, 1992), reverse-transcription polymerase reaction (RT-PCR) (Weis et al., 1992) and cDNA microarray (Pieterse et al., 2005; Barrangou et al., 2006). Microarray technology is a powerful tool for analyzing the transcriptional response of microorganisms, but its application is still somewhat limited due to relatively high cost and difficulty in instrument accessibility (Bucher, 1999). Northern blotting provides the information related to mRNA size, alternative splicing and the integrity of RNA samples (Bustin, 2000). The RNAse protection assay is a useful method for mapping transcript initiation and termination sites and for discrimination between related mRNAs of similar size, which would migrate at similar positions on a northern blot. Both northern blotting and RNAse protection assay methods have been the major techniques used in the past to determine mRNA levels to estimate gene expression (Kelleher, 2001). In situ hybridization is a complex method and is the only one that allows localization of transcripts to specific cells within a sample. The limitation of these three methods is their comparatively low sensitivity. Moreover, they require large 
amounts of total RNA to estimate the concentration of a specific transcript (Zamorano et al., 1996; Bustin and Nolan, 2004).

RT-PCR has become a standard technique for assessing differential expression of genes (Pfaffl, 2001; Walker, 2002), and it is the most sensitive and specific method for the detection of low-abundance mRNA (Carding et al., 1992; Bustin, 2000). It can be used to compare the levels of mRNAs in different sample populations, to characterize patterns of mRNA expression, to discriminate between closely related mRNAs, and to analyze RNA structure (Wang and Brown, 1999).Numerous studies used RT-PCR for analyzing gene expression of Lactobacillus species (Fitzsimons et al., 2003; Piuri et al., 2003; Spano et al., 2004; Marco and Kleerebezem; 2007; Fiocco et al., 2008). Fitzsions et al. (2003) also suggested that RT-PCR should be applicable in assessing the in vivo gene expression producing both long and short half-life mRNAs from enteric probiotic bacteria. Although cDNA microarrays are becoming more sought-after among scientists, RT-PCR is still required to validate the gene expression profile (Bustin and Nolan, 2004).

The use of gene technology in dairy or food microorganisms is controversial in many parts of the world (Dellaglio, 2005). Molecular methods will be useful not only for studying the effects of probiotics on the distribution of normal intestinal flora but also the activity of the probiotic in the gastrointestinal tract. Molecular techniques will certainly play a main role in understanding the mechanism the probiotics. This understanding will help design and develop probiotics strains, and improve industrial production of probiotic food ingredients. 


\subsection{Objectives and Hypotheses}

Probiotics are increasingly popular due to their purported health benefits. Since many health benefits require consumption of sufficient viable cells, many studies have been conducted regarding the survival of probiotics in fermented products, especially in yogurt. However, probiotic activities are strain-dependent, rendering many studies not useful due to the lack of strain identity. Additionally, in the absence of a standard selective medium for probiotic enumeration from commercial fermented milks, it is difficult to compare current published reports on probiotic survival in the products. In this thesis project, we will focus on the survival of multiple L. acidophilus strains in yogurt manufactured with commercial starter cultures. Furthermore, we will study the gene expression of stress genes (dnaK and groEL) in selected L. acidophilus strains to better understand the survival capability during refrigerated storage.

The hypotheses of this study were:

1. Some Lactobacillus acidophilus strains exhibit poor survival in yogurt due to the presence of yogurt starter cultures, while some strains remain stable throughout the refrigerated storage period.

2. Loss of viable cell counts of some L. acidophilus strains in yogurt is not due to low $\mathrm{pH}$.

3. Expression of stress genes in L. acidophilus in yogurt is associated with survival capability. 
The objectives of this study were:

1. To determine the effect of starter cultures and their metabolic products on survival of multiple L. acidophilus strains (ATCC700396, LA-5, NCFM, PIM703 and SBT2062)

2. To determine the survival of L. acidophilus in yogurt independent of starter culture fermentation by using glucono-delta-lactone as an acidulant

3. To determine gene expression of stress genes of selected L. acidophilus strains in yogurt during refrigerated storage period using reverse-transcription polymerase chain reaction 


\section{0}

\section{JUSTIFICATION}

Probiotics have been widely incorporated in fermented foods for years due to their potential therapeutic effects. To realize their desirable health benefits, many publications have suggested that a high amount of viable probiotics $\left(>10^{6} \mathrm{cfu} / \mathrm{g}\right.$ or $\left.\mathrm{mL}\right)$ must be consumed to compensate for any possible loss during transit through the gastrointestinal tract of the host. Although numerous commercial products containing probiotics are available worldwide, many publications have revealed disappointing results with regards to misidentification and low viability of probiotics (less than $10^{6} \mathrm{cfu} / \mathrm{g}$ or $\mathrm{mL}$ by the end of expiration date). However, results among these studies are inconsistent, which may be due to the difference in selective media used for probiotic enumeration.

Probiotics are fastidious microorganisms, and are highly susceptible to a variety of environmental stress, such as organic acid accumulation, high temperature and oxygen toxicity such as production of hydrogen peroxide (refer to Chapter 2.4). Consequently, maintaining a sufficient amount of viable probiotics in fermented foods throughout the shelf life has always been a great challenge to dairy industries and scientists. In the US, yogurt is perhaps the most familiar fermented milk product that is used as a probiotic delivery vehicle. Many studies demonstrated that several factors, such as lactic acid accumulation and production of hydrogen peroxide from yogurt starter cultures (especially L. delbrueckii ssp. bulgaricus), may affect probiotic survival during fermentation and storage, However, these studies normally used different strains of starter cultures or probiotics. As activity of microorganisms is strain dependent, results may vary, and it is therefore difficult to rely on few publications with different probiotic 
strain use. In this project, multiple probiotic strains will be used to study their survival in various types of yogurt during refrigerated storage period. This may show strain-to-strain variation in survivability. Among these probiotic strains, L. acidophilus NCFM and LA-5 will be studied due to their well-documented health claims.

When probiotics are subjected to environmental stress, the expression of a group of proteins called "heat shock proteins" is upregulated. Among these proteins, Dnak and GroEL (encoded by dnaK and groEL) function as intracellular chaperones for denatured proteins by re-folding and assembling the proteins. Many studies have been conducted with the purpose of understanding the relationship between probiotic survival and the regulation of heat shock proteins (or gene). While many investigated pathogens, few studies used L. acidophilus as a model. As with survival capabilities of probiotics, mechanisms of gene regulation are likely strain dependent. Therefore, we will study mRNA expression of dnaK and groEL of L. acidophilus while they coferment with yogurt starter cultures by using reverse-transcription polymerase chain reaction. The expression of these genes will help elucidate their roles in aiding microbial survival under stressful environment. Beyond the scope of this project, genome-wide gene expression analysis will provide us a more comprehensive understanding with regards to molecular mechanisms in stress conditions. Once the mechanism of probiotic survival is better understood, later it may be more likely to optimize their viability. This will ultimately lead to more efficacious delivery of probiotic and increased health benefits from yogurt. Moreover, the identification of the heat shock genes will provide targets 1) for specific manipulation (to promote or limit growth), 2) to develop tools to screen for tolerant or sensitive strains and 3) to evaluate the level of adaptation of a strain. 
Overall, this thesis project will focus on the survival and gene expression of multiple L. acidophilus strains in yogurt during refrigerated storage period. By understanding their physiological properties, we can formulate and/or improve a probiotic strain used in fermented dairy products with better survivability and desired therapeutic effects. 


\section{0}

\section{MATERIALS AND METHODS}

\subsection{Bacterial Strains, Propagation and Storage}

Commercial yogurt starter cultures (YoFlex-L702), which contained Streptococcus thermophilus and Lactobacillus delbrueckii ssp. bulgaricus, were provided from Chr. Hansen (Milwaukee, WI) in Direct Vat Set (DVS) form. To prepare frozen stocks from a commercial DVS containing S. thermophilus and L. delbrueckii ssp. bulgaricus, approximately 25 g of DVS were transferred into a sterile whirlpak ${ }^{\circledR}$ bag (Fisher Scientific, Tustin, CA), and let thaw at room temperature. Then, a loopful of thawed concentrated suspension was streaked on MRS agar (BD Diagnostics, Sparks, MD) and was incubated at $37^{\circ} \mathrm{C}$ in a $\mathrm{CO}_{2}$ incubator (Isotemp Incubator, Fisher Scientific). The aeromicrophilic condition and the presence of $\mathrm{CO}_{2}$ in this incubator could stimulate the growth of L. delbrueckii ssp. bulgaricus. After 48 hours of incubation, two different colony morphologies were observed. Each type was tested with a Gram stain kit (BD Diagnostics) to determine their species identity -L. delbrueckii ssp. bulgaricus is gram positive bacillus whereas $S$. thermophilus is gram positive coccus. The procedure of Gram stain was as follows: on a clean microscopic slide, a single colony was mixed with a drop of water. After the suspension was air-died and heat-fixed, the slide was stained with crystal violet for $1 \mathrm{~min}$, iodine solution for $1 \mathrm{~min}$, 95\% ethanol for $10 \mathrm{~s}$ and safranin for $30 \mathrm{~s}$. After each reagent added, the slide was gently rinsed with tap water. Microscopic cell morphologies were observed under a light microscope with a total magnification of $1,000 \mathrm{X}$, and identification of each starter culture was further confirmed by API 50 CHL test (BioMérieux Vitek, Hazelwood, MO) according to the 
manufacturer's recommended procedure (refer to section 4.2). Each starter culture was streaked for single colony isolation on M17 (S. thermophilus) or MRS media ( $L$. delbrueckii ssp. bulgaricus) (Ravula and Shah, 1998). After incubated at $37^{\circ} \mathrm{C}$ for $24-36$ h, broth media supplemented with $20 \%$ glycerol (Fisher Scientific) were used to make frozen stocks of these cultures in $1.2 \mathrm{~mL}$ Nalgene cryogenic vials (Fisher Scientific), which were stored at $-50^{\circ} \mathrm{C}$.

Five strains of L. acidophilus were used as probiotics in this study. These strains include NCFM, ATCC700396, PIM703, SBT2062 and LA-5. The first four strains were obtained from the Dairy Products Technology Center (DPTC) culture collection (Yeung et al., 2002) at California Polytechnic State University, San Luis Obispo, and L. acidophilus LA-5 was kindly provided by Chr. Hansen (Milwaukee, WI). The identity of all L. acidophilus strains was also confirmed by API 50 CHL and Gram stain tests.

To prepare working stocks, frozen stocks of all strains were scraped with a sterile pipette tip and transferred into $10 \mathrm{~mL}$ of M17 (S. thermophilus) or MRS (lactobacilli) broth and were incubated overnight at $37^{\circ} \mathrm{C}$. On the following day, a loopful of overnight culture was streaked onto an appropriate agar medium. After incubation at $37^{\circ} \mathrm{C}$ for $24-$ $36 \mathrm{~h}$, all plates were stored at $4^{\circ} \mathrm{C}$. Prior to each experiment, inocula of all L. acidophilus strains, S. thermophilus and L. delbrueckii ssp. bulgaricus were individually prepared by sub-culturing twice in $10 \mathrm{~mL}$ of the appropriate medium (MRS or $10 \%$ [w/w] sterile reconstituted nonfat dry milk $[\mathrm{NFDM}])$ at the rate of $1 \%$ and incubated at $37^{\circ} \mathrm{C}$ for $16-18$ h. 


\subsection{Bacterial Species Identification}

API 50 CHL or carbohydrate fermentation test from BioMeriuex was performed for bacterial species identification. For each strain, three colonies of working stocks were heavily streaked on MRS (lactobacilli) or M17 (S. thermophilus) agar. After incubation at $37^{\circ} \mathrm{C}$ for 24-48 h, a loopful of cultures were suspended into $2 \mathrm{~mL}$ of sterile $\mathrm{dIH}_{2} \mathrm{O}$. Increments of $25 \mu \mathrm{L}$ of this suspension were added to $5 \mathrm{~mL}$ sterile $\mathrm{dIH}_{2} \mathrm{O}$ until the turbidity matched a McFarland Standard \#2 (BioMériuex). Then, double amounts of 25 $\mu \mathrm{L}$ were added to the CHL medium (BioMériuex). After mixing by pipette up and down several times, $110 \mu \mathrm{L}$ of this suspension were added to each cupule of the API $50 \mathrm{CH}$ strips followed by overlaying with few drops of sterile mineral oil. Then, the API strips were incubated at $37^{\circ} \mathrm{C}$ for 24,48 and $72 \mathrm{~h}$. A positive reaction was given when the media turned from purple to yellow, except for the esculin test, which turned from purple to black. A negative reaction was interpreted when the media color remained purple. The results were input to the web-based apiweb ${ }^{\mathrm{TM}}$ System (http://apiweb.biomerieux.com) (BioMériuex) for speciation.

\subsection{Selective Media for Lactobacillus acidophilus}

A selective media was required to enumerate L. acidophilus amidst the closely related yogurt starter cultures. To this end, maltose, mannitol and sorbitol (BD Diagnostics, Franklin Lakes, NJ) were tested as dextrose replacement in MRS agar. Modified MRS preparation was made according to the ingredients shown in Table 4.1 and sterilized by autoclave at $121^{\circ} \mathrm{C}$ for $15 \mathrm{~min}$. Disaccharide or sugar alcohol solution was prepared separately by filter sterilization through a membrane with a pore size of 
$0.22 \mu \mathrm{m}$ (Corning, Fisher Scientific). The filter-sterilized solution was then added to the molten media to achieve a final concentration of $2 \%$ maltose, mannitol or sorbitol. Preliminary testing was done on all $L$. acidophilus strains, S. thermophilus and $L$. delbrueckii ssp. bulgaricus by streaking them heavily on each selective media followed by incubation at $37^{\circ} \mathrm{C}$ for $48-72 \mathrm{~h}$. Then, results were recorded as growth or no growth. The experiment was done in duplicate. M17 and MRS agar media were used as positive control for S. thermophilus and L. delbrueckii ssp. bulgaricus, respectively. The best selective media from this experiment, which was MRS-maltose agar, was chosen to be used in subsequent experiments requiring $L$. acidophilus enumeration from samples containing S. thermophilus and L. delbrueckii ssp. bulgaricus.

Table 4.1.Ingredients of MRS agar without dextrose per 1 liter

\begin{tabular}{|c|c|}
\hline Ingredient & Amount (g) \\
\hline Proteose peptone No. $3^{1}$ & 10 \\
\hline Beef extract ${ }^{1}$ & 10 \\
\hline Yeast extract $^{1}$ & 5 \\
\hline Polysorbate $80{\text { (Tween } 80)^{2}}^{2}$ & 1 \\
\hline Ammonium Citrate $^{2}$ & 2 \\
\hline Magnesium Sulfate $^{2}$ & 0.1 \\
\hline Manganese Sulfate $^{2}$ & 0.05 \\
\hline Dipotassium phosphate $^{2}$ & 2 \\
\hline Sodium Acetate ${ }^{2}$ & 5 \\
\hline Granulated agar $^{1}$ & 15 \\
\hline Deionized water & 950 \\
\hline
\end{tabular}

${ }^{1}$ Ingredients supplied by BD Diagnostics

${ }^{2}$ Ingredients supplied by Fisher Scientific

\subsection{Enumeration of $L$. acidophilus}

Standard plate count (SPC) was used to quantify viable L. acidophilus cells. The procedure was as follows: $1 \mathrm{~g}$ or $\mathrm{mL}$ of sample was diluted with $99 \mathrm{~mL}$ of sterile phosphate buffer saline (PBS), pH 7.2 from Hardy Diagnostics (Santa Maria, CA). 
Subsequent 10-fold serial dilutions were then made with PBS, and $0.1 \mathrm{~mL}$ of the diluted samples was spread on MRS-maltose agar (section 4.3). After incubation at $37^{\circ} \mathrm{C}$ for 48 $72 \mathrm{~h}$, colony-forming units (CFU) per g or mL were calculated.

\subsection{Agar Diffusion Assay}

Negative impacts of starter cultures on the survival of L. acidophilus strains were directly assessed with the agar diffusion assay method. On MRS agar, $10 \mu \mathrm{L}$ of overnight cultures of S. thermophilus and L. delbrueckii ssp. bulgaricus were spotted as shown in Figure 4.1. All plates were incubated at $37^{\circ} \mathrm{C}$ for $24 \mathrm{~h}$. For each $L$. acidophilus strain (NCFM, ATCC700396, PIM703, SBT2062 or LA-5), $0.1 \mathrm{~mL}$ of overnight culture was inoculated into $10 \mathrm{~mL}$ of $0.7 \%$ molten MRS agar, and was overlaid on pre-grown starter cultures. After incubation at $37^{\circ} \mathrm{C}$ for $48 \mathrm{~h}$, the presence of inhibition zones around the starter culture colonies was observed.

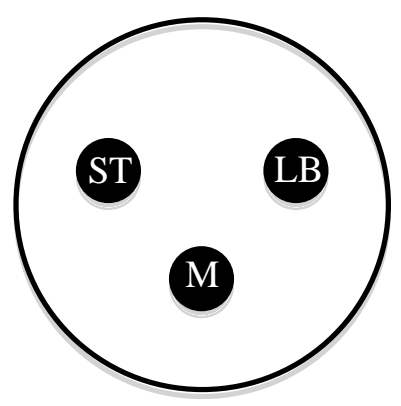

Figure 4.1. Agar diffusion assay using MRS agar spotted with overnight starter cultures (10 $\mu \mathrm{L}$ S. thermophilus [ST]; $10 \mu \mathrm{L}$ L. delbrueckii ssp. bulgaricus [LB]; $10 \mu \mathrm{L} S$. thermophilus and L. delbrueckii ssp. bulgaricus [M]) 


\subsection{Survival Assays of Lactobacillus acidophilus}

\subsubsection{Effect of Yogurt Starter Cultures}

To study the effect of the presence and absence of starter cultures on the survival of probiotics strains, two types of yogurt were manufactured - one made with starter cultures and one made with glucono-delta-lactone (GDL) (PMP Fermentation Products, Inc, Peoria, IL) as shown in Figure 4.2. GDL is an acidulant that gradually lowers the pH of milk. Therefore, the purpose of adding GDL was to study the effect of pH independent of any metabolic activity of starter cultures. Table 4.2 summarizes the factor and response variables for this experiment.

Yogurt mixture was made from 14\% reconstituted low-heat NFDM (Dairy America, Inc., Fresno, CA) in the laboratory. For yogurt made with starter cultures, a package of 250-g starter cultures (YF-L702) was thawed in a water bath at room temperature. A 10-fold dilution of the starter cultures was made with sterile reconstituted NFDM (10\% total solids), and $6 \mathrm{~mL}$ of this diluted culture were added into $3 \mathrm{~L}$ of pasteurized (heat treatment at $85^{\circ} \mathrm{C}$ for $30 \mathrm{~min}$ ) reconstituted NFDM being held at $43^{\circ} \mathrm{C}$. For yogurt made without starter cultures, GDL was added to the pasteurized reconstituted NFDM at a concentration of $1.6 \%(\mathrm{w} / \mathrm{v})$ instead of starter cultures.

To study the survival of L. acidophilus strains in these two types of yogurt, they were inoculated (as separate samples) immediately after the addition of starter cultures or GDL at a concentration of $5 \%(\mathrm{v} / \mathrm{v})$ which was equivalent to $\sim 10^{6} \mathrm{cfu} / \mathrm{mL}$ of milk. The $\mathrm{pH}$ of the mixtures was monitored periodically during the incubation at $43^{\circ} \mathrm{C}$. Incubation was ceased when $\mathrm{pH}$ reached 4.6; upon which the mixtures became semisolid and were considered finished products. Samples were stored at $4^{\circ} \mathrm{C}$ for 28 days, the typical shelf 
life of commercial yogurts. Aliquots of each sample were removed from the refrigerator on day $0,7,14,21$ and 28, and were tested for $\mathrm{pH}$ and viable cell counts with standard plate count procedure. Relative survival for each strain was determined by dividing the number of viable cells on day 7, 14, 21 or 28 by the initial cell count on day 0 and multiplied by 100. The experiment was carried out in triplicate; the strains demonstrating the best (SBT2062) and the poorest (NCFM) survival from this experiment were used in subsequent experiments.

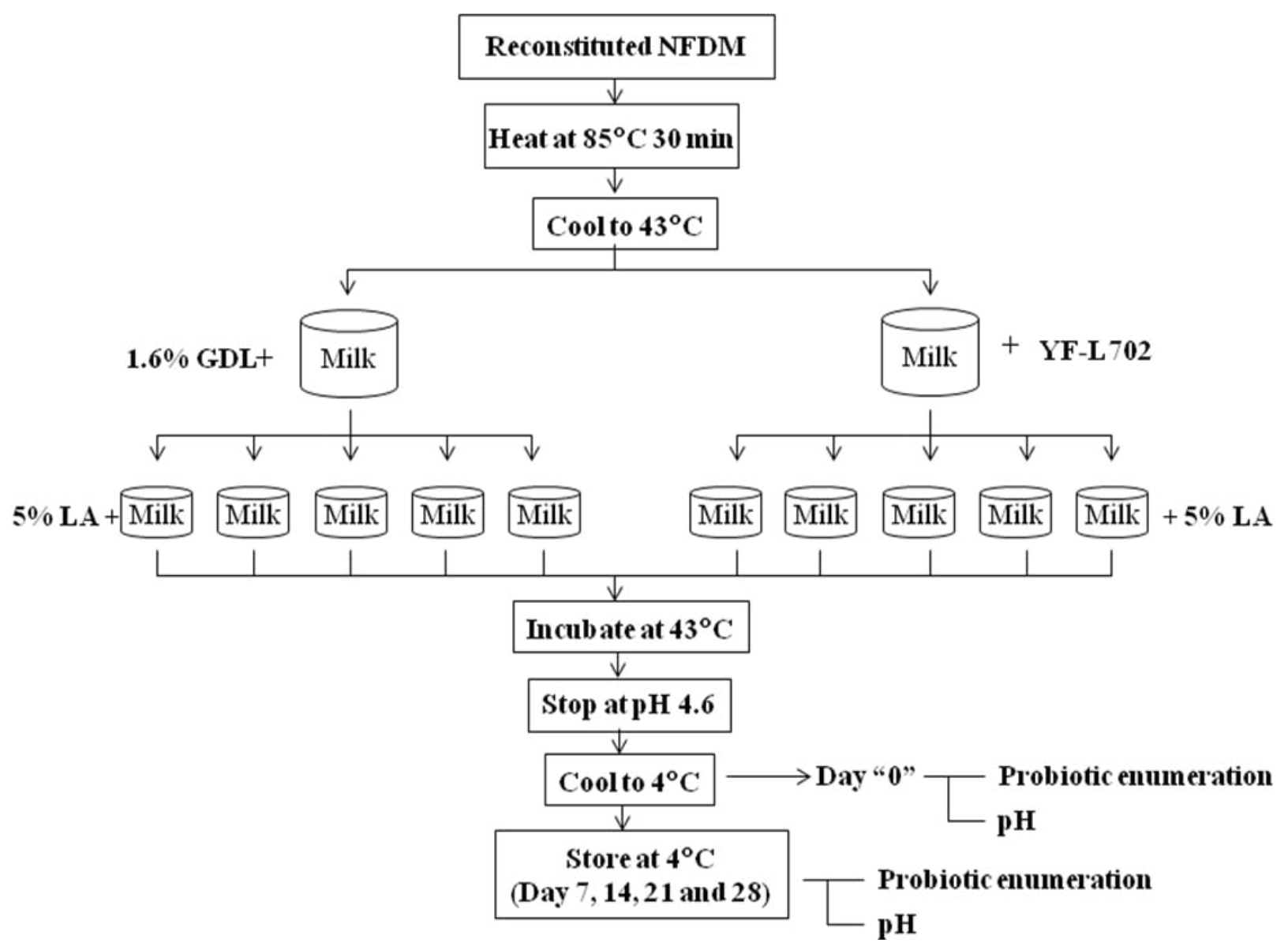

Figure 4.2. Outline of yogurt production with and without starter culture fermentation 
Table 4.2. Experimental design (effect of starter culture) factor and response variables

\begin{tabular}{|l|l|l|}
\hline \multicolumn{2}{|c|}{ Effect of Starter Cultures in Yogurt } \\
\hline \multicolumn{1}{|c|}{ Factor } & Treatment Levels & \multicolumn{1}{c|}{ Response } \\
\hline \multirow{2}{*}{ Acid producer } & Starter Cultures & \\
\cline { 2 - 2 } & GDL & \\
\hline \multirow{4}{*}{ L. acidophilus strain } & ATCC700396 & \\
\cline { 2 - 2 } & LA-5 & \\
\cline { 2 - 2 } & NCFM & \\
\cline { 2 - 2 } & PIM703 & \\
\cline { 2 - 2 } & SBT2062 & \\
\hline
\end{tabular}

\subsubsection{Effect of Yogurt Filtrate}

To study the effect of metabolic products produced from starter cultures on probiotics survival, yogurt filtrate was collected and was added into MRS broth containing L. acidophilus NCFM. Yogurt filtrate was prepared by adding $100 \mathrm{~mL}$ of sterile phosphate buffer, pH 7.2 (Hardy Diagnostics), into $100 \mathrm{~g}$ of yogurt made with starter cultures or with GDL. These yogurts did not contain probiotics. The diluted yogurt mixture was prefiltered through a Whatman \#42 filter (Fisher Scientific) and then a cellulose acetate membrane with a pore size of $0.22 \mu \mathrm{m}$ (Fisher Scientific). Various amounts of sterile filtrate collected from two types of yogurt (Table 4.3) was added into MRS broth containing overnight-grown cultures of L. acidophilus NCFM. Enumeration of $L$ acidophilus NCFM was performed for 15 days at 3-day intervals. The experiment was carried out in duplicate.

Table 4.3.Amount of yogurt filtrate added into L. acidophilus NCFM

\begin{tabular}{|c|c|c|c|c|c|c|c|}
\hline Sample & 10G & 9G1S & 8G2S & 5G5S & 2G8S & 1G9S & 10S \\
\hline YF-STLB $^{\text {a }}$ (mL) & 0 & 1 & 2 & 5 & 8 & 9 & 10 \\
\hline YF-GDL $^{\mathbf{b}}$ (mL) & 10 & 9 & 8 & 5 & 2 & 1 & 0 \\
\hline
\end{tabular}

${ }^{a}$ YF-STLB is the yogurt filtrate originated from yogurt with starter cultures

${ }^{b}$ YF-GDL is the yogurt filtrate originated from yogurt with GDL 


\subsubsection{Effect of Killed Starter Cultures}

This experiment was conducted to investigate the survival of L. acidophilus strains in yogurt post-fermentation and in the presence of non-viable starter cultures. Yogurt was made as previously described in section 4.6.1 except that L. acidophilus strains were not added. When the $\mathrm{pH}$ reached 4.6, the fermentation was ceased by immediately cooling down to $4^{\circ} \mathrm{C}$ in an ice bath. The finished product was re-pasteurized by heating at $75^{\circ} \mathrm{C}$ for 15 min to kill all starter cultures. After cooling down to $4^{\circ} \mathrm{C}, 5 \%$ (v/v) of L. acidophilus NCFM or SBT2062 was mixed thoroughly. Enumeration of $L$. acidophilus was conducted for 15 days at 3-day intervals.

\subsubsection{Effect of Individual Starter Culture Species}

To further study the competition between individual species of the yogurt starter cultures and L. acidophilus, yogurts were made with S. thermophilus or L. delbrueckii ssp. bulgaricus alone using a similar procedure described in section 4.6.1. After pasteurizing 14\% reconstituted NFDM, the heated milk was divided into 4 portions. To each portion, 5\% (v/v) of the best survival probiotics strain (L. acidophilus SBT2062) or the poorest (NCFM) survival of L. acidophilus and $1 \%(\mathrm{v} / \mathrm{v})$ of starter cultures (S. thermophilus, ST; L. delbrueckii ssp. bulgaricus, LB) were separately inoculated as outlined in Figure 4.3. All samples were incubated at $43^{\circ} \mathrm{C}$ until the $\mathrm{pH}$ reached 4.6. After cooling the samples to $4^{\circ} \mathrm{C}$ in an ice bath, enumeration of L. acidophilus was performed on MRS-maltose agar, and the remaining samples were stored at $4^{\circ} \mathrm{C}$ for 28 days. The experiment was carried out in triplicate. Table 4.4 describes the factor and response variables for this study. 
Table 4.4. Experimental design (effect of individual starter culture species) factor and response variables

\begin{tabular}{|c|l|l|}
\hline \multicolumn{2}{|c|}{ Effect of Individual Starter Culture Species Fermentation } \\
\hline Factor & \multicolumn{1}{|c|}{ Treatment Levels } & Response \\
\hline \multirow{2}{*}{ Starter Culture Species } & S. thermophilus & \\
\cline { 2 - 2 } & L. delbrueckii ssp. bulgaricus & \multirow{2}{*}{ \% Survival of L. acidophilus } \\
\hline \multirow{2}{*}{ L. acidophilus strain } & NCFM & \\
\cline { 2 - 2 } & SBT2062 & \\
\hline
\end{tabular}

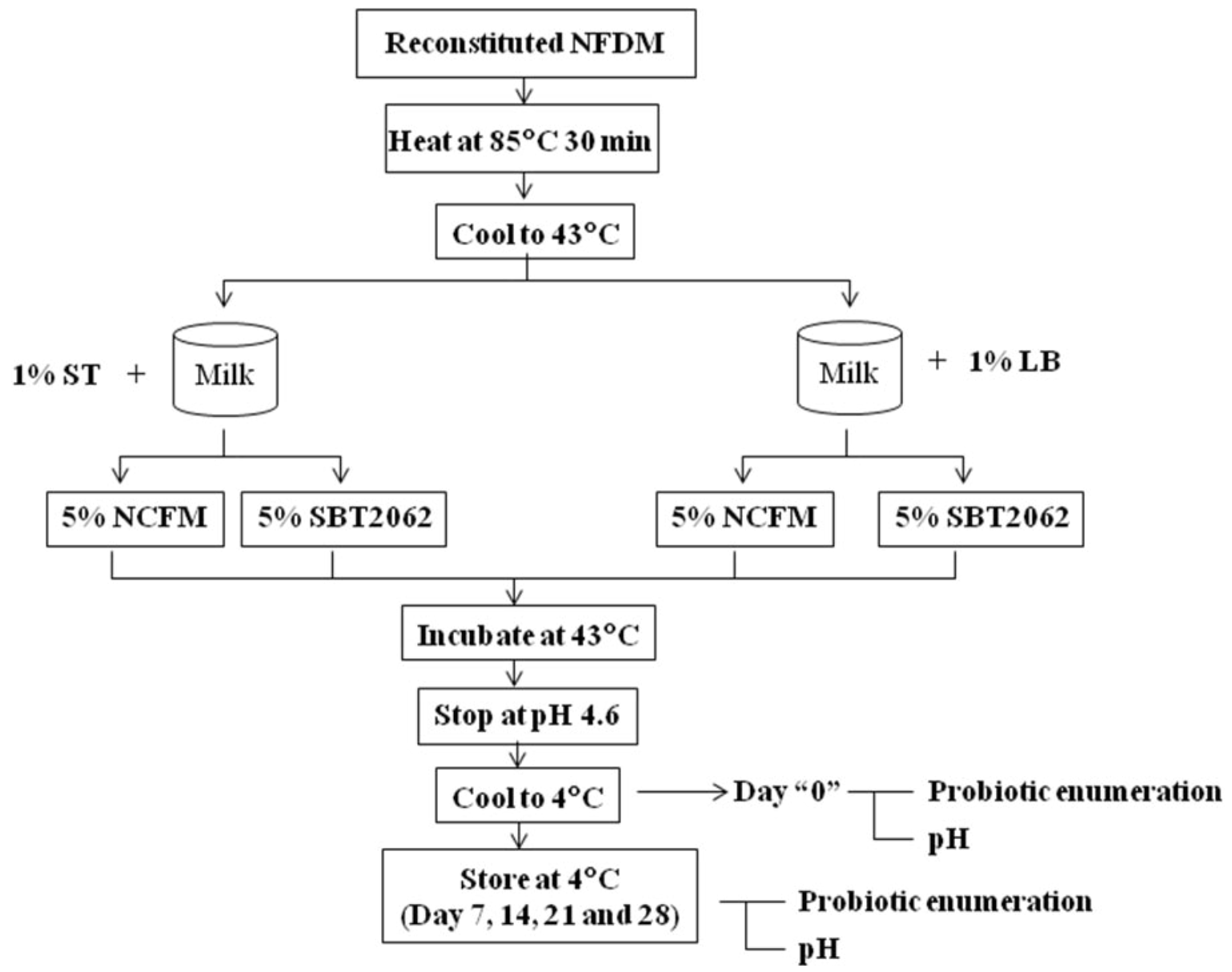

Figure 4.3. Outline of yogurt production with individual starter culture species (ST: $S$. thermophilus; LB: L. delbrueckii ssp. bulgaricus) and L. acidophilus strains (SBT2062 and NCFM) 


\subsubsection{Survival of Probiotics in Soy Milk and Reconstituted Milk}

Due to the popularity of soy-based products along with probiotics, we conducted a supplemental experiment regarding the survival of $L$. acidophilus in soy milk and in reconstituted milk. Commercial plain soymilk was purchased from a local supermarket, and milk was prepared from 9\% reconstituted low-heat NFDM. Prior to inoculation of $L$. acidophilus strains, soymilk and milk ( $9 \%$ total solids) were sterilized by autoclave $\left(121^{\circ} \mathrm{C}\right.$ for $15 \mathrm{~min}$ ). After cooling down to $37^{\circ} \mathrm{C}, 2 \%$ (v/v) of overnight cultures (refer to section 4.1 for inoculum preparation) was added to each medium, and was incubated in a water bath at $37^{\circ} \mathrm{C}$ for $6 \mathrm{~h}$. All samples were immediately cooled down to $4^{\circ} \mathrm{C}$ in an ice water bath, then stored for enumeration of $L$. acidophilus weekly for 28 days.

\subsection{6 $\mathrm{pH}$ Measurement}

Prior to $\mathrm{pH}$ measurement, the $\mathrm{pH}$ meter (Orion model 410 A plus, USA) was calibrated with standard buffer $\mathrm{pH} 4$ and 7 (Fisher Scientific). Then, the $\mathrm{pH}$ of each sample was measured at room temperature.

\subsubsection{Statistical Analysis}

Log transformation was used to evaluate the relative survival of L. acidophilus strains, and a two-way analysis of variance (ANOVA) was performed using the general linear model in Minitab software version 15.1 to analyze the differences between samples and within L. acidophilus strains. Data reported in all tables were the means \pm SD of two or three replicates. 


\subsection{Gene Expression Study of Lactobacillus acidophilus}

To further understand the physiology of survival of L. acidophilus NCFM and SBT2062 in yogurt, gene expression analysis using semi-quantitative RT-PCR was performed. Table 4.5 describes the factor and response variables for this study.

Table 4.5. Experimental design (gene expression) factor and response variables

\begin{tabular}{|l|c|c|}
\hline \multicolumn{2}{|c|}{ Effect of Starter Cultures on Gene Expression } \\
\hline \multicolumn{1}{|c|}{ Factor } & Treatment Levels & Response \\
\hline \multirow{2}{*}{ Stress genes } & $d n a K$ & \multirow{2}{*}{ Intensity of amplification } \\
& groEL & products (Intensity*mm ${ }^{2}$ ) \\
\cline { 2 - 2 } \multirow{2}{*}{ L. acidophilus strain } & NCFM & \\
\cline { 2 - 2 } & SBT2062 & \\
\hline
\end{tabular}

\subsubsection{Stress Genes and Primer Design}

Seven genes related to stress response (dnaJ, dnaK, gadC, groEL, groES, grpE and $h r c A)$ and one housekeeping gene (16S rDNA) were chosen to determine the gene expression profiles of L. acidophilus in yogurt. Species-specific primers (see Table 4.6) were designed by using Amplicon (Jarman, 2004). For each gene, DNA sequences from L. acidophilus NCFM (Altermann et al., 2005), L. delbrueckii ssp. bulgaricus ATCC11847 (Van de Guchte et al., 2006) and S. thermophilus CNRZ1066 (Bolotin et al., 2004) were aligned using CLUSTAL W version 1.4 (Higgins, 1994) in the BioEdit program (http://www.mbio.ncsu.edu/bioedit/bioedit.html), and then the most unique regions to L. acidophilus were selected for designing the forward and reverse primers. Primers were purchased from Integrated DNA Technologies (San Diego, CA). 
Table 4.6. Sequences of primer sets for L. acidophilus

\begin{tabular}{|l|l|l|}
\hline \multicolumn{1}{|c|}{ Gene } & Primer & \multicolumn{1}{c|}{ Sequence (5' to $\mathbf{3}^{\prime}$ ) } \\
\hline \multirow{2}{*}{$d n a J$} & Forward & AAGCCACCTTGACCATTGAC \\
\cline { 2 - 3 } & Reverse & CATGAACCTGGTGCAGAAGA \\
\hline \multirow{2}{*}{$d n a K$} & Forward & GCACCACCATTGTTACCATC \\
\cline { 2 - 3 } & Reverse & GCTTTATCAAAAGCTGCTCAAG \\
\hline \multirow{2}{*}{ gadC } & Forward & TGGCAAGACTGGTGCTACTG \\
\cline { 2 - 3 } & Reverse & TCGCCCAGTGAACCTTTTAC \\
\hline \multirow{2}{*}{ groEL } & Forward & GAAATTGGTTACAATGCTGCAAC \\
\cline { 2 - 3 } groES & Reverse & CTTGAGGAGCTTCTGGCTTATC \\
\cline { 2 - 3 } & Forward & TTGGCGGTATTGTTTTAGCA \\
\cline { 2 - 3 } grpE & Reverse & TCGTTAAAGTTAAAGAAGAAGAAG \\
\cline { 2 - 3 } & Forward & TAAGTTGCGCACGTTCTTTG \\
\hline \multirow{2}{*}{ hrcA } & Reverse & GGCTAAAGGCGAAGAAACAA \\
\cline { 2 - 3 } & Forward & TCCTTCACATTATGCTCAGATG \\
\hline \multirow{2}{*}{$16 \mathrm{~S}$ rDNA } & Reverse & AGTGAGCTAGGCGGAGAACA \\
\cline { 2 - 3 } & Forward & AGCAGATCGCATGATCAGCT \\
\hline
\end{tabular}

The specificity of the designed primers was evaluated by polymerase chain reaction (PCR) with template DNA of $L$. acidophilus NCFM and SBT2062, $L$. delbrueckii ssp. bulgaricus and S. thermophilus in a GeneAmp PCR System 2400 (Perkin-Elmer, Foster City, CA). The amplification condition is described in section 4.7.3.

\subsubsection{Total RNA Extraction}

Extracting RNA directly from yogurt was not successfully achieved due to the high viscosity of the yogurt matrix. Therefore, yogurt samples must be diluted prior to RNA extraction: $2 \mathrm{~g}$ of yogurt were diluted with $6 \mathrm{~mL}$ of warm $\left(\sim 40^{\circ} \mathrm{C}\right) \mathrm{PBS}$. The diluted 
yogurt was mixed by vortexing at room temperature for $30 \mathrm{sec}$. Then, $2 \mathrm{~mL}$ of the sample were added into $4 \mathrm{~mL}$ of RNAprotect Bacteria Reagent (Qiagen, Valencia, CA). After incubation at room temperature for $5 \mathrm{~min}$, the sample was centrifuged at 3,000 $\mathrm{xg}$ at room temperature for $25 \mathrm{~min}$. The supernatant was carefully removed, and the pellet was re-suspended with $1 \mathrm{~mL}$ of PBS. To the suspension, $0.5 \mathrm{~mL}$ of clearing solution [0.15M $N$-[2-Acetamido]iminodiacetic acid (ADA) (Sigma-Aldrich, Atlanta, GA); 0.01\% w/v uniform polystyrene particles (Bangs Laboratories, Inc., Fisher, IN, size $0.80 \mu \mathrm{m}$ ); $0.5 \%$ w/v Triton-X100, Promega, Madison, WI)] was added. After mixing by inverting 10 times, the sample was centrifuged at $14,000 \times \mathrm{g}$ for $10 \mathrm{~min}$. Then, the supernatant was carefully discarded.

Total RNA extraction was performed by using RNeasy Mini kit from Qiagen (Valencia, CA). In a separate microfuge tube, $20 \mu \mathrm{L}$ of Proteinase K (Qiagen) were added to $100 \mu \mathrm{L}$ of TE buffer (30 mM Tris-Cl; $1 \mathrm{mM}$ EDTA, pH 8.0) (Promega) containing $15 \mathrm{mg} / \mathrm{mL}$ lysozyme (Sigma-Aldrich), and the entire mixture was added to the pellet. The suspension was mixed at room temperature by vortexing every 2 min for 10 $\min$.

To the suspension, $700 \mu \mathrm{L}$ of Buffer RTL from the RNeasy Mini kit was added, and the entire volume was transferred to a new $2 \mathrm{~mL}$ safe-lock tube containing $50 \mathrm{mg}$ of acid-washed glass beads (Sigma). The cells were disrupted in a Tissue Lyser at the maximum speed for 5 min. After the cell disruption step, the tube was briefly centrifuged at $14,000 \times \mathrm{g}$ for $10 \mathrm{sec}$. Then, $760 \mu \mathrm{L}$ of the supernatant was carefully transferred to a new 2-mL microcentrifuge tube, and $590 \mu \mathrm{L}$ of $80 \%$ ethanol (Fisher Scientific, Tustin, CA) was added. After mixing by pipetting up and down several times, the lysate was 
transferred into an RNeasy Mini spin column and was centrifuged at 10,000 x $g$ for 15 sec. Three hundred and fifty $\mu \mathrm{L}$ of Buffer RW1 were added to the RNeasy spin column, and the column was centrifuged at $10,000 \times \mathrm{g}$ for $15 \mathrm{sec}$.

DNase Digestion was applied at this point to eliminate any possible DNA contamination during the RNA extraction by using RNase-Free DNase set from Qiagen (Valencia, CA). In a separate tube, $10 \mu \mathrm{L}$ of DNase I stock solution was added to $70 \mu \mathrm{L}$ Buffer RDD. Then $80 \mu \mathrm{L}$ of the diluted DNase I was added directly to the column membrane and was incubated at room temperature for $15 \mathrm{~min}$. This step was repeated after centrifugation (at 10,000 $\mathrm{x} g$ for $15 \mathrm{sec}$ ) for efficient DNA elimination.

Three hundred and fifty $\mu \mathrm{L}$ Buffer of RW1 was added to the column and was incubated for additional $5 \mathrm{~min}$. The column was centrifuged at $10,000 \times \mathrm{g}$ at room temperature for $15 \mathrm{~s}$. Then, the column was placed in a new 2-mL collection tube, and $500 \mu \mathrm{L}$ Buffer RPE was added followed by centrifugation at $10,000 \times \mathrm{g}$ for $15 \mathrm{~s}$. After the flow-through was discarded, addition of $500 \mu \mathrm{L}$ Buffer RPE was repeated, and the column was centrifuged at $10,000 \times g$ at room temperature for 2 min. The column was once again placed to a new 1.5-mL RNase-free microfuge tube, and $30 \mu \mathrm{L}$ of RNase-free water were added directly to the column membrane followed by centrifugation at 10,000 $\mathrm{x} g$ at room temperature for $1 \mathrm{~min}$. This step was repeated with the RNA elute for higher RNA concentration.

The integrity of RNA was determined by gel electrophoresis using FlashGel ${ }^{\circledR}$ RNA system (Lonzo, Cottonwood, AZ). Five $\mu \mathrm{L}$ of each sample were loaded to each well. The electrophoresis was conducted at room temperature at 225V for 5 min. Gels were stained with ethidium bromide and were visualized on a UV transilluminator 
(ChemiDoc XRS imaging device, Bio-Rad, Hercules, CA). RNA concentration and purity were determined by a UV spectrophotometer at 260 and $280 \mathrm{~nm}$, respectively. All samples were stored at $-20^{\circ} \mathrm{C}$.

\subsubsection{Reverse Transcription - Polymerase Chain Reaction (RT-PCR)}

Reverse transcription (mRNAs converted to cDNAs) was carried out by using Superscript III (Invitrogen, Carlsbad, CA) according to the manufacturer's protocol. All reagents and supplies used in this step were nuclease-free and were purchased from Invitrogen (Carlsbad, CA). One hundred ng of total RNA, $2.5 \mu \mathrm{L}$ of random hexamers (100 ng/ $\mu \mathrm{L}$ ) and $1 \mu \mathrm{L}$ of $10 \mathrm{mM}$ dNTPs were mixed in a $0.2-\mathrm{mL}$ microcentrifuge tube. Then, nuclease-free water was added to a total volume of $13 \mu \mathrm{L}$. The mixture was heated to $65^{\circ} \mathrm{C}$ for 5 min and was incubated on ice for at least $1 \mathrm{~min}$. After a brief centrifugation, $4 \mu \mathrm{L}$ of $5 X$ First-Strand buffer, $1 \mu \mathrm{L}$ of $0.1 \mathrm{M}$ DTT, $1 \mu \mathrm{L}$ of RNaseOUT ${ }^{\mathrm{TM}}$ Recombinant RNase Inhibitor and $1 \mu \mathrm{L}$ of SuperScript ${ }^{\mathrm{TM}}$ III RT were added to the contents. The sample was mixed carefully by pipette up and down followed by incubating at $25^{\circ} \mathrm{C}$ for $5 \mathrm{~min}$, $50^{\circ} \mathrm{C}$ for 60 and $70^{\circ} \mathrm{C}$ for $15 \mathrm{~min}$. After cooling down to $37^{\circ} \mathrm{C}, 2$ units of $E$. coli RNase $\mathrm{H}$ were added to remove DNA:RNA hybrids as the sample was incubated at $37^{\circ} \mathrm{C}$ for 20 min. All cDNA samples were stored at $-20^{\circ} \mathrm{C}$ until use.

PCR was then conducted using the above cDNA as templates and the primer sets specified in Table 4.6 in a GeneAmp PCR System 2400 (Perkin-Elmer). For each gene, a reaction mixture of $50 \mu \mathrm{L}$ consisted of $5 \mu \mathrm{L}$ of $10 \mathrm{X}$ buffer without $\mathrm{MgCl}_{2}$ (Roche Applied Science), $3 \mu \mathrm{L}$ of $25 \mathrm{mM} \mathrm{MgCl}_{2}$ (Roche), $0.5 \mu \mathrm{L}$ of $10 \mathrm{mM} \mathrm{dNTP}$ mix (Invitrogen), $1.5 \mu \mathrm{L}$ of $10 \mu \mathrm{M}$ forward and reverse primers, $0.25 \mu \mathrm{L}$ of $5 \mathrm{U} / \mu \mathrm{L}$ Taq 
Polymerase (Roche), $2 \mu \mathrm{L}$ of template DNA and $36.25 \mu \mathrm{L}$ of nuclease-free water (Invitrogen). The thermocycling condition was programmed as follows: $94^{\circ} \mathrm{C}$ for $5 \mathrm{~min}$; 40 cycles of $94^{\circ} \mathrm{C}$ for $30 \mathrm{~s}, 60^{\circ} \mathrm{C}$ for $30 \mathrm{~s}$, and $72^{\circ} \mathrm{C}$ for $1 \mathrm{~min}$; and $72^{\circ} \mathrm{C}$ for $10 \mathrm{~min}$. Ten $\mu \mathrm{L}$ of the PCR products were electrophoresed in 1.5\% (w/v) agarose gel (Fisher Scientific) in 0.5X TBE buffer (44.5 mM Tris-borate and 1 mM EDTA, pH 8.3) (Sigma) containing ethidium bromide (Fisher Scientific) (final concentration $0.5 \mu \mathrm{g} / \mathrm{mL}$ ) at $90 \mathrm{~V}$ for 45 min. Gels were visualized with a UV transilluminator (ChemiDoc XRS imaging device, Bio-Rad), and the density (units of signal intensity) of each band was quantified using Quantity One ${ }^{\circledR}$ Software program version 4.6.4 (Bio-Rad). 


\section{0}

\section{RESULTS}

\subsection{Identification of Bacterial Species}

Carbohydrate fermentation (API $50 \mathrm{CH}$ ) was performed on seven strains (five Lactobacillus acidophilus, one Lactobacillus delbrueckii ssp. bulgaricus, and one Streptococcus thermophilus) to confirm the bacterial species from the Dairy Products Technology Center (DPTC) culture collection and from the manufacturer. After 24, 48 and 72 hours of incubation, a numeric value of 0 to 5 was given according to the color of the media. Values of 0-2 (negative results) represent media color change from purple to blue, and values of 3-5 (positive results) denote the color change from purple to yellow. After inputting the data to the manufacturer's web-based program (http://apiweb.biomerieux.com), speciation of each bacterial strain was returned with relative identification and profile status as seen in Table 5.1. The profile status describes the reliability of the speciation. The carbohydrate fermentation raw data are shown in Appendix A.

Table 5.1. Speciation results obtained from carbohydrate fermentation tests

\begin{tabular}{|l|l|c|l|l|}
\hline $\begin{array}{c}\text { Bacteria ID provided } \\
\text { by the supplier }\end{array}$ & \multicolumn{1}{|c|}{$\begin{array}{c}\text { Speciation } \\
\text { Result }\end{array}$} & $\begin{array}{c}\text { Relative } \\
\text { Identification }\end{array}$ & Profile Status & $\begin{array}{c}\text { Microscopic Cell } \\
\text { Morphology }\end{array}$ \\
\hline $\begin{array}{l}\text { L. acidophilus } \\
\text { ATCC700396 }\end{array}$ & L. acidophilus & $99.0 \%$ & Good & Gram positive rods \\
\hline L. acidophilus LA-5 & L. acidophilus & $99.0 \%$ & Good & Gram positive rods \\
\hline L. acidophilus NCFM & L. acidophilus & $99.0 \%$ & Good & Gram positive rods \\
\hline L. acidophilus PIM703 & L. acidophilus & $99.0 \%$ & Good & Gram positive rods \\
\hline L. acidophilus SBT2062 & L. acidophilus & $97.9 \%$ & Good & Gram positive rods \\
\hline $\begin{array}{l}\text { L. delbrueckii SSp. } \\
\text { delbrueckii }\end{array}$ & $\begin{array}{l}\text { L. delbrueckii } \\
\text { ssp. delbrueckii }\end{array}$ & $92.8 \%$ & Doubtful & Gram positive rods \\
\hline S. thermophilus & S. thermophilus & $64.7 \%$ & $\begin{array}{l}\text { Low } \\
\text { discrimination }\end{array}$ & Gram Positive cocci \\
\hline
\end{tabular}




\subsection{Selective Media for Lactobacillus acidophilus}

Three selective media, MRS-maltose, MRS-mannitol and MRS-sorbitol agars, were preliminarily tested as selective media for L. acidophilus but not the yogurt starter cultures. After 48 hours of incubation at $37^{\circ} \mathrm{C}$, all five L. acidophilus strains grew on these media, while no growth of S. thermophilus and L. delbrueckii ssp. bulgaricus was observed. The colony morphology of L. acidophilus on MRS-maltose and MRS-mannitol agars was slightly whitish (PIM703 was white and creamy) with colony size of 1-2 mm. However, a technical disadvantage of mannitol was that its solubility was fairly low, and re-crystallization of this sugar alcohol occurred quickly. For MRS-sorbitol agar, the colony size of all L. acidophilus strains was pin-point and translucent, rendering colony counting rather difficult. Therefore, MRS-maltose agar was selected for the enumeration of L. acidophilus from yogurt samples containing S. thermophilus and L. delbrueckii ssp. bulgaricus.

\subsection{Determination of Survival of Lactobacillus acidophilus}

\subsubsection{Effect of Yogurt Starter Cultures}

Enumeration of L. acidophilus at various time points during the refrigerated storage period was determined by standard plate count on MRS-maltose. To evaluate the difference in the strains' survival in two types of yogurts (made with GDL or starter cultures), the mean relative survival of three replicates was plotted as shown in Figures 5.1 and 5.2. The initial viable cell counts post-fermentation of L. acidophilus strains (day 0) ranged from $1 \times 10^{7}$ to $1 \times 10^{8} \mathrm{cfu} / \mathrm{g}$. During the refrigerated storage period, the $\mathrm{pH}$ of both types of yogurts stayed at $\sim \mathrm{pH} 4.6$ (ranged from 4.59 to 4.62). Statistical analysis 
was performed using a two-way analysis of variance (ANOVA) with the log relative survival as the response variable, the yogurt type (GDL or starter cultures) and $L$. acidophilus strain (ATCC700396, LA-5, NCFM, PIM703 and SBT2062) as factors. All relative survival data were transformed using a based-10 logarithm (log relative survival), and a value of 0.00001 was added to all data values, since some values were zero. The transformation for statistical analysis was performed due to the correction of normality and constant variance tests. Although, among L. acidophilus strains in yogurt in the absence of starter cultures (i.e., yogurt made with GDL), the p-values also demonstrated a significant difference $(p<0.05)$, survival of all strains remained stable throughout the storage period with a maximum of 1 log reduction (NCFM and PIM703) (see Table 5.2 and Figure 5.1), and L. acidophilus SBT2062 exhibited the best relative survival.

On the other hand, throughout the 28-day storage period of the standard yogurt (made with starter cultures), survival of five probiotic strains showed strain-to-strain variation as shown in Figure 5.2 suggesting a distinction in probiotic survival behavior within the same species. Among these five strains, the best survival was L. acidophilus SBT2062, and the poorest survival was L. acidophilus NCFM exhibiting a 4.6-log reduction, followed by ATCC700396and LA-5 (3.0-log and 1.6-log reduction, respectively)(see Table 5.3 and Figure 5.2). The drastic drops of L. acidophilus NCFM and ATCC700396 started on day 14, and the final viable cell counts on day 28 were $1.3 \mathrm{x}$ $10^{4}$ and $1.1 \times 10^{5}$, respectively. Statistical analysis on the average relative survival of $L$. acidophilus in regular yogurt showed that the survival of NCFM was significantly lowered than that of LA-5, PIM703 and SBT2062 ( $p<0.05)$. 
By analyzing the survival of L. acidophilus based on the presence and absence of starter cultures in yogurt, we expected to see difference in the survival behavior of some strains due to some inhibitory effects from starter cultures (refer to Chapter 2.4). After 28-day storage period, L. acidophilus ATCC700396 and NCFM showed that there is a significant difference in survival in two types of yogurts $(p<0.05)$, which indicates that the survival of these two strains was adversely affected by the presence of starter cultures. Since L. acidophilus SBT2062 and NCFM exhibited the best and the poorest survival in both types of yogurts, respectively, these strains were subsequently used in other experiments.

Table 5.2. Viable cell count of $L$. acidophilus strains in yogurt made with GDL during 28 days of storage period at $4^{\circ} \mathrm{C}$. Means and standard deviations were calculated from three replicates.

\begin{tabular}{|l|c|c|c|c|c|}
\hline \multirow{2}{*}{$\begin{array}{c}\text { L. acidophilus } \\
\text { Strain }\end{array}$} & \multicolumn{5}{|c|}{ Colony forming unit (CFU)/g (x10 $\mathbf{6})$} \\
\cline { 2 - 6 } & Day 0 & Day 7 & Day 14 & Day 21 & Day 28 \\
\hline ATCC700396 & $39.0 \pm 21.0$ & $21.8 \pm 7.6$ & $23.0 \pm 13.5$ & $21.2 \pm 19.9$ & $15.1 \pm 14.7$ \\
\hline LA-5 & $84.0 \pm 20.0$ & $75.7 \pm 16.0$ & $73.7 \pm 14.5$ & $52.2 \pm 28.7$ & $29.2 \pm 15.6$ \\
\hline NCFM & $48.3 \pm 10.5$ & $33.9 \pm 10.6$ & $23.3 \pm 14.9$ & $10.7 \pm 9.8$ & $7.4 \pm 8.0$ \\
\hline PIM703 & $33.3 \pm 7.1$ & $27.5 \pm 6.1$ & $24.9 \pm 10.3$ & $13.7 \pm 5.1$ & $6.0 \pm 1.9$ \\
\hline SBT2062 & $11.4 \pm 6.0$ & $13.2 \pm 9.0$ & $13.2 \pm 7.53$ & $11.7 \pm 6.1$ & $11.0 \pm 5.8$ \\
\hline
\end{tabular}




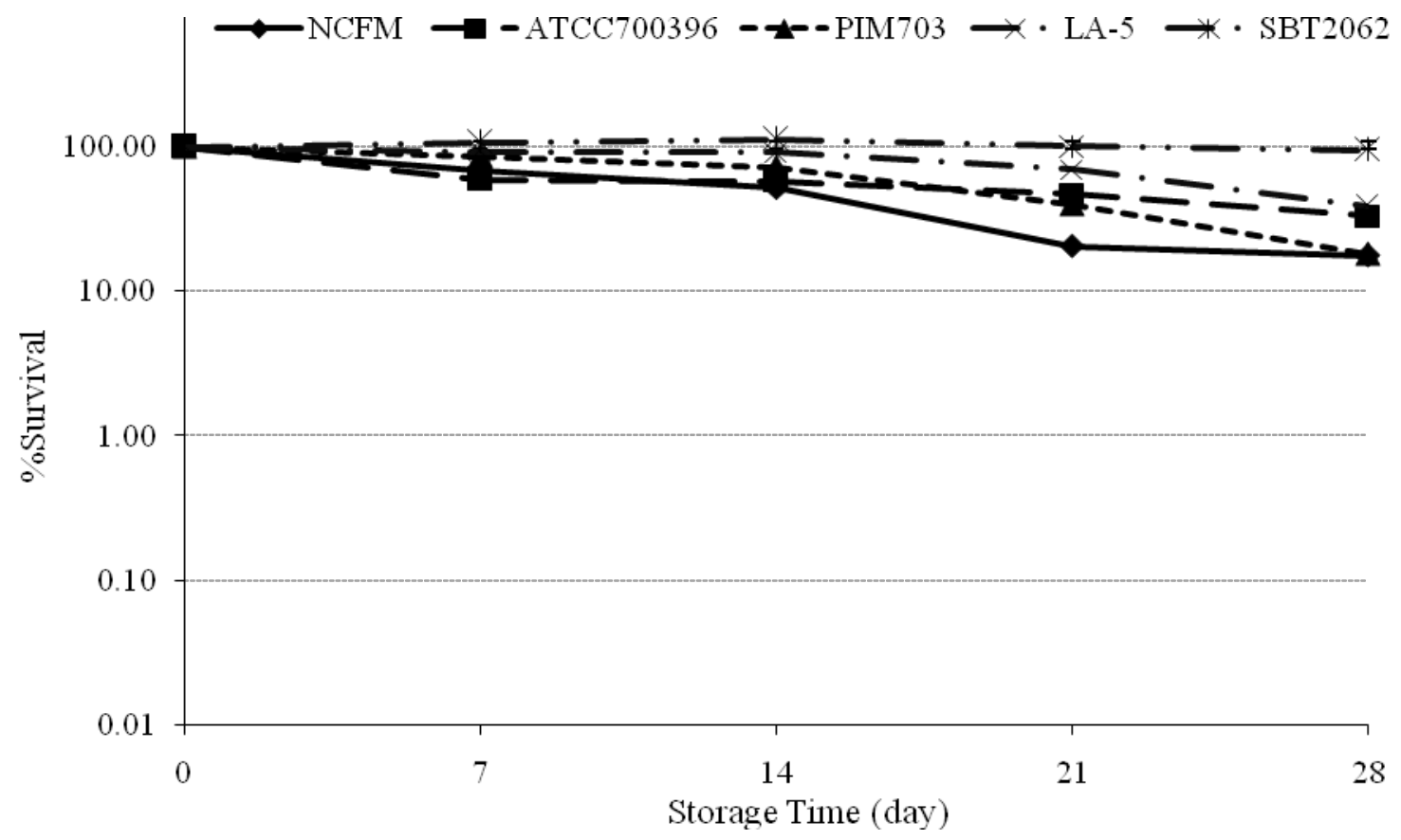

Figure 5.1. Relative survival of five different L. acidophilus strains in yogurt made with GDL during 28 days of storage period at $4^{\circ} \mathrm{C}$.

Table 5.3. Viable cell count of L. acidophilus strains in yogurt made with starter cultures during 28 days of storage period at $4^{\circ} \mathrm{C}$. Means and standard deviations were calculated from three replicates.

\begin{tabular}{|l|c|c|c|c|c|}
\hline \multirow{2}{*}{$\begin{array}{c}\text { L. acidophilus } \\
\text { Strain }\end{array}$} & \multicolumn{5}{|c|}{ Colony forming unit (CFU)/g (x10 $\mathbf{~})$} \\
\cline { 2 - 6 } & Day 0 & Day 7 & Day 14 & Day 21 & Day 28 \\
\hline ATCC700396 & $99.7 \pm 34.2$ & $53.8 \pm 25.3$ & $6.6 \pm 7.1$ & $1.0 \pm 0.8$ & $0.1 \pm 0.1$ \\
\hline LA-5 & $136.0 \pm 33.9$ & $73.0 \pm 35.2$ & $35.7 \pm 52.2$ & $21.6 \pm 33.7$ & $3.3 \pm 5.1$ \\
\hline NCFM & $61.2 \pm 18.1$ & $10.4 \pm 10.0$ & $0.9 \pm 1.2$ & $0.1 \pm 0.1$ & $0.01 \pm 0.02$ \\
\hline PIM703 & $68.3 \pm 21.5$ & $51.2 \pm 21.3$ & $31.5 \pm 23.5$ & $14.3 \pm 9.6$ & $19.5 \pm 30.8$ \\
\hline SBT2062 & $105.0 \pm 10.0$ & $97.7 \pm 45.6$ & $93.7 \pm 53.2$ & $69.6 \pm 69.6$ & $94.0 \pm 67.2$ \\
\hline
\end{tabular}




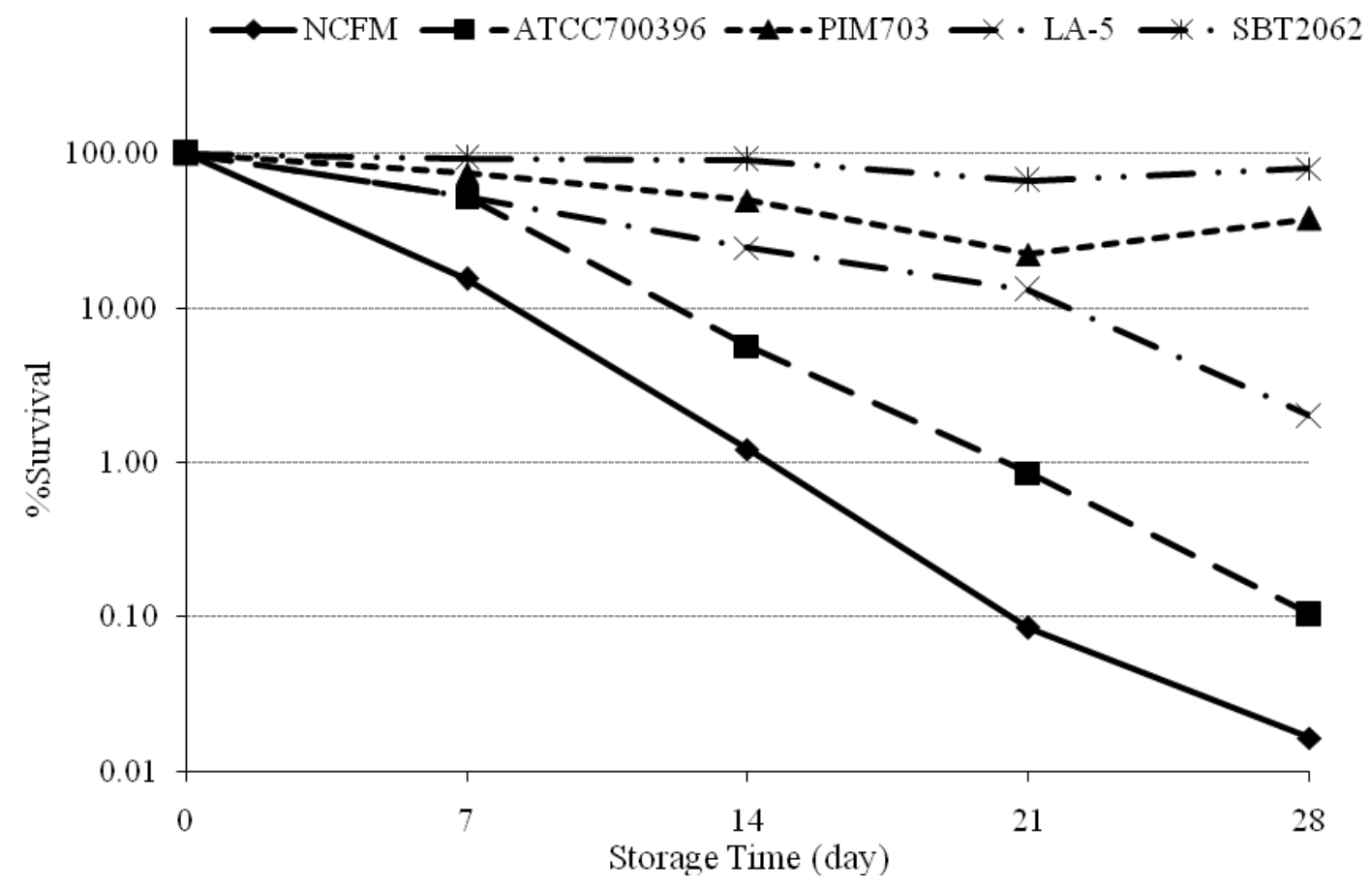

Figure 5.2. Relative survival of five different L. acidophilus strains in yogurt made with starter cultures during 28 days of storage period at $4^{\circ} \mathrm{C}$.

\subsubsection{Effect of Yogurt Filtrate}

To determine if yogurt starter cultures produced secretory metabolic inhibitory to the L. acidophilus strains, yogurt filtrate was collected and was added directly to overnight-grown cultures of L. acidophilus NCFM (the poorest survival from section 5.3.1).The final volume of each sample was brought to equal amount with yogurt filtrate originated from yogurt made with GDL instead of $\mathrm{dI} \mathrm{H}_{2} \mathrm{O}$ or PBS to control for possible variations due to nutrient loss. Figure 5.3 shows the average relative survival of two replicates of L. acidophilus NCFM in MRS with varying amounts of filtrate from 
different types of yogurt. Survival of L. acidophilus NCFM in all samples remained stable for 15 days, except it exhibited 1.7-log reduction $\left(2.2 \times 10^{9}\right.$ to $\left.4.1 \times 10^{7} \mathrm{cfu} / \mathrm{mL}\right)$ in the treatment where the $2 \mathrm{~mL}$ of "yogurt filtrate" and $8 \mathrm{~mL}$ of "GDL filtrate" was added. which (Table 5.4). Statistical analysis was performed using one-way ANOVA using the log relative survival as the response variable, yogurt filtrate amount as the factor. The transformation of relative survival values was similarly performed as mentioned in section 5.3.1. Yogurt filtrate was found to pose no negative effect on L. acidophilus survival.

Table 5.4. Viable cell count of $L$. acidophilus NCFM in MRS broth containing various amounts of yogurt filtrate during 15 days of storage period at $4^{\circ} \mathrm{C}$. Means and standard deviations were calculated from two replicates.

\begin{tabular}{|l|c|c|c|c|c|c|}
\hline \multirow{2}{*}{ Treatment } & \multicolumn{7}{|c|}{ Colony forming unit $\left(\mathbf{C F U ) / g}\left(\mathbf{x 1 0}^{\mathbf{7}}\right)\right.$} \\
\cline { 2 - 7 } & Day 0 & Day 3 & Day 6 & Day 9 & Day 12 & Day 15 \\
\hline 10G & $34.5 \pm 7.8$ & $28.7 \pm 6.9$ & $13.4 \pm 5.6$ & $9.6 \pm 3.4$ & $7.2 \pm 3.1$ & $5.9 \pm 3.2$ \\
\hline 9G1S & $33.0 \pm 3.5$ & $27.4 \pm 0.2$ & $13.0 \pm 1.7$ & $10.8 \pm 4.7$ & $8.4 \pm 4.0$ & $6.3 \pm 3.9$ \\
\hline 8G2S & $60.0 \pm 33.2$ & $29.3 \pm 1.1$ & $13.0 \pm 1.9$ & $7.8 \pm 0.3$ & $7.5 \pm 3.7$ & $6.8 \pm 1.3$ \\
\hline 5G5S & $32.5 \pm 2.8$ & $34.1 \pm 4.9$ & $8.4 \pm 4.2$ & $5.1 \pm 2.4$ & $3.8 \pm 2.9$ & $3.7 \pm 2.9$ \\
\hline 2G8S & $216.0 \pm 247.0$ & $31.7 \pm 4.7$ & $9.98 \pm 6.3$ & $7.2 \pm 5.2$ & $5.8 \pm 3.9$ & $4.1 \pm 3.0$ \\
\hline 1G9S & $41.3 \pm 15.2$ & $30.0 \pm 9.9$ & $8.4 \pm 1.2^{7}$ & $7.4 \pm 2.3$ & $6.1 \pm 1.8$ & $4.5 \pm 0.7$ \\
\hline 10S & $34.8 \pm 7.4$ & $30.7 \pm 3.9$ & $7.5 \pm 0.6$ & $6.0 \pm 0.7$ & $4.6 \pm 1.5$ & $4.1 \pm 0.6$ \\
\hline
\end{tabular}




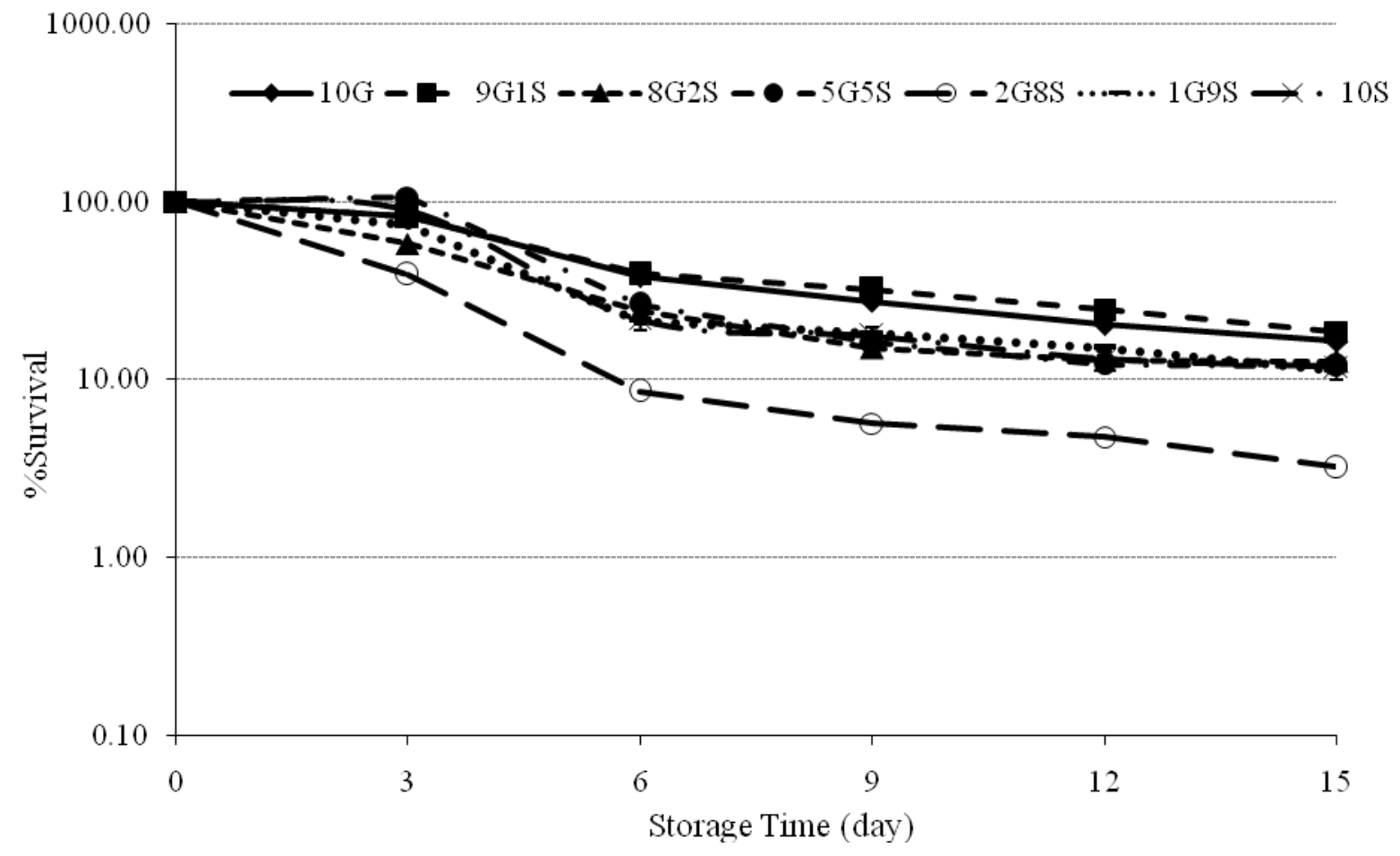

Figure 5.3. Relative survival of L. acidophilus NCFM in MRS broth containing various amounts of yogurt filtrate (GDL [G] and starter cultures [S]) during 15 days of storage period at $4^{\circ} \mathrm{C}$.

\subsubsection{Effect of Killed Starter Cultures}

Another approach was taken to further study if starter cultures produced metabolites that are inhibitory to L. acidophilus. Yogurt was pasteurized to eliminate the effect of viable starter cultures still present in yogurt. Yogurt made with GDL was also heated with the same pasteurization condition for comparison. During the 15-day storage period, L. acidophilus NCFM and SBT2062 showed steady survival with a maximum of 0.9-log reduction $\left(1.4 \times 10^{7}\right.$ to $\left.9.9 \times 10^{6} \mathrm{cfu} / \mathrm{g}\right)$ in both types of yogurt (Table 5.5 and Figure 5.4). Since the experiment was done only once, statistical analysis was not performed. However, the results from this preliminary study indicate that killed starter cultures do not impair the survival of L. acidophilus NCFM and SBT2062. 
Table 5.5. Viable cell count (CFU/g) of L. acidophilus strains (NCFM and SBT2062) in pasteurized yogurt during 15 days of storage period at $4^{\circ} \mathrm{C}$.

\begin{tabular}{|l|c|c|c|c|c|}
\hline \multirow{2}{*}{ Sample } & \multicolumn{5}{|c|}{ Colony forming unit (CFU)/g } \\
\cline { 2 - 6 } & Day 0 & Day 3 & Day 9 & Day 12 & Day 15 \\
\hline GNCFM $^{\text {a }}$ & $1.4 \times 10^{7}$ & $1.4 \times 10^{7}$ & $8.1 \times 10^{6}$ & $8.4 \times 10^{6}$ & $1.2 \times 10^{7}$ \\
\hline SNCFM $^{\mathrm{b}}$ & $1.1 \times 10^{7}$ & $1.3 \times 10^{7}$ & $9.5 \times 10^{6}$ & $1.1 \times 10^{7}$ & $9.8 \times 10^{6}$ \\
\hline GSBT2062 $^{\mathrm{c}}$ & $1.4 \times 10^{7}$ & $1.1 \times 10^{7}$ & $1.3 \times 10^{7}$ & $8.2 \times 10^{6}$ & $9.9 \times 10^{6}$ \\
\hline SSBT2062 $^{\mathrm{d}}$ & $1.5 \times 10^{7}$ & $1.1 \times 10^{7}$ & $1.1 \times 10^{7}$ & $1.2 \times 10^{7}$ & $1.2 \times 10^{7}$ \\
\hline
\end{tabular}

${ }^{\mathrm{a}} \mathrm{GNCFM}=$ L. acidophilus NCFM in pasteurized yogurt made with GDL

${ }^{\mathrm{b}}$ SNCFM $=$ L. acidophilus NCFM in pasteurized yogurt made with starter cultures

${ }^{\mathrm{c}}$ GSBT2062 $=$ L. acidophilus SBT2062 in pasteurized yogurt made with GDL

${ }^{\mathrm{d}}$ SSBT2062 $=$ L. acidophilus SBT2062 in pasteurized yogurt made with starter cultures

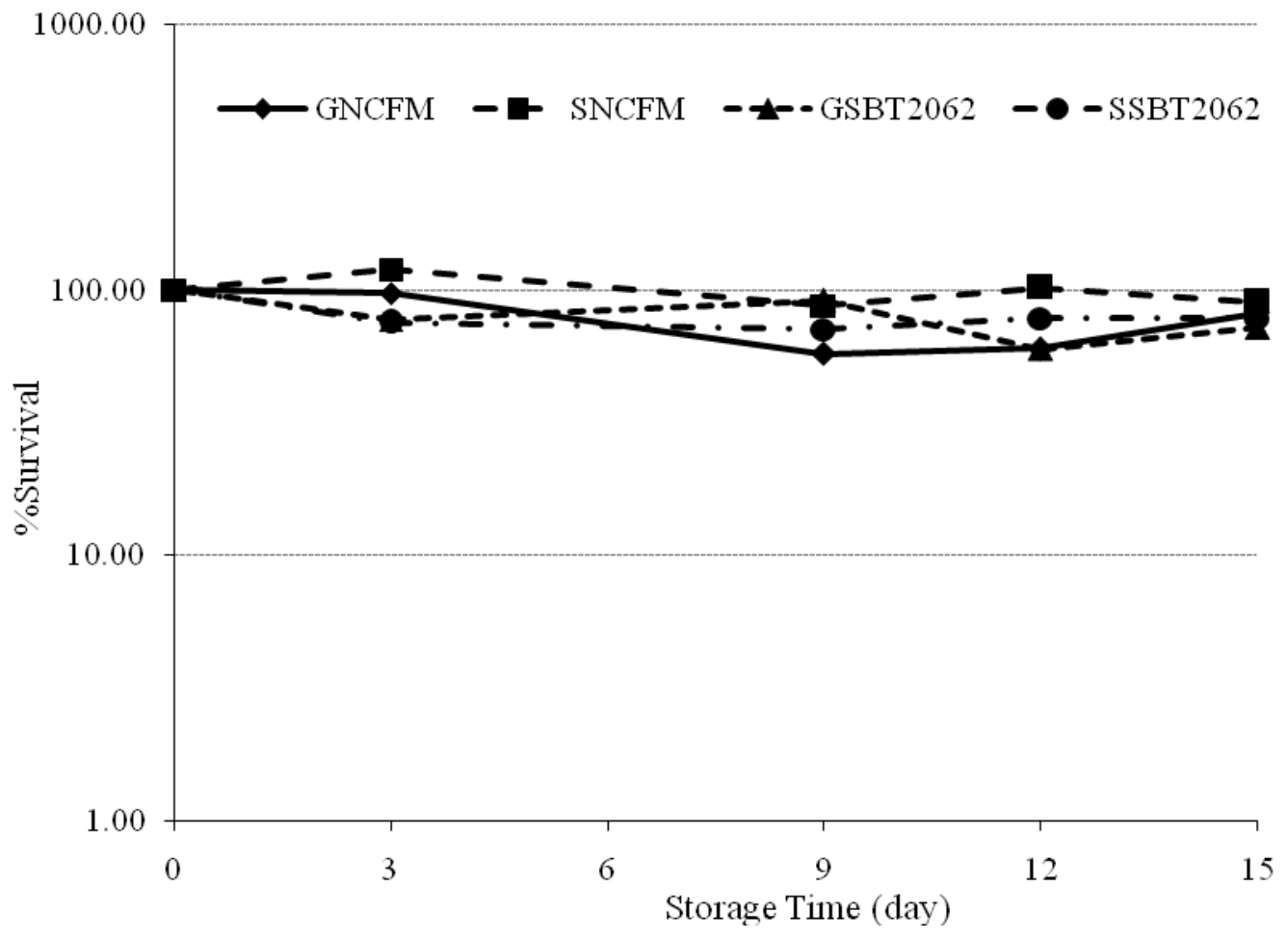

Figure 5.4. Relative survival of L. acidophilus NCFM and SBT2062 in pasteurized yogurts made with GDL $(\mathrm{G})$ or starter cultures (S) during 15 days of storage period at $4^{\circ} \mathrm{C}$. 


\subsubsection{Effect of Individual Starter Culture Species}

To study the antagonistic effects imposed by each starter culture species on the survival of L. acidophilus NCFM and SBT2062, two types of yogurts were made: one with S. thermophilus alone and another with $L$. delbrueckii ssp. bulgaricus alone. The fermentation duration (to acidify milk to $\mathrm{pH}$ 4.6) for both types of yogurt was approximately 6 hours. Viable cell counts of $L$. acidophilus were monitored weekly for 28 days. Figure 5.5 shows the mean \pm SD relative survival of $L$. acidophilus NCFM and SBT2062 in both types of yogurts from three replicates. L. acidophilus NCFM exhibited the poorest survival in yogurt made with $L$. delbrueckii ssp. bulgaricus alone, showing a 2.5-log reduction $\left(4.0 \times 10^{7}\right.$ to $\left.1.3 \times 10^{5} \mathrm{cfu} / \mathrm{g}\right)$. L. acidophilus SBT2062 showed a 0.6$\log$ reduction in yogurt made with $L$. delbrueckii ssp. bulgaricus alone. On the other hand, these two strains survived well in yogurt made with $S$. thermophilus alone (Table 5.6 and Figure 5.5). Statistical analyses on transformed data were performed as described in section 5.3.1. The type of starter cultures (S. thermophilus and L. delbrueckii ssp. bulgaricus) and L. acidophilus strain (NCFM and SBT2062) were analyzed as factors. The p-values from Minitab demonstrated the difference was not significant, except that a marginal significant difference was observed in the survival of L. acidophilus NCFM in yogurt made with L.delbrueckii ssp. bulgaricus with that of SBT2062 in yogurt made with S. thermophilus $(p=0.0569)$. 
Table 5.6. Viable cell count (CFU/g) of L. acidophilus strains (NCFM and SBT2062) in yogurt with $L$. delbrueckii ssp. bulgaricus or $S$. thermophilus during 28 days of storage period at $4^{\circ} \mathrm{C}$. Means and standard deviations were calculated from three replicates.

\begin{tabular}{|l|c|c|c|c|c|}
\hline \multirow{2}{*}{ Sample } & \multicolumn{5}{|c|}{ Colony forming unit (CFU)/g (x10 $\left.\mathbf{~}^{\mathbf{}}\right)$} \\
\cline { 2 - 6 } & Day 0 & Day 7 & Day 14 & Day 21 & Day 28 \\
\hline NCFM-ST $^{\mathrm{a}}$ & $68.7 \pm 20.2$ & $46.0 \pm 43.2$ & $29.2 \pm 46.6$ & $21.3 \pm 36.5$ & $21.8 \pm 25.1$ \\
\hline NCFM-LB $^{\mathrm{b}}$ & $39.6 \pm 30.8$ & $3.6 \pm 3.3$ & $0.4 \pm 0.5$ & $0.1 \pm 0.2$ & $0.1 \pm 0.2$ \\
\hline SBT2062-ST $^{\mathrm{c}}$ & $119.0 \pm 15.2$ & $129.0 \pm 14.8$ & $125.0 \pm 25.7$ & $127.0 \pm 35.8$ & $127.0 \pm 33.9$ \\
\hline SBT2062-LB $^{\mathrm{d}}$ & $71.2 \pm 6.3$ & $47.7 \pm 14.0$ & $29.2 \pm 10.8$ & $14.4 \pm 2.2$ & $18.3 \pm 6.3$ \\
\hline
\end{tabular}

${ }^{a}$ NCFM-ST $=$ L. acidophilus NCFM in yogurt made with $S$. thermophilus

${ }^{\mathrm{b}}$ NCFM-LB $=$ L. acidophilus NCFM in yogurt made with L. delbrueckii ssp. bulgaricus

${ }^{\mathrm{c}} \mathrm{SBT2062-ST}=$ L. acidophilus SBT2062 in yogurt made with $S$. thermophilus

${ }^{\mathrm{d}}$ SBT2062-LB $=$ L. acidophilus SBT2062 in yogurt made with $L$. delbrueckii ssp. bulgaricus

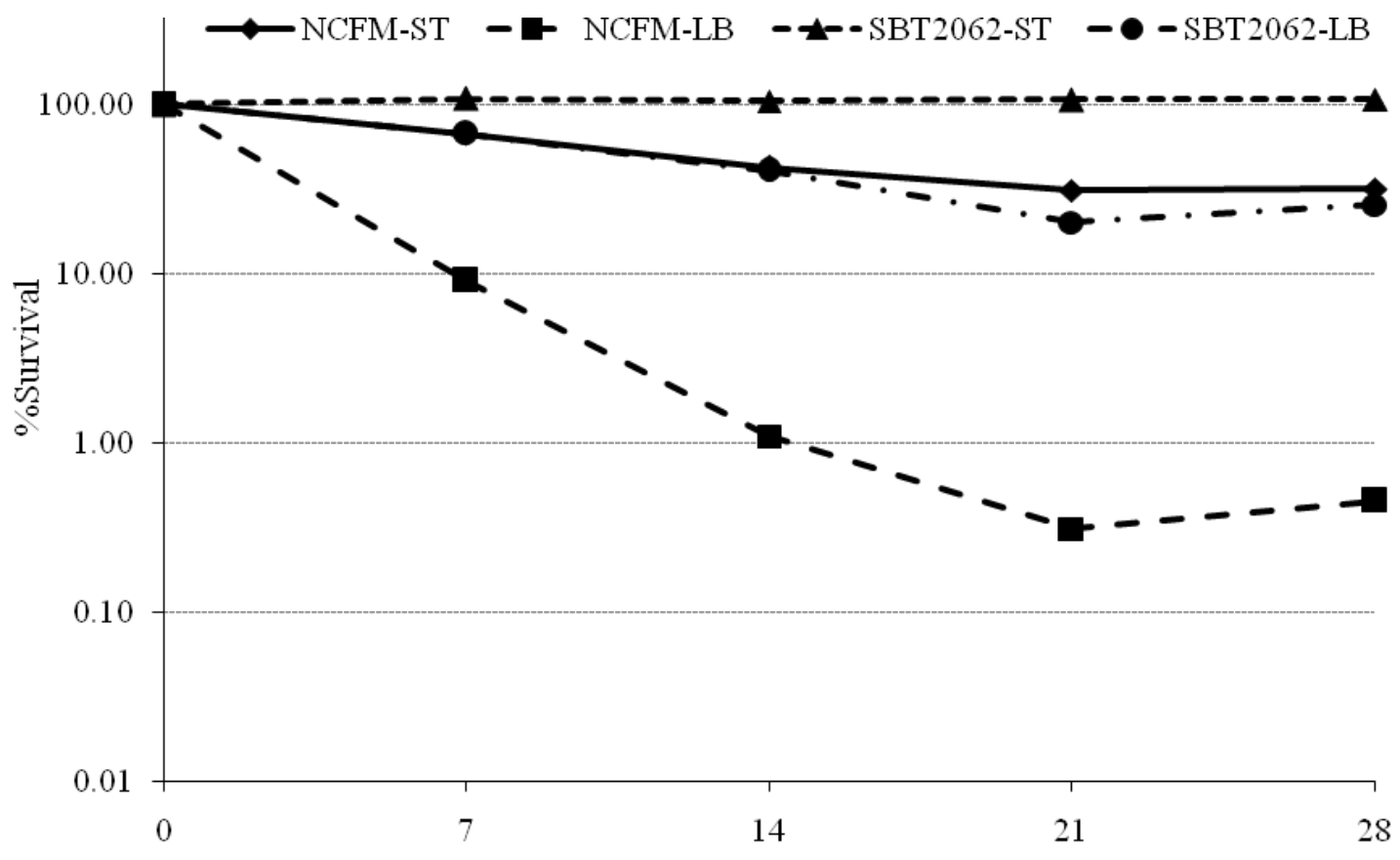

Storage Time (day)

Figure 5.5. Relative survival of L. acidophilus NCFM and SBT2062 in yogurt made with individual starter culture species (S. thermophilus or L. delbrueckii ssp. bulgaricus) during 28 days of storage period at $4^{\circ} \mathrm{C}$ (NCFM in yogurt made with $S$. thermophilus (NCFM-ST); NCFM in yogurt made with L. delbrueckii ssp. bulgaricus (NCFM-LB); SBT2062 in yogurt made with S. thermophilus (SBT2062-ST); SBT2062 in yogurt made with L. delbrueckii ssp. bulgaricus (SBT2062-LB)). 


\subsubsection{Survival of L. acidophilus in Soy Milk and Milk}

Soymilk has always been an alternative product for lactose intolerant or non-dairy consumers due to the absence of lactose. To deliver probiotics to this consumer group, soymilk should be an effective vehicle that does not affect the viability of the probiotic strains. Therefore, survival of four L. acidophilus strains in soymilk were investigated as a preliminary study; and the results were compared with data using (cow) milk. The relative survival in milk and in soymilk was plotted in Figure 5.6 and 5.7, respectively. Table 5.7 shows that the viable cell counts $(\mathrm{CFU} / \mathrm{mL})$ of all four $L$. acidophilus strains in milk remained stable throughout the 28-day storage period with a maximum of 0.6-log reduction for ATCC700395 (2.6 x $10^{7}$ to $\left.6.5 \times 10^{6} \mathrm{cfu} / \mathrm{mL}\right)$. In contrast, survival of $L$. acidophilus in soymilk exhibited strain-to-strain variation as observed in Figure 5.7; the poorest survival strain was $L$. acidophilus NCFM with 2.8-log reduction (6.5 x $10^{6}$ to 9.6 x $10^{3}$ cfu/g; Table 6.7) followed by L. acidophilus ATCC700396 and SBT2062 with 2.47- $\log$ and $1.60-\log$ reduction $\left(1.7 \times 10^{7}\right.$ to $5.8 \times 10^{4} \mathrm{cfu} / \mathrm{mL}$ and $8.0 \times 10^{7}$ to $2.0 \times 10^{6}$ $\mathrm{cfu} / \mathrm{mL}$; Table 5.8), respectively. A drastic drop of the relative survival of all four strains in soymilk was noted on day 14 .

Table 5.7. Viable cell count (CFU/mL) of L. acidophilus strains in milk during 28 days of storage period at $4^{\circ} \mathrm{C}$.

\begin{tabular}{|l|c|c|c|c|c|}
\hline \multirow{2}{*}{$\begin{array}{c}\text { L. acidophilus } \\
\text { Strain }\end{array}$} & \multicolumn{5}{|c|}{ Colony forming unit (CFU)/mL } \\
\cline { 2 - 6 } & Day 0 & Day 7 & Day 14 & Day 21 & Day 28 \\
\hline NCFM & $2.1 \times 10^{7}$ & $3.1 \times 10^{7}$ & $1.5 \times 10^{7}$ & $3.6 \times 10^{7}$ & $5.0 \times 10^{7}$ \\
\hline ATCC700396 & $2.6 \times 10^{7}$ & $3.9 \times 10^{7}$ & $2.7 \times 10^{7}$ & $4.1 \times 10^{7}$ & $6.5 \times 10^{7}$ \\
\hline PIM703 & $4.0 \times 10^{7}$ & $4.9 \times 10^{7}$ & $6.5 \times 10^{7}$ & $2.5 \times 10^{7}$ & $1.7 \times 10^{7}$ \\
\hline SBT2062 & $9.0 \times 10^{7}$ & $1.1 \times 10^{8}$ & $1.0 \times 10^{8}$ & $9.6 \times 10^{7}$ & $9.3 \times 10^{7}$ \\
\hline
\end{tabular}




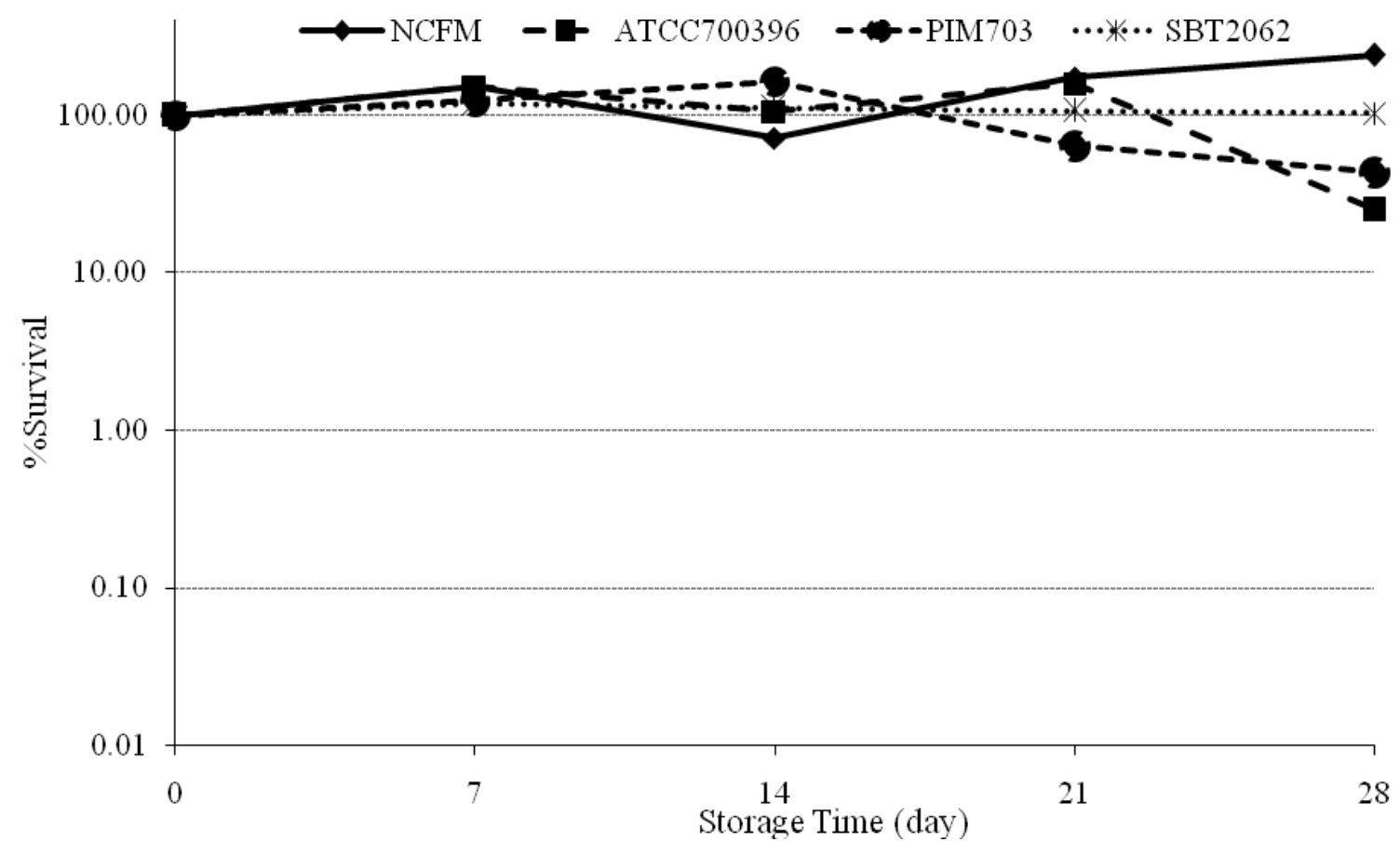

Figure 5.6. Relative survival of L. acidophilus strains in milk during 28 days of storage period at $4^{\circ} \mathrm{C}$.

Table 5.8. Viable cell count (CFU/mL) of L. acidophilus strains in soymilk during 28 days of storage period at $4^{\circ} \mathrm{C}$.

\begin{tabular}{|l|c|c|c|c|c|}
\hline \multirow{2}{*}{$\begin{array}{c}\text { L. acidophilus } \\
\text { Strain }\end{array}$} & \multicolumn{5}{|c|}{ Colony forming unit (CFU)/mL } \\
\cline { 2 - 6 } & Day 0 & Day 7 & Day 14 & Day 21 & Day 28 \\
\hline NCFM & $6.5 \times 10^{6}$ & $7.4 \times 10^{6}$ & $2.4 \times 10^{6}$ & $1.2 \times 10^{5}$ & $9.6 \times 10^{3}$ \\
\hline ATCC700396 & $1.7 \times 10^{7}$ & $5.9 \times 10^{6}$ & $1.8 \times 10^{6}$ & $2.9 \times 10^{5}$ & $5.8 \times 10^{4}$ \\
\hline PIM703 & $1.2 \times 10^{6}$ & $1.7 \times 10^{6}$ & $1.5 \times 10^{6}$ & $3.8 \times 10^{5}$ & $1.8 \times 10^{5}$ \\
\hline SBT2062 & $8.0 \times 10^{7}$ & $5.6 \times 10^{7}$ & $3.1 \times 10^{7}$ & $7.0 \times 10^{6}$ & $2.0 \times 10^{6}$ \\
\hline
\end{tabular}




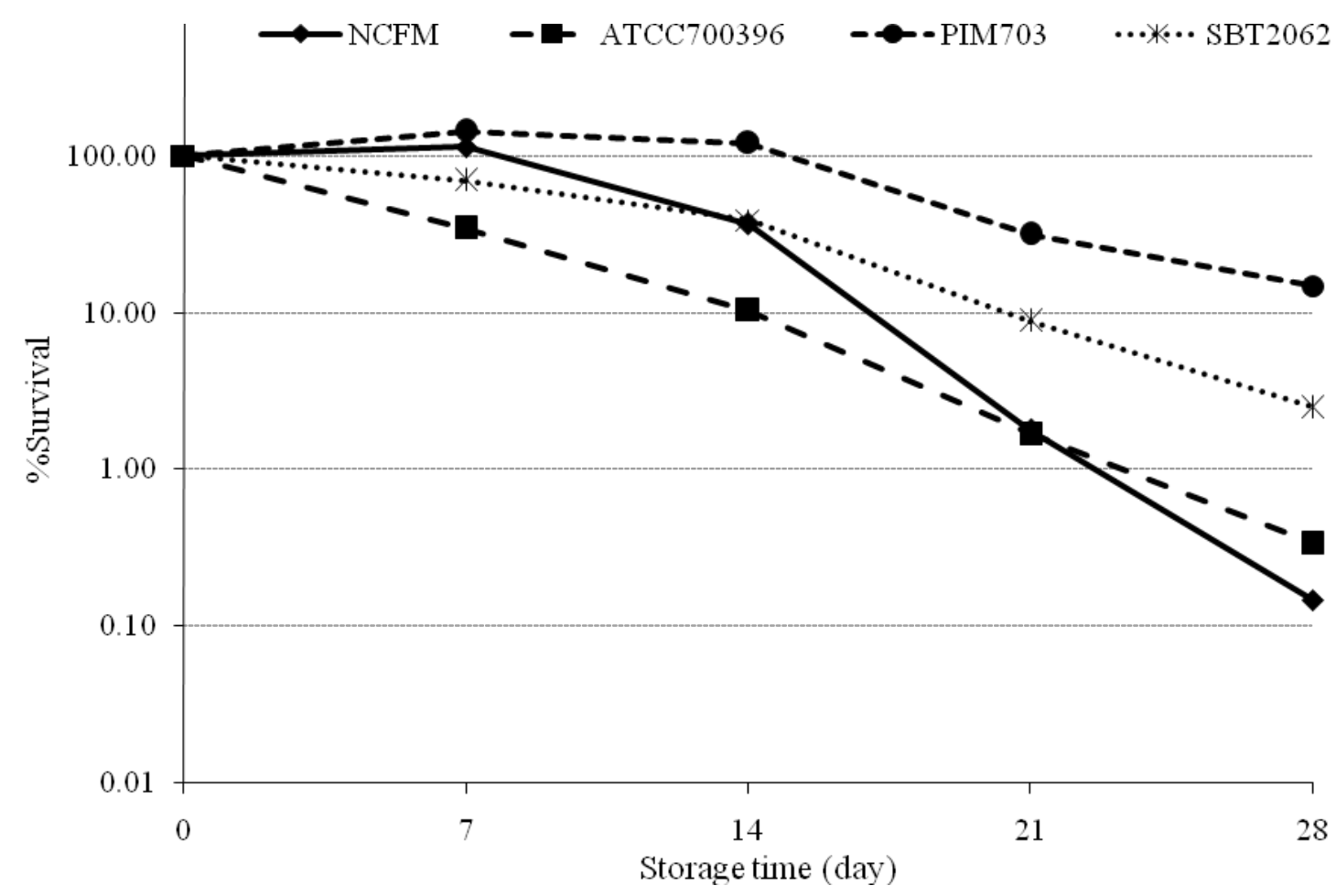

Figure 5.7. Relative survival of $L$. acidophilus strains in soymilk during 28 days of storage period at $4^{\circ} \mathrm{C}$.

\subsection{Agar Diffusion Assay}

The diffusion assay used in this experiment aimed to determine if inhibitors were produced from $S$. thermophilus and $L$. delbrueckii ssp. bulgaricus cells against $L$. acidophilus. In this assay, the presence of inhibitors would be indicated by an inhibition zone, or a clearance ring, around the producers. L. acidophilus NCFM was chosen in this experiment because its viability was the most impacted from previous experiments (section 5.3.1, 5.3.3 and 5.3.4). We hypothesized that this strain was more sensitive to the inhibitors produced by the starter cultures. Figure 5.8 shows an experiment with $S$. thermophilus and L. delbrueckii ssp. bulgaricus grown on MRS, either alone or as a mixture, followed by overlaying with L. acidophilus NCFM. After incubation, a lawn of 
culture of L. acidophilus NCFM was developed and no distinct inhibition zone was observed around the starter cultures. Fuzzy zones appeared around L. delbrueckii ssp. bulgaricus (LB) and the mixture of both species (M) colonies.

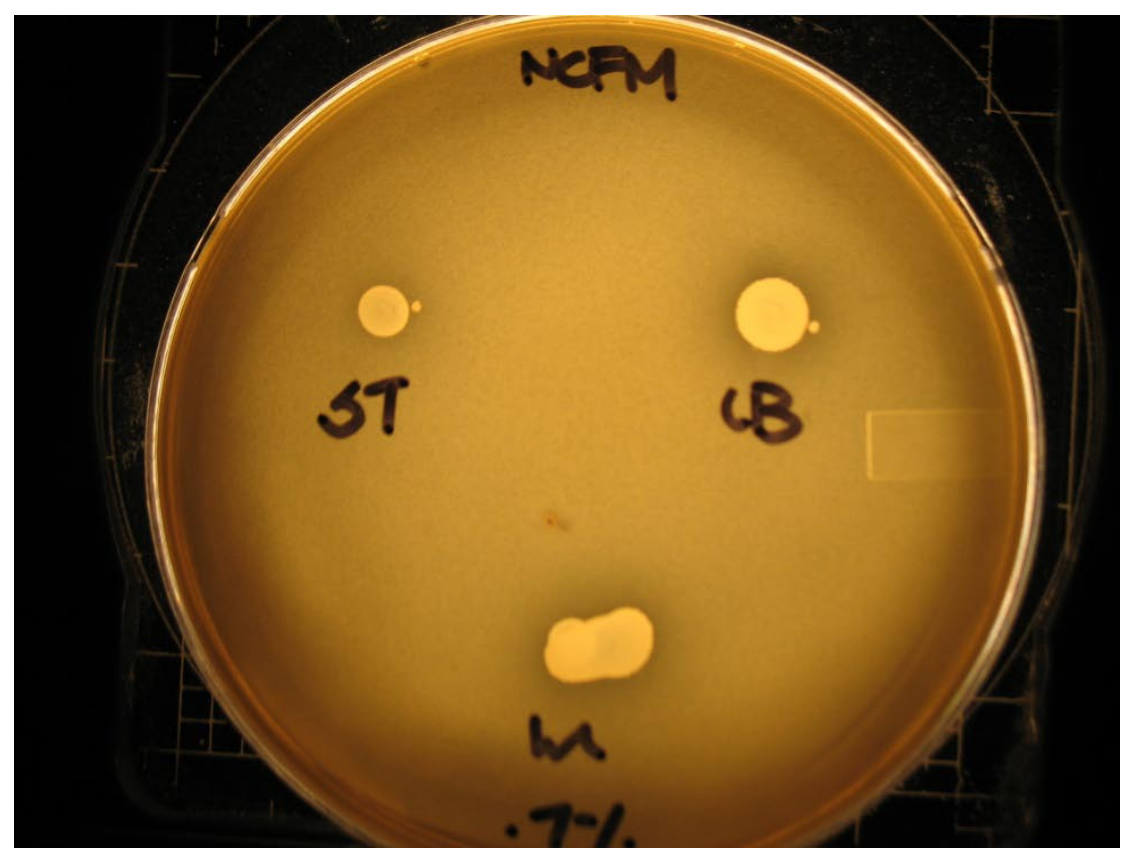

Figure 5.8. Agar diffusion assay on MRS agar spotted with starter cultures (ST: S. thermophilus; LB: L. delbrueckii ssp. bulgaricus; M: S. thermophilus and L. delbrueckii ssp. bulgaricus) using L. acidophilus NCFM as an indicator.

\subsection{Expression of Stress Genes in Lactobacillus acidophilus}

\subsubsection{Designing Species-Specific Primers}

Primers specific to L. acidophilus were designed on eight genes (seven stress and one housekeeping genes). For each gene, the specificity of the primers was determined by polymerase chain reaction using DNA from L. acidophilus NCFM and/or SBT2062, S. thermophilus and L. delbrueckii ssp. bulgaricus as template. A PCR mix without DNA template was used as negative control. Based on sequence homology to published 
sequence, all primers were expected to solely bind to DNA template of L. acidophilus NCFM and SBT2062. However, empirical data (Fig. 5.9) showed that only two stress genes (dnaK and groEL) and the housekeeping gene (16S rDNA) were specific to $L$. acidophilus strains. The rest cross-reacted with yogurt starter cultures to various degrees. Therefore, dnaK, groEL and 16S rDNA genes were further studied in the subsequent experiments.

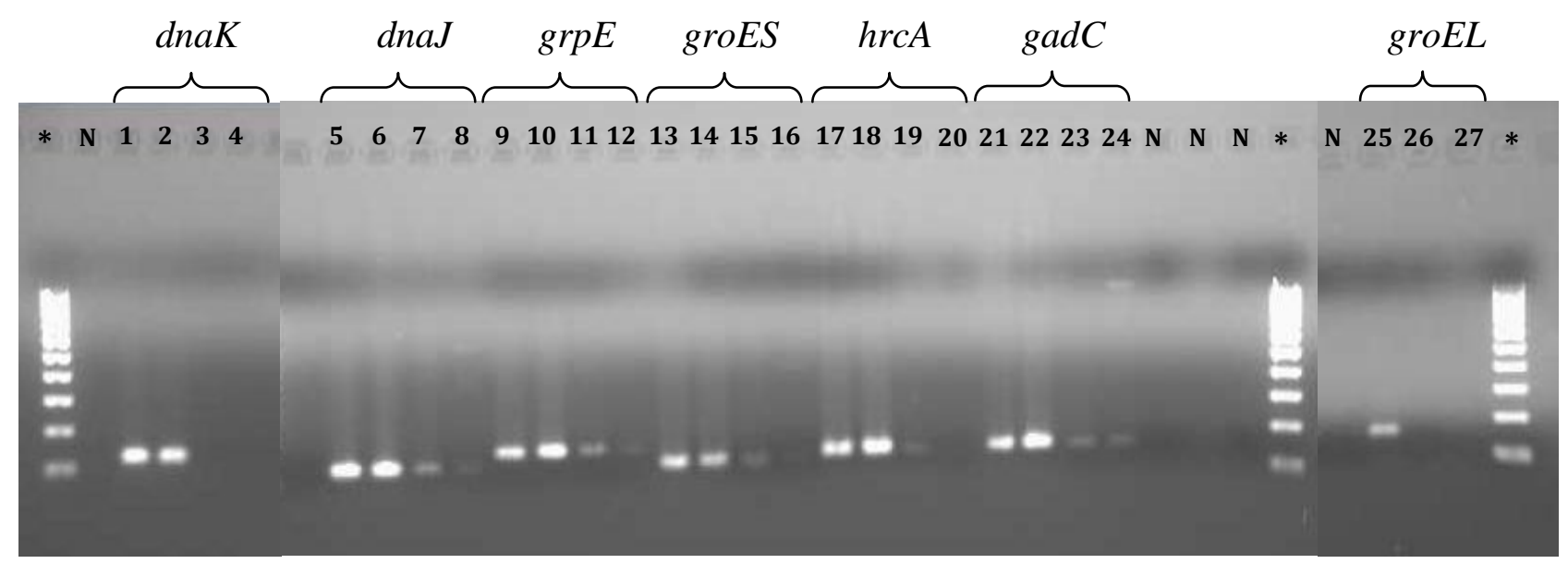

Figure 5.9. A 1.5\% agarose gel of PCR products using species-specific primers to stress genes (dnakK, dnaJ, grpE and groES, hrcA, gadC and groEL). Gels were stained using ethidium bromide, and images were taken using a BioRad ChemiDoc XRS Densitometer. Lanes 1, 5, 9, 13, 17, 21, 25- L. acidophilus NCFM; lanes 2, 6, 10, 14, 18, 22- L. acidophilus SBT2062; lanes 3, 7, 11, 15, 19, 23, 26- L. delbrueckii ssp. bulgaricus; and lanes 4, 8, 12, 16, 20, 24, 27- S. thermophilus; *- 100bp Ladder (100-1000 bp in 100 bp increments); $\mathrm{N}$ - negative control

\subsubsection{Semi-Quantitative Reverse-Transcription-Polymerase Chain Reaction} (RT-PCR)

The purpose of this experiment was to provide preliminary data on the stress response of L. acidophilus at a molecular level. Yogurt was similarly prepared as described in Section 4.6.1. After a 14-day storage period of yogurt, PCR reaction was 
conducted, and the amplicons were electrophoresed through 1.5\% agarose gel containing ethidium bromide at $90 \mathrm{~V}$ for $50 \mathrm{~min}$. The gel was visualized using a BioRad ChemiDoc XRS Densitometer (see Figure 5.10), and the adjusted volume (intensity*mm²), which is the reading with background subtracted, of each band was quantified using Quantity ${ }^{\circledR}$ One software. To normalize the adjusted volume values (intensity* $\mathrm{mm}^{2}$ ), the ratio of each sample was calculated by dividing the adjusted volume of the stress gene (dnaK or groEL) by the adjusted volume of the housekeeping gene (16S rDNA). Results for all samples are shown in Table 5.9. A comparison of the average adjusted volume (intensity*mm ${ }^{2}$ ) between $d n a K$ and groEL is plotted in Figure 5.11. This figure shows that the expression of groEL of both $L$. acidophilus strains remained steady during the 14-day refrigerated storage period, while that of $d n a K$ of L. acidophilus NCFM increased as the storage time increased. Statistical analysis was performed using one-way analysis of variance (ANOVA) with the ratio of intensity as the response variable, and showed that the average ratio of intensity of these two genes was significantly different $(p<0.01)$ for both strains. By the end of day 14, expression of dnaK of both strains was the strongest, suggesting that this gene was required to counteract the stressful conditions in yogurt. 


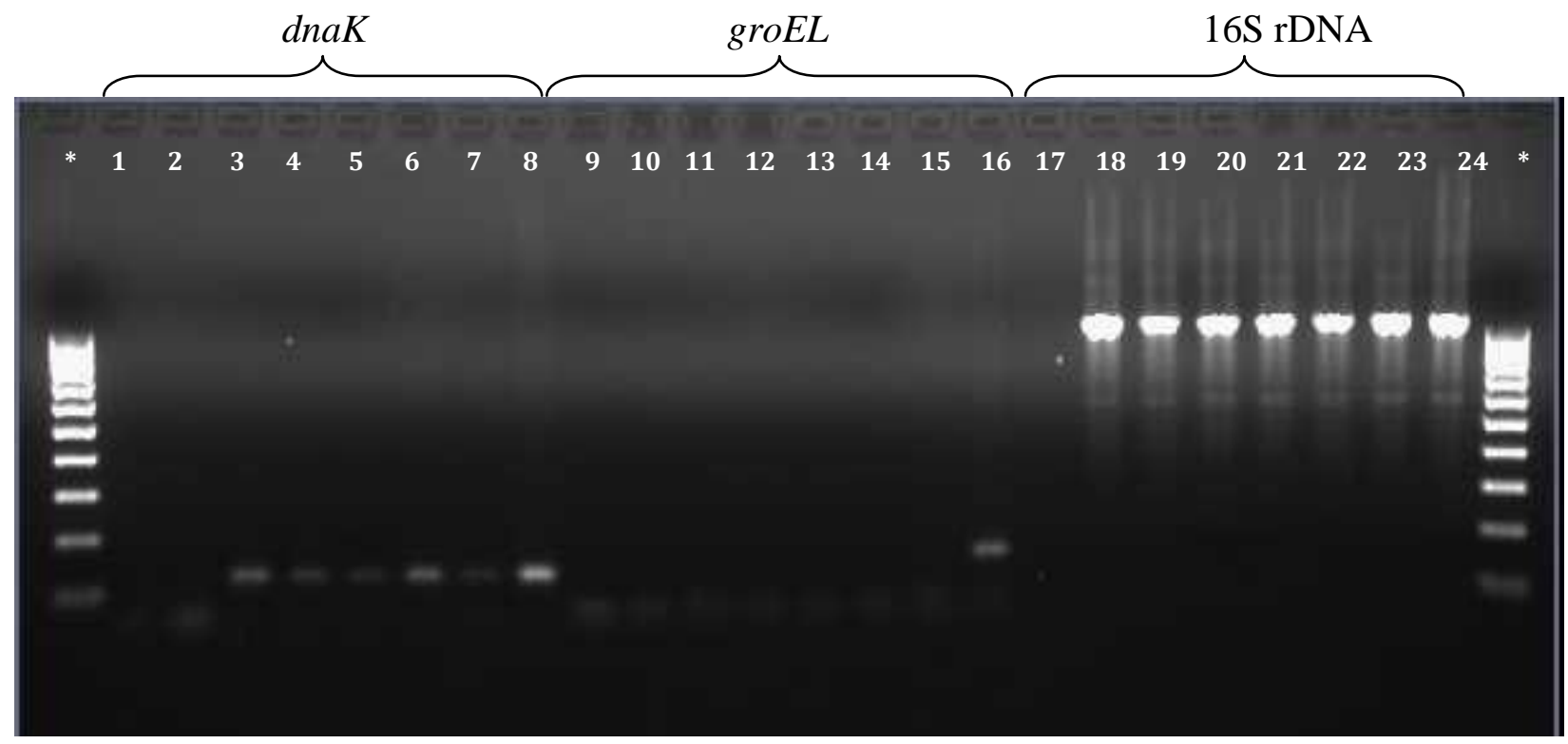

Figure 5.10. A 1.5\% agarose gel of PCR products of dnaK, groEL and 16S rDNA genes. Gels were stained using ethidium bromide, and images were taken using a BioRad ChemiDoc XRS Densitometer. Lanes 1, 9, 17- negative control; lanes 2, 10, 18- L. acidophilus NCFM from day1; lanes 3, 11, 19- L. acidophilus SBT2062 from day1; lanes 4, 12, 20- NCFM from day7; lanes 5, 13, 21- SBT2062 from day7; lanes 6, 14, 22NCFM from day14; lanes 7, 15, 23- SBT2062 from day14; and lanes 8, 16, 24- positive control using DNA template of L. acidophilus NCFM; *- 100bp Ladder (100-1000 bp in 100 bp increments)

Table 5.9. Average adjusted volume (intensity* $\mathrm{mm}^{2}$ ) comparison of dnaK gene from Lactobacillus acidophilus NCFM and SBT2062 in yogurt during 14 days of storage period at $4^{\circ} \mathrm{C}$. Means and standard deviations were calculated from two replicates.

\begin{tabular}{|c|c|c|c|}
\hline \multirow{2}{*}{ Strain } & \multicolumn{3}{|c|}{ Refrigerated Storage Period (day) } \\
\cline { 2 - 4 } & $\mathbf{1}$ & $\mathbf{7}$ & $\mathbf{1 4}$ \\
\hline NCFM & $0.2079 \pm 0.0770$ & $0.2271 \pm 0.0469$ & $0.3257 \pm 0.1104$ \\
\hline SBT2062 & $0.2817 \pm 0.0739$ & $0.1904 \pm 0.0080$ & $0.2971 \pm 0.1654$ \\
\hline
\end{tabular}




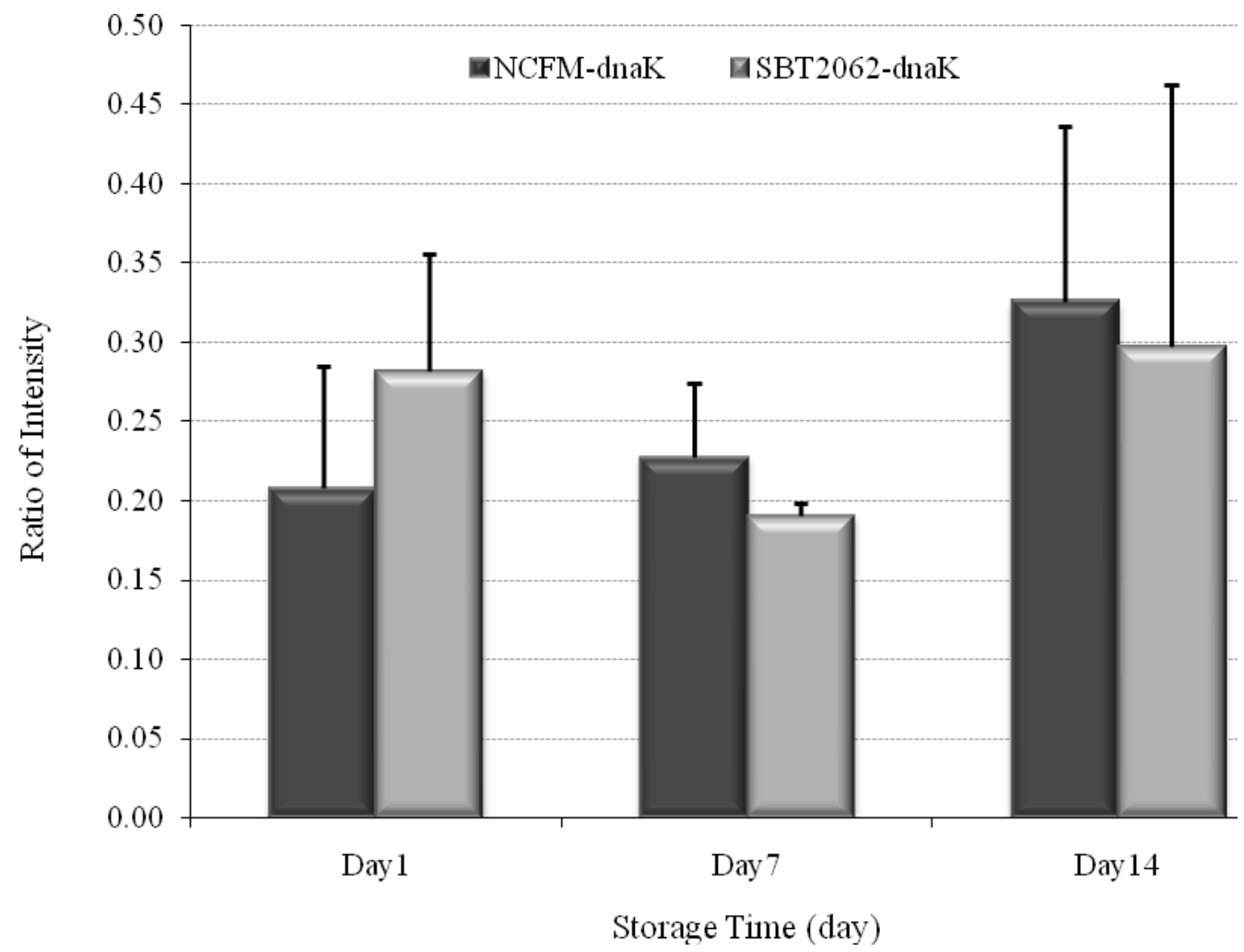

$\mathrm{Fi}$

gure 5.11. Average adjusted volume (intensity* $\mathrm{mm}^{2}$ ) comparison of dnaK gene from Lactobacillus acidophilus NCFM and SBT2062 in yogurt during 14 days of storage period at $4^{\circ} \mathrm{C}$. 


\section{0}

\section{DISCUSSION}

\subsection{Bacterial identification}

The purpose of identifying the microorganisms used in this study was to validate the species identification of the bacterial strains, which were previously isolated (Yeung et al., 2002) or provided by the manufacturer. Identities of all microorganisms used in this study were verified with Gram stain and API $50 \mathrm{CH}$ test. Gram strain is a screening method to differentiating bacteria into two large groups based upon their cell wall composition. Microscopically, Lactobacillus species and Streptococcus thermophilus are gram positive (purple after Gram stain) rods and cocci, respectively. These results confirmed the morphology as mentioned previously in section 2.4. API $50 \mathrm{CH}$ is a common biochemical test for further bacterial identification based on the ability of the microorganisms to ferment different types of carbohydrates. This test is widely used in many scientific research studies for bacteria identification(Champagne et al., 2008; Hedberg et al., 2008; Klein et al., 1998; Nighswonger et al., 1996). In our study, commercial starter cultures (L. delbrueckii ssp. bulgaricus and S. thermophilus)obtained from the manufacturer fermented lactose, and lactose and saccharose, respectively, and lactose was the disaccharide fermented by both microorganisms. For L. acidophilus, carbohydrate fermentation profile varied among strains, suggesting that carbohydrate utilization is a strain-dependent trait. Hamilton-Miller and Shah (1998) reported that commercial kits did not always provide accurate species identification results. Therefore, further tests (e.g. pulsed field gel electrophoresis or 16S rDNA sequencing) are desired for bacterial identification. In accordance with Yeung et al. (2002), who previously 
isolated and identified L. acidophilus ATCC700396, NCFM, PIM703 and SBT2062 by pulsed field gel electrophoresis, our API $50 \mathrm{CH}$ results confirm their findings, although DNA typing methods were not performed in this study.

\subsection{Survival of Lactobacillus acidophilus in Yogurt}

Delivering probiotics via food vehicle has been an interest to food scientists for decades due to their purported health-associated benefits to customers. As mentioned in Chapter 2, maintaining viable probiotic cell count above the recommendation level $\left(>10^{6}\right.$ cfu/g or $\mathrm{mL}$ ) by the end of the expiration date is required for most health benefit. Nevertheless, it has been a challenge since probiotics are subjected to various environmental stresses during food production and process, thereby decreasing their survival. Since most commercial fermented dairy products in worldwide contain viable probiotic cells less than the recommendation level, foundation of factors negatively affecting survival of probiotics can lead to improvement of better probiotic strains as well as formulation of better fermented products. In this project, we studied the survival of $L$. acidophilus in four different conditions to determine 1) the effect of yogurt starter cultures; 2) the effect of yogurt filtrate; 3) the effect of pasteurized yogurt; and 4) the effect of individual starter culture species fermentation.

Many studies have reported that one of the most important contributing factors for the loss of cell viability of probiotics is low $\mathrm{pH}$ and/or the accumulation of organic acids, especially lactic acid (produced mainly by $L$. delbrueckii ssp. bulgaricus), in the products(Lourens-Hattingh and Viljeon, 2001; Kailasapathy and Chin, 2000; Vinderola et al., 2002). Since there is a correlation between acid accumulation and low $\mathrm{pH}$ (the lactic 
acid increases, pH level correspondingly decreases), well-designed experiments regarding these two factors on the survival of probiotics are important. Kailasapathy et al. (2007) studied the survival of L. acidophilus LAFTI ${ }^{\circledR}$ L10 in stirred fruit yogurt and concluded that the $\mathrm{pH}$ from the fruit preparation might influence the viability of the probiotics.

On the other hand, Donkor et al. (2006) showed that the decrease in cell numbers of probiotics in yogurt was, in fact, the result of organic acids (lactic acid and acetic acid) accumulation rather than the actual $\mathrm{pH}$ value. Additionally, Azcarate-Peril et al. (2004) found that L. acidophilus NCK1398 drastically lost its viability in acidified MRS broth with lactic acid, whereas no loss was detected when exposed to acidified MRS broth with hydrochloric acid to the same $\mathrm{pH}$. In our study, we also found that low $\mathrm{pH}$ alone did not explain the loss of viable cell count of all five L. acidophilus strains (ATCC700396, NCFM, LA-5, PIM703 and SBT2062) because the survival of all L. acidophilus strains in yogurt made with GDL was stable throughout the 28 days of refrigerated storage period. According to Lorca and de Valdez (2001a; 2001b),this may be due to the acid tolerance response in L. acidophilus. In the presence of organic acids, the $\mathrm{F}_{1} \mathrm{~F}_{0}$-ATPase played an important role in maintaining the intracellular $\mathrm{pH}\left(\mathrm{pH}_{\mathrm{i}}\right)$. Moreover, the inducible $\mathrm{pH}$ homeostasis system, mediated by a proton-translocating ATPase as a mechanism to increase the $\mathrm{pH}_{\mathrm{i}}$, might be an important mechanism in the success of L. acidophilus to survive low $\mathrm{pH}$ environment. Therefore, we speculate that this may be due their acid tolerance response, since low $\mathrm{pH}$ can serve as an important signal for the induction of this mechanism (Lorca et al., 2002). Another explanation is that L. acidophilus has high cytoplasmic buffering capacity (pH 3.72-7.73), which may increase its stability and allow the microorganism to resist changes in $\mathrm{pH}_{\mathrm{i}}$ under acidic conditions (Ruis et al., 2000). 
From our study, we found that the survival of some L. acidophilus strains, especially ATCC700396 and NCFM, were negatively affected by the presence of starter cultures, L. delbrueckii ssp. bulgaricus in particular. In yogurt made with starter cultures, the survival of L. acidophilus NCFM decreased markedly after 14 days of refrigerated storage period, whereas L. acidophilus SBT2062 remained stable, indicating strain-tostrain variation in survivability. To determine if the negative impact is caused by a particular individual starter culture species, yogurts fermented with $S$. thermophilus alone or L. delbrueckii ssp. bulgaricus alone were made. Our results show that survival of $L$. acidophilus NCFM was markedly declined in the presence of L. delbrueckii ssp. bulgaricus, but remained stable in the presence of $S$. thermophilus. According to Tamime (2005), L. delbrueckii ssp.bulgaricus is known for its post-acidification and high production of hydrogen peroxide $\left(\mathrm{H}_{2} \mathrm{O}_{2}\right)$. As mentioned previously that low $\mathrm{pH}$ in yogurt was not the main factor impairing the survival of L. acidophilus. Therefore, the negative impact on survival of L. acidophilus NCFM was presumably based upon the presence of L. delbrueckii ssp. bulgaricus and/or its metabolites (such as $\mathrm{H}_{2} \mathrm{O}_{2}$ ). Due to its lack of catalase (an enzyme for decomposition of $\mathrm{H}_{2} \mathrm{O}_{2}$ ) along with the presence of $\mathrm{H}_{2} \mathrm{O}_{2}, L$. acidophilus is subject to oxidative stress, and this may lead to protein and DNA damage and eventually lead to cell death.

Gilliland and Speck (1997) demonstrated the instability of L. acidophilus in yogurt with L. delbrueckii ssp. bulgaricus. They found that the addition of catalase (an enzyme, which hydrolyze $\mathrm{H}_{2} \mathrm{O}_{2}$ to water and oxygen, and therefore, reduce the level of $\mathrm{H}_{2} \mathrm{O}_{2}$ in yogurt) improved the viability of $L$. acidophilus. They also suggested that $L$. delbrueckii ssp. bulgaricus was responsible for the loss in viability of L. acidophilus 
when added in yogurt. Therefore, exclusion of L. delbrueckii ssp. bulgaricus in yogurt production has been suggested to eliminate the antagonistic effects caused by this starter culture (Lourens-Hattingh and Viljeon, 2001).

In agreement with Dave and Shah (1997a), they demonstrated that $\mathrm{H}_{2} \mathrm{O}_{2}$ was higher in yogurts manufactured from starter cultures, which contained L. delbrueckii ssp. bulgaricus along with S. thermophilus, L. acidophilus and bifidobacteria, than in yogurt with only S. thermophilus and probiotics. Moreover, they found that viable cell counts of L. acidophilus markedly decreased in yogurt with $L$. delbrueckii ssp. bulgaricus, which might be responsible for the production of $\mathrm{H}_{2} \mathrm{O}_{2}$. According to Talwalkar and Kailasapathy (2003), another enzyme known as NADH peroxidase in L. acidophilus 2400 and 2409 can scavenge the presence of $\mathrm{H}_{2} \mathrm{O}_{2}$. However, this enzyme functions optimally at $\mathrm{pH} 5$, and the activity of the enzyme markedly dropped at $\mathrm{pH} 4.5$. Since the $\mathrm{pH}$ of yogurt is $\sim \mathrm{pH} 4.6$, NADH peroxidase may not be as active. Thus, further studies regarding the activity of NADH peroxidase of L. acidophilus NCFM and SBT2062 in milk and yogurt at various $\mathrm{pH}$ may be conducted to better understand the mechanism of the enzyme and the survival of L. acidophilus.

To study the effect of metabolites (such as $\mathrm{H}_{2} \mathrm{O}_{2}$ ) produced from yogurt starter cultures, we conducted a survival study using yogurt filtrate and an agar diffusion assay spotted with starter cultures using L. acidophilus NCFM as an indicator. During the incubation of agar diffusion assay, S. thermophilus and L. delbrueckii ssp. bulgaricus were presumed to produce some metabolites that can inhibit the growth of $L$. acidophilus. However, no inhibition zone was observed around S. thermophilus and L. delbrueckii ssp. bulgaricus. This also agrees with our survival study of L. acidophilus NCFM in MRS 
broth with yogurt filtrate that the survival of L. acidophilus NCFM remained stable throughout the 15-refrigerated storage period. To further study the effect of metabolites in yogurt, we conducted an additional survival study of L. acidophilus in pasteurized yogurt. Similarly, survival of L. acidophilus NCFM and SBT2062 was not significantly different. Both strains remained stable during the 15-day refrigerated storage period. With respect to our results, the loss of viable cells of $L$. acidophilus in yogurt may not be due to metabolites from starter cultures.

We also proposed a supplemental experiment regarding the survival of $L$. acidophilus NCFM in soymilk, which is an alternative product for lactose intolerance consumers. Our results show that except for L. acidophilus SBT2062, all other strains (ATCC700396, NCFM and PIM703)exhibited poor survival during the 28-day storage. This might be due to the lack of fermentable carbohydrates to the probiotics. Soymilk contains about 1 percent of fermentable carbohydrate (stachyose and raffinose); however, these carbohydrates are not fermentable by most lactic acid bacteria. Wang et al. (2002) reported that soymilk could support the growth of L. acidophilus CCRC 14079, but, in our study, three of four L. acidophilus strains had $<10^{6} \mathrm{CFU} / \mathrm{mL}$ after 28-day storage (the final cfu/ml does not sound very low). In addition, Canganella et al. (2000) demonstrated that the survivability of L. acidophilus in cowmilk yogurt and soymilk yogurt and speculated that survival of probiotics might be higher in soymilk yogurt than in cowmilk yogurt. As mentioned previously that survival of microorganisms is strain dependent, $L$. acidophilus strains used in our study may be more susceptible to soymilk environment. 


\subsection{Expression of stress genes in L. acidophilus}

From our survival studies, we found that there was a strain-to-strain variation in survival of L. acidophilus. Consequently, we questioned that the variation in this survival property might be due to the difference at a molecular level, gene expression in particular. To address this question, total RNA was extracted and was transcribed into cDNA followed by DNA amplification. The amplicons were then electrophoresed. This entire process is known as "RT-PCR". However, due to the homogeneity of gene sequences among S. thermophilus, L. delbrueckii ssp. bulgaricus and L. acidophilus strains, selection of specific primers for L. acidophilus was strongly challenging, especially highly conserved regions Therefore, out of our selected seven stress genes, primers specific to L. acidophilus were successfully designed for only two genes (dnaK and $\operatorname{groEL})$.

Gene expression of two stress responsive genes (dnaK and groEL)of $L$. acidophilus in yogurt during 14 days of refrigerated storage period was conducted as a preliminary study to understand the difference in survival capability between two strains of L. acidophilus (NCFM and SBT2062) at a molecular level. In yogurt, microorganisms may be subjected to many environmental stresses, such as high acidity, the presence of inhibitors (lactic acid and $\mathrm{H}_{2} \mathrm{O}_{2}$ ) and low temperature. Consequently, we hypothesized that these various types of stress present in yogurt made with starter cultures may strongly affect the survival of L. acidophilus NCFM. After conducting the study of gene expression, we found that dnaK was highly expressed in both strains (NCFM and SBT2062), whereas the expression of groEL was not observed. Moreover, the expression of $d n a K$ in L. acidophilus NCFM was positively associated with the storage time. There 
was a difference in gene expression of dnaK in L. acidophilus NCFM and SBT2062, indicating that the physiology with respect to gene expression capacity was strain specific. Although the results were not significantly different, we speculated that dnaK was important in maintaining the survival of both L. acidophilus strains in yogurt during the storage period. In correlation with Lorca et al. (2002), they demonstrated that GroES, GrpE and DnaJ of L. acidophilus were highly expressed after exposure to a synthetic medium at $\mathrm{pH}$ 5.0. As mentioned in section 2.6.2, DnaJ and GrpE have the utmost importance for the chaperone activity of DnaK in vivo and in vitro (Bukau and Horwich, 1998; Rosen and Ron, 2002).The partially folded polypeptide (protein) released from the DnaK chaperone is passed to the GroES chaperone for further folding within its cage structure (Vorob’eva, 2004). From our study, expression of groEL was not observed; therefore, most denatured proteins may be successfully re-folded by the complex DnaK/DnaJ/GrpE. Sugimoto et al. (2008) also reviewed that a dnaK mutant of Lactococcus lactis ssp. lactis (one of well-studied lactic acid bacteria) showed thermosensitivity, which can create cross-responses (such as acid and alcohol sensitivity). With the limitation of primer design in this study, we could not determine the expression of $g r p E$, dnaJ and other stress responsive genes. Thus, further experiments regarding these stress-related genes would be interesting to address the importance of the complex DnaK/DnaJ/GrpE and GroEL/GroES. This can also elucidate the mechanisms of survival action of this probiotic species as well as others. 


\section{0}

\section{CONCLUSIONS}

Probiotics are widely incorporated into fermented dairy products, especially yogurt, due to their purported health-promoting effects. As viability of probiotics is crucial for delivery most desirable health benefit, the survival capabilities and physiological characteristics of several strains of Lactobacillus acidophilus in yogurt were addressed in this thesis project. Two primary studies were performed: 1) survival studies of multiple strains of L. acidophilus, and 2) gene expression analyses of dnaK and groEL of selected L. acidophilus strains (NCFM and SBT2062).

The survival of L. acidophilus in yogurt during 28 days of storage period showed strain-to-strain variation. Among the strains used in this study, the survival of $L$. acidophilus SBT2062 was the best and that of L. acidophilus NCFM the poorest. In addition, the results demonstrated that the presence of starter cultures, predominantly $L$. delbrueckii ssp. bulgaricus, had a significant detrimental effect on the survival of $L$. acidophilus NCFM, presumably due to the production of hydrogen peroxide.

To understand the variation of survivability between these two L. acidophilus strains, gene expression of two stress response genes ( $d n a K$ and $g r o E L)$ was conducted. Overall, this experiment demonstrated that $d n a K$ is highly expressed in both strains, whereas the expression of groEL was not observed. Moreover, the expression of $d n a K$ of L. acidophilus NCFM is associated with the storage time; the level increases as storage time increases. This indicates that $d n a K$ is highly expressed under refrigerated storage conditions in yogurt, suggesting that it is necessary to maintain the viability of $L$. acidophilus. Although results from the experiment exploring the gene expression 
between two L. acidophilus strains were not significantly different, this thesis project provides preliminary results for future studies. Additional studies on more genes would still be useful to elucidate the molecular mechanisms of survival capability of this probiotic species as well as others. Other gene candidates including dnaJ, grpE, groES, hrcA and gadC should be investigated to provide additional understanding into the physiology and function of $L$. acidophilus. The new insights will help develop novel strains or optimize existing strains with robust survival and a suite of desirable properties. Accordingly, this would ultimately guarantee the delivery of certain probiotic strains conferring therapeutic effects to the consumers. 


\section{0}

\section{FUTURE RESEARCH}

Additional research for further exploration in the relationship between the survivability and stress response of probiotics in fermented dairy products during storage period may provide a better understanding in their physiological characteristics and mechanisms. Following is a list of possible research directions:

1. Perform survival study on other commercial Lactobacillus and Bifidobacterium species

2. Further investigate the effect of soy- and milk-based media on the survival of probiotics to validate milk-based medium is a better delivery system for probiotics

3. Measure the amount of hydrogen peroxide and lactic acid in yogurt made with commercial starter cultures and GDL for the purpose of comparing the inhibitors produced from S. thermophilus and L. delbrueckii ssp. bulgaricus

4. Additional experiments on the survival of L. acidophilus in acidified milk using lactic acid and GDL to verify the effect of organic acids in yogurt

5. Optimize species-specific primers and further study the gene expression of other stress response genes, such as dnaJ, grpE, groES, hrcA and gadC, of $L$. acidophilus using reverse-transcription polymerase chain reaction to correlate the survival capability and expression of these genes during refrigerated storage period 
6. Develop a method for extracting mRNA from probiotics in the presence of yogurt starter cultures so that gene expression profile can be determine by using cDNA microarray analysis 


\section{0}

\section{REFERENCES}

Adams, M. R. and Marteau, P. 1995. On the safety of lactic acid bacteria. International Journal of Microbiology 27:263-264.

Agerholm-Larsen, L., Raben, A., Haulrik, N., Hansen, A. S., Manders, M. and Astrup, A. 2000. Effect of 8 week intake of probiotic milk products on risk factors for cardiovascular diseases. European Journal of Clinical Nutrition 54:288-289.

Aiba, Y., Suzuki, N., Kabir, A. M. A., Takagi, A. and Koga, Y. 1998. Lactic acidmediated suppression of Helicobacter pyroli by the oral administration of Lactobacillus salivarius as probiotic in a gnotobiotic murine model. American Journal of Gastroenterology 93:2097-2101.

Altermann, E., Buck, L., Cano, R. and Klaeenhammer, T. 2004. Identification and phenotypic characterization of the cell-division protein CdpA. Gene 342:189-197.

Altermann, E., Russell, W. M., Azcarate-Peril, M. A., Barrangou, R., Buck, B. L., McAuliffe, O., Souther, N., Dobson, A., Duong, T., Callanan, M., Lick, S., Hamrick, A., Cano, R. and Klaenhammer, T. R. 2005. Complete genome sequence of the probiotic lactic acid bacterium Lactobacillus acidophilus NCFM. Proceedings of the National Academy of Sciences USA 102:3906-3912.

Ang, D., Libereck, K., Skowyra, D., Zylicz, M. and Georgopoulos, C. 1991. Biological roles and regulation of the universally conserved heat shock proteins. Journal of Biological Chemistry 266:24233-24236.

Anukam, K. C. and Reid, G. 2007. Probiotics: 100 years (1907-2007) after Elie Metchnikoff's observation. In: Communicating Current Research and Educational Topics and Trends in Applied Microbiology. Méndez-Vilas, A. ed., Formatex. pp. 466-474.

Azcarate-Peril, A., Altermann, E., Hoover-Fitzula, R., Cano, R. and Klaenhammer, T. 2004. Identification and inactivation of genetic loci involved with Lactobacillus acidophilus acid tolerance. Applied and Environmental Microbiology 70:53155322.

Azcarate-Peril, A., Tallon, R. and Klaenhammer, T. R. 2009. Temporal gene expression and probiotic attributes of Lactobacillus during growth in milk. Journal of Dairy Science 92:870-886.

Barrangou, R., Altermann, E., Hurkins, R., Cano, R. and Klaenhammer, T. 2003. Functional and comparative genomic analyses of an operon involved in 
fructooligosaccharide utilzation by Lactobacillus acidophilus.Proceedings of the National Academy of Sciences USA 100:8957-8962.

Barrangou, R., Azcarate-Peril, M. A., Duong, T., Conners, S. B. Kelly, R. M. and Klaenhammer, T. R. 2006. Global analysis of carbohydrate utilization by Lactobacillus acidophilus using cDNA microarrays. Proceedings of the National Academy of Sciences USA 103:3816-3821.

Bolotin, A., Quinquis, B., Renault, P., Sorokin, A., Ehrlich, S. D., Kulakauskas, S., Lapidus, A., Goltsman, E., Mazur, M., Pusch, G. D., Fonstein, M., Overbeek, R., Kyprides, N., Purnelle, B., Prozzi, D., Ngui, K., Masuy, D., Hancy, F., Burteau, S., Boutry, M., Delcour, J., Goffeau, A. and Hols, P. 2004. Complete sequence and comparative genome analysis of the dairy bacterium Streptococcus thermophilus. Nature Biotechnology 22:1554 -1558.

Bolton, M., van der Straten, A. and Cohen, C. R. 2008. Probiotics: Potential to prevent HIV and sexually transmitted infections in women. Sexually Transmitted Diseases $35: 214-225$.

Boot, H. J., Kolen, C. P. A. M., Andreadaki, F. J., Leer, R. J. and Pouwels, P. H. 1996. The Lactobacillus acidophilus S-layer protein gene expression site comprises two consensus promoter sequences, one of which directs transcription of stable mRNA. Journal of Bacteriology 178(18):5388-5394.

Borriello, S. P., Hammes, W. P., Holzapfel, W., Marteau, P., Schrezenmeir, J., Vaara, M. and Valtonen, V. 2003. Safety of Probiotics That Contain Lactobacilli or Bifidobacteria. Clinical Infectious Diseases 36:775-780.

Broadbent, J. R., Oberg, C. J. and Wei, L. 1998. Characterization of Lactobacillus helveticus groESL operon. Research in Microbiology 149:247-253.

Bucher, P. 1999. Regulatory elements and expression profiles. Current Opinion in Structure Biology 9:400-407.

Bukau, B. and Horwich, A. L. 1998. The Hsp70 and Hsp60 chaperone machines. Cell 92:351-366.

Bustin, S. A. 2000. Absolute quantification of mRNA using real-time reverse transcription polymerase chain reaction assays. Journal of Molecular Endocrinology 25:169-193.

Bustin, S. A. 2002. Quatification of mRNA using real-time reverse transcription PCR (RT-PCR): Trends and problems. Journal of Molecular Endocrinology 29:23-39.

Bustin, S. A. and Nolan, T. 2004. Pitfalls of quantitative real-time reverse-transcription polymerase chain reaction. Journal of Biomolecular Techniques 15:155-166. 
Cannon, J. P., Lee, T. A., Bolano, J. T. and Danziger, L. H. 2005. Pathogenic relevance of Lactobacillus: a retrospective review of over 200 cases. European Journal of Clinical Microbiology and Infectious Diseases 24:31-40.

Canganella, F. Giontella, D. Nespica, M. L., Massa, S. and Trovatelli, L. D. 2000. Survival of Lactobacillus acidophilus and Bifidobacterium infantis in yogurts manufactured from cowmilk and soymilk during storage at two temperatures. Annals of Microbiology 50:43-53.

Carding, S. R., Lu, D. and Bottomly, K. A. 1992. A polymerase chain reaction of cytokine gene expression in small number of cells. Journal of Immunological Methods 151:277-287.

Champagnea, C. P., Green-Johnsonb, J., Raymonda, Y., Barrettea, J. and Buckley, N. 2008. Selection of probiotic bacteria for the fermentation of a soy beverage in combination with Streptococcus thermophilus. Food Research International.

Champomier-Verges, M. C., Maguin, E., Mistou, M. Y., Anglade, P. and Chich, J. F. 2002. Lactic acid bacteria and proteomics: Current knowledge and perspectives. Journal of Chromatography 771:329-342.

Chandan, R. C. 1999. Enhancing market value of milk by adding cultures. Journal of Dairy Science 82:2245-2256.

Chandan, R. C. and O’Rell, K. R. 2006. Principles of yogurt processing. In: Manufacturing yogurt and fermented milks. Chandan, R. C. ed., Blackwell Publishing: Oxford. pp. 195-209.

Charteris, W. P., Kelly, P. M., Morelli, L. and Collins, J. K. 1997. Review article: Selective detection, enumeration and identification of potential probiotics Lactobacillus and Bifidobacterium species in mixed bacterial populations. International Journal of Food Microbiology 35:1-27.

Choi, S. S., Kim, Y., Han, K. S., You, S., Oh, S. and Kim, S. H. 2005. Effects of Lactobacillus strains on cancer cell proliferation and oxidative stress in vitro. Letters in Applied Microbiology 42:452-458.

Claesson, M. J., van Sinderen, D. and O’Toole, P. W. 2007. The genus Lactobacillus - a genomic basis for understanding its diversity. FEMS Microbiology Letters 269:22-28.

Coeuret, V., Dubernet, S., Bernardeau, M., Gueguen, M. and Vernoux, J. P. 2003. Isolation, characterization and identification of lactobacilli focusing mainly on cheeses and other dairy products. Lait 83:269-306. 
Conway, P. L., Gorbach, S. L. and Goldin, B. R. 1987. Survival of Lactic Acid Bacteria in the Human Stomach and Adhesion to Intestinal Cells. Journal of Dairy Science 70:1-12.

Craig, E. A., Weissman, J. S. and Horwich, A. L. 1994. Heat shock proteins and molecular chaperones: Mediators of protein conformation and turnover in the cell. Cell 78:365-372.

Darukaradhya, J., Phillips, M. and Kailasapathy, K. 2006. Selective enumeration of Lactobacillus acidophilus, Bifidobacterium spp., starter lactic acid bacteria and non-starter lactic acid bacteria from cheddar cheese. International Dairy Journal 16:439-445.

Dave, R. and Shah, N. P. 1996. Evaluation of media for selective enumeration of $S$. thermophilus, L. delbrueckii ssp. bulgaricus, Lactobacillus acidophilus and Bifidobacterium species. Journal of Dairy Science 79:1529-1536.

Dave, R. I. and Shah, N. P. 1997a. Viability of yoghurt and probiotic bacteria in yoghurts made from commercial starter cultures. International Dairy Journal 7:31-41.

Dave, R. I. and Shah, N. P. 1997b. Effectiveness of ascorbic acid as an oxygen scavenger in improving viability of probiotics in yoghurts made with commercial starter cultures. International Dairy Journal 7:435-443.

De Angelis, M. and Gobbetti, M. 2004. Environmental stress response in Lactobacillus: A review. Proteomics 4:106-122.

De Vrese, M., Stegelmann, A., Richter, B., Fenselau, S., Laue, C. and Schrezenmeir, J. 2001. Probiotics - compensation for lactase insufficiency. American Journal of Clinical Nutrition 73: 421S-429S.

Del Piano, M., Morelli, L., Strozzi, G. P., et al. 2006. Probiotics: From research to consumers. Digestive Liver Diseases 38:S248-S255.

Delcour, J., Ferain, T. and Hols, P. 2000. Advances in the genetics of thermophilic lactic acid bacteria. Current Opinion of Biotechnology 11:497-504.

Dellaglio, F., Felis, G. E., Torriani, S., Sorensen, K. and Johansen, E. 2005. Genomic characterisation of starter cultures. In: Probiotic Dairy Products. Tamime, A. Y. ed., Blackwell Publishing: Oxford. pp. 16-38.

Desai, A. R., Powell, I. B. and Shah, N. P. 2004. Survival and activity of probiotics lactobacilli in skim milk containing probiotics. Journal of Food Science 69:FMS557-FMS60. 
Donkor, O. N., Henriksson, A., Vasiljevica, T. and Shah, N. P. 2006. Effect of acidification on the activity of probiotics in yogurt during cold storage. International Dairy Journal 16(10):1181-1189.

FAO/WHO. 2001. Health and nutritional properties of probiotics in food including powder milk with live lactic acid bacteria. Report of a Joint FAO/WHO Expert Consultation on Evaluation of Health and Nutritional Properties in Food Including Powder Milk with Live Lactic Acid Bacteria. Cordoba, Argentina.

FAO/WHO. 2002. Guidelines for the evaluation of probiotics in food. Report of Joint FAO/WHO Working Group on Drafting Guidelines for the Evaluation of Probiotics in Food. Cordoba, Argentina.

Felis, G. E. and Dellaglio, F. 2007. Taxonomy of lactobacilli and bifidobacteria. Current Issues Intestinal Microbiology 8:44-61.

Fiocco, D., Crisetti,E., Capozzi, V. and Span, G. 2008. Validation of an internal control gene to apply reverse transcription quantitative PCR to study heat, cold and ethanol stresses in Lactobacillus plantarum. World Journal of Microbiology and Biotechnology 24:899-902.

Fitzsimons, N. A., Akkermans, A. D. L., de Vos, W. M. and Vaughan, E. E. 2003. Bacterial gene expression detected in human feces by reverse transcription-PCR. Journal of Microbiological Methods 55:133-140.

Foster, J. W. 1993. The acid tolerance response of Salmonella typhimurium involves transient synthesis of key acid shock proteins. Journal of Bacteriology 175:19811987.

Foster, J. W. and Hall, H. K. 1990. Adaptive acidification tolerance response if Salmonella typhimurium. Journal of Bacteriology 172:771-778.

Fu, W. J., Hu, J., Spencer, T., Carroll, R. and Wu, G. 2006. Statistical models in assessing fold change of gene expression in real-time RT-PCR experiments. Computational Biology and Chemistry 30:21-26.

Fuller, R. 1992. History and development of probiotics. In: Probiotics, the scientific basis. Fuller, R. ed., Chapman and Hall: London. pp. 1-8.

Galdeano, C. M. and Perdigón, G. 2004. Role of viability of probiotic strains in their persistence in the gut and in mucosal immune stimulation. Journal of Applied Microbiology 97:673-681.

Gibson, G. R. and Fuller, R. 2000. Aspects of in vitro and in vivo research approaches directed toward identifying probiotics and prebiotics for human use. The Journal of Nutrition 130:391S-395S. 
Gilliland, S. E. and Speck, M. L. 1977. Instability of Lactobacillus acidophilus in yogurt. Journal of Dairy Science 60:1394-1397.

Godward, G., Sultana, K., Kailasapathy, K., Peiris, P., Arumugaswamy, R. and Reynolds, N. 2000. The importance of strain selection on the viability and survival or probiotics bacteria in dairy foods. Milchwissenschaft 55:441-445.

Gorbach, S. L. 2000. Probiotics and gastrointestinal health. American Journal of Gastroenterology 95:S1-S4.

Gotteland, M. and Cruchet, S. 2003. Suppressive effect of frequent ingestion of Lactobacillus johnsonii La1 on Helicobacter pylori colonization in asymptomatic volunteers. The Journal of Antimicrobial Chemotherapy 51:1317-1319.

Hamilton-Miller, J. M. T., Gibson, G. R. and Bruck, W. 2003. Some insight into the derivation and early uses of the word 'probiotics'. British Journal of Nutrition 90:845.

Hamilton-Miller, J. M. T. and Shah, N. P. 1998. Vancomycin susceptibility as an aid to the identification of lactobacilli. Letters ion Applied Microbiology 26:153-154.

Heller, K. J. 2001. Probiotic bacteria in fermented foods: Product characteristics and starter organisms. American Journal of Clinical Nutrition 73:374S-379S.

Hedberg, M., Hasslöf, P., Sjöström, I., Twetman, S. and Stecksén-Blicks, C. 2008. Sugar fermentation in probiotic bacteria - an in vitro study. Oral Microbiology and Immunology 23:482-485.

Henderson, B., Allan, E. and Coates, A. R. M. 2006. Stress wars: The direct role of host and bacterial molecular chaperones in bacterial infection. Infection and Immunity 74:3693-3706.

Hod, Y. 1992. A simplified ribonuclease protection assay. Biotechniques 13:852-853.

Holm, F. 2003. Gut health and diet: The benefits of probiotic and probiotics on human health. The World of Ingredients 2:52-55.

Holzapfel, W. H., Haberer, P., Snel, J., Schillinger, U. and Huis in’t Veld, J. H. J. 1998. Overview of gut flora and probiotics. International Journal of Food Microbiology 41:85-101.

Hull, R. R., Roberts, A. V. and Mayes, J. J. 1984. Survival of Lactobacillus acidophilus in yogurt. Australian Journal of Dairy Technology 39:164-166. 
Huys, G., Vancanneyt, M., D’Haene, K., Vankerckhoven, V., Goossens, H. and Swings, J. 2006. Accuracy of species identity of commercial bacterial cultures intended for probiotic or nutritional use. Research in Microbiology 157:803-810.

IDF. 1995. Detection and enumeration of Lactobacillus acidophilus. Bulletin No. 306/1995.

Kailasapathy, K. and Chin, J. 2000. Survival and therapeutic potential of probiotic organisms with reference to Lactobacillus acidophilus and Bifidobacterium spp. Immunology Cell Biology 78:80-88.

Kailasapathy, K., Harmstorf, I. and Phillips, M. 2007. Survival of Lactobacillus acidophilus and Bifidobacterium animalis ssp. lactis in stirred fruit yogurts. LWT 41:1317-1322.

Kailasapathy, K. and Rybka, S. 1997. Lactobacillus acidophilus and Bifidobacterium spp. - their therapeutic potential and survival in yogurt. Australian Journal of Dairy Technology 52:28-35.

Kelleher, K. L., Leck, K. J., Hendry, I. A. and Matthaei, K. I. 2001. A one-step quantitative reverse transcription polymerase chain reaction procedure. Brain Research Protocols 6:100-107.

Kim, W. S., Perl, L., Park, J. H. Tandianus, J. E. and Dunn, N. W. 2001. Assessment of stress response of the probiotic Lactobacillus acidophilus 43:346-350.

Klein, G., Pack, A., Bonaparte, C. and Reuter, G. 1998. Taxonomy and physiology of probiotic lactic acid bacteria. International Journal of Food Microbiology 41:103125.

Kullen, M. J. and Klaenhammer, T. R. 1999. Identification of the pH-inducible, protontranslocating $\mathrm{F}_{1} \mathrm{~F}_{0}$-ATPase (atpBEFHAGDC) operon of Lactobacillus acidophilus by differential display: gene structure, cloning and characterization. Molecular Microbiology 33:1152-1161.

Kurmann, J. A. and Rasic, J. L. 1991. The health potential of products containing bifidobacteria. In: Therapeutic properties of fermented milks. Robinson, R. K. ed. Elsevier Applied Food Science: London. pp. 117-158.

La Torre, L., Tamime, A. Y. and Muir, D. D. 2003. Rheology and sensor9y profiling of set-type fermented milks made with different commercial probiotic and yogurt starter cultures. International Journal of Dairy Technology 56:163-170.

Lankaphuthra, W. E. V. and Shah, N. P. 1996. A simple method for selective enumeration of Lactobacillus acidophilus in yogurt supplemented with $L$. acidophilus and Bifidobacterium spp. Milchwissenschaft 51(8):446-451. 
Lankaputhra, W. E. and Shah, N. P. 1998. Antimutagenic properties of probiotic bacteria and of organic acids. Mutation Research 397:169-182.

Lankaphuthra, W. E. V., Shah, N. P. and Britz, M. L. 1996. Evaluation of media for selective enumeration of Lactobacillus acidophilus and Bifidobacterium species. Food Technology in Australia 48:113-118.

Laroia, S. and Martin, J. H. 1991. Methods for enumerating and propagating bifidobacteria. Cultured Dairy Products Journal 32-33.

Lee, Y. K. and Salminen, S. 1995. The coming of age of probiotics. Trends in food science and technology 6:241-245.

Leroy, F. and Vuyst, L. 2004. Lactic acid bacteria as functional starter cultures for the food fermentation industry. Trends in Food Science and Technology 15:67-78.

Liberek, K., Marszalek, J., Ang, D. and Georgopoulos, C. 1991. Escherichia coli DnaJ and GrpE heat shock proteins jointly stimulate ATPase activity of DnaK. Proceedings of the National Academy of Sciences USA 88:2874-2878.

Lim, E. M., Ehrlich, S. D. and Maguin, E. 2000. Identification of stress-inducible proteins in Lactobacillus delbrueckii ssp. bulgaricus. Electrophoresis 21:25572561.

Lin, W. H., Hwang, C. F., Chen, L. W. and Tsen, H. Y. 2006. Viable counts, characteristic evaluation for commercial lactic acid bacteria products. Food Microbiology 23:74-81.

Liong, M. T. and Shah, N. P. 2005. Acid and bile tolerance and cholesterol removal ability of lactobacilli strains. Journal of Dairy Science 88:55-66.

Lorca, G. L. and de Valdez, G. F. 2001a. A low-pH inducible, stationary-phase acid tolerance response in Lactobacillus acidophilus CRL639. Current Microbiology 42:21-25.

Lorca, G. L. and de Valdez, G. F. 2001b. Acid tolerance mediated by membrane ATPases in Lactobacillus acidophilus. Biotechnology Letters 23:777-780.

Lorca, G. L., de Valdez, G. F. and Ljungh, A. 2002. Characterization of the proteinsynthesis dependent adaptive acid tolerance response in Lactobacillus acidophilus. Journal of Molecular Microbiology and Biotechnology 4(6):525-532.

Lourens-Hattingh, A. and Viljeon, C. B. 2001. Yoghurt as probiotic carrier food, International Dairy Journal 11:1-17. 
Lucas, A., Sodini, I., Monnet, C., Jolivet, P. and Corrieu, G. 2004. Probiotic cell counts and acidification in fermented milks supplemented with milk protein isolates. International Dairy Journal 14:47-53.

Mackey, A. D., Taylor, M.B., Kibbler, C. C. and Hamilton-Miller, J. M. T. 1999. Lactobacillus endocarditis caused by a probiotics organism. Clinical Microbiology and Infection 5:290-292.

Marco, M. L. and Kleerebezem, M. 2007. Assessment of real-time RT-PCR for quantification of Lactobacillus plantarum gene expression during stationary phase and nutrient starvation. Journal of Applied Microbiology 104:587-594.

McCarty, J. S., Buchberger, A., Reinstein, J. and Bukau, B. 1995. The Role of ATP in the Functional Cycle of the DnaK Chaperone System. Journal of Molecular Biology 249:126-137.

Mitsuoka, T. 1992. The human gastrointestinal tract. Lactic Acid Bacteria 1:69-114.

Montes, R. G., Bayless, T. M. Saavedra, J. M. and Perman, J. A. 1995. Effect of milks inoculated with Lactobacillus acidophilus or a yogurt starter culture in lactosemaldigesting children. Journal of Dairy Science 78:1657-1664.

Morelli, L. 2007. In vitro assessment of probiotic bacteria: From survival to functionality. International Dairy Journal 17:1278-1283.

Nighswonger, B. D., Brashears, M. M. and Gilliland, S. E. 1996. Viability of Lactobacillus acidophilus and Lactobacillus casei in fermented milk products during refrigerated storage. Journal of Dairy Science 79:212-219.

Olivares, M., Díaz-Ropero, M. P., Martín, R., Rodríguez, J. M.and Xaus, J. 2005. Antimicrobial potential of four Lactobacillus strains isolated from breast milk. Journal of Applied Microbiology 101:72-79.

Ouwehand, A. C., Kirjavainen, P. V., Shortt, C. and Salminen, S. 1999. Probiotics: mechanisms and established effects. International Dairy Journal 9:43-52.

Parvez, S., Malik, K. A., Kang, S. Ah. And Kim, H. -Y. 2006. Probiotics and their fermented food products are beneficial for health. Journal of Applied Microbiology 100:1171-1185.

Percival, M. 1997. Choosing a probiotic supplement. Clinical Nutrition Insights 6(1):1-4.

Pfaffl, M. W. 2001. A new mathematical model for relative quantification in real-time RT-PCR. Nucleic Acids Research 29:2002-2007. 
Pieterse, B., Leer, R. J., Schuren, F. H. J. and van der Werf, M. 2005. Unravelling the multiple effects of lactic acid stress on Lactobacillus plantarum by transcription profiling. Microbiology 151:3881-3894.

Pineiro, M. and Stanton, C. 2007. Probiotic bacteria: Legislative framework-requirements to evidence basis. The Journal of Nutrition 137:850S-853S.

Piuri, M., Sanchez-Rivas, C. and Ruzal, S. M. 2003. Adaptation to high salt in Lactobacillus: Role of peptides and proteolytic enzymes. Journal of Applied Micrbiology 96:372-379.

Playne, M. J., Bennet, L. E. and Smithers, G. W. 2003. Functional dairy foods and ingredients. Australian Journal of Dairy Technology 58:242-264.

Rautio, M., Jousimes-Somer, H., Kauma, H., Pirtarinen, I., Saxelin, M., Tynkkynen, S. and Koskela, M. 1999. Liver abcess due to a Lactobacillus rhamnosus strain indinguishable from Lactobacillus rhamnosus strain GG. Clinical Infectious Diseases 29:1159-1160.

Ravula, R. R. and Shah, N. P. 1998. Selective enumeration of Lactobacillus casei from yogurts and fermented milk drinks. Biotechnology Techniques 12(11):819-822.

Reid, G. 1999. The scientific basis for probiotic strains of Lactobacillus. Applied and Environmental Microbiology 65(9):3763-3766.

Reid, G. 2005. The importance of guidelines in the development and application of probiotics. Current Pharmaceutical Design 11:11-16.

Rosen, R. and Ron, E. Z. 2002. Proteome analysis in the study of the bacterial heat shock. Mass Spectrometry Reviews 21:244-265.

Ruis, N., M. Sole, Francis, A. and Loren, J. G. 1994. Buffering capacity and membrane $\mathrm{H}^{+}$conductance of lactic acid bacteria. FEMS Microbiology Letters 120:291-296.

Rybka, S. and Kailasapathy, K. 1996. Media for the enumeration of yogurt bacteria. International Dairy Journal 6:839-850.

Saarela, M., Mogensen, G. Fonden, G. Mättö, J. and Mattila-Sandholm, T. 2000. Probiotic bacteria: Safety, functional and technological properties. Journal of Biotechnology 84:197-215.

Saito, T. 2004. Selection of useful probiotic lactic acid bacteria from Lactobacillus acidophilus group and their application o functional foods. Animal Science Journal 75:1-13. 
Salminen, S., von Wright, A., Morelli, L., Marteau, P., Brassart, D., de Vos, W. M., Fonden, R., Saxelin, M., Collins, K., Mogensen, G., Birkeland, S. E. and MattilaSondholm, T. 1998. Demonstration of safety of probiotics - a review. International Journal of Food Microbiology 44:93-106.

Sanders, M. E. 1998. Development of consumer probiotics for the US market. British Journal of Nutrition 80:S213-S218.

Sanders, M. E. 2003. Probiotics: Considerations for human health. Nutrition Reviews 61(3):91-99.

Sanders, M. E. and Klaenhammer, T. R. 2001. Invited review: The scientific basis of Lactobacillus acidophilus NCFM functionality as a probiotic. Journal of Dairy Science 84:319-331.

Sanders, M. E. and Huis in’t Veld, J. 1999. Bringing a probiotic-containing functional food to the market: Microbiological, product, regulatory and labeling issues. Antonie van Leeuwenhoek 76:293-315.

Sanders, M. E., Walker, D. C. and Walker, K. M. 1996. Performance of commercial cultures in fluid milk application. Journal of Dairy Science 79:943-953.

Scarpellini, E., Cazzato, A., Lauritano, C., Gabrielli, M., Lupascu, A., Gerardino, L., Abenavoli, L., Petruzzellis, C., Gasbarrini, G. and Gasbarrini, A. 2008. Probiotics: Which and when? Digestive Diseases 26:175-182.

Scheinbach, S. 1998. Probiotics: Functionality and commercial status. Biotechnology Advances 16:581-608.

Schlee, M., Harder, J., Köten, B., Stange, E. F., Wehkamp, J. and Fellermann, K. 2008. Probiotic lactobacilli and VSL\#3 induce enterocyte $\beta$-defensin 2. Clinical and Experimental Immunology 151:528-535.

Shah, N. P. 1999. Probiotic bacteria: Antimicrobial and antimutagenic properties. Probiotica 6:1-3.

Shah, N. P. 2000. Probiotic bacteria: selective enumeration and survival in dairy foods. Journal of Dairy Science 83:894-907.

Shah, N. P. 2004. Probiotics and prebiotics. Agro-Food Industry Hi-tech 15:13-16.

Shah, N. P. 2006. Probiotics and fermented milks. In: Manufacturing yogurt and fermented milks. Chandan, R. C. ed., Blackwell Publishing: Oxford. pp. 341-354.

Shah, N. P. 2007. Functional cultures and health benefits. International Dairy Journal 17:1262-1277. 
Shah, N. P. and Ravula, R. R. 2000. Influence of water activity on fermentation organic acids production and viability of yogurt and probiotic bacteria. Australian Journal of Dairy Technology 55:127-131.

Shortt, C. 1999. The probiotic century: Historical and current perspectives. Trends Food Science Technology 10:411-417.

Somkuti, G. A. and Steinberg, D. H. 1999. Distribution of plasmid-borne stress protein genes in Streptococcus thermophilus and other lactic acid bacteria. Current Microbiology 38:43-47.

Spano, G., Rinaldi, A., Ugliano, M., Moio, L., Beneduce, L. and Massa, S. 2004. A $\beta$ glucosidase gene isolated from wine Lactobacillus plantarum is regulated by abiotic stresses. Journal of Applied Microbiology 98:855-861.

Stanton, C., Coakley, M., Murphy, J. J., Fitzgerald, G., Devery, R. and Ross, R. P. 2002. Development of dairy-based functional foods. Sciences des Aliments 22:439-447.

Staton, C., Ross, R. P., Fitzgerald, G. F. and van Sinderen, D. 2005. Fermented functional foods based on probiotics and their biogenic metabolites. Current Opinion in Biotechnology 16:198-203.

Sukimoto, S., Mahin, A. A. and Sonomoto, K. 2008. Molecular chaperones in lactic acid nacteria: Physiological consequences and biochemical properties. Journal of Bioscience and Bioengineer 106:324-336.

Szabo, A., Langer, T., Schröder, H., Flanagan, J., Bukau, B. and Hartl, F. U. 1994. The ATP hydrolysis-dependent reaction cycle of the Escherichia coli Hsp70 system DnaK, DnaJ, and GrpE. Proceedings of the National Academy of Sciences USA 91:10345-10349.

Talwalkar, A. and Kailasapathy, K. 2003. A review of oxygen toxicity in probiotic yogurts: Influence on the survival of probiotic bacteria and protective techniques. Comprehensive Reviews in Food Science and Food Safety 3:117-124.

Talwalkar, A. and Kailasapathy, K. 2003. Metabolic and biochemical responses of probiotics bacteria in oxygen. Journal of Dairy Science 86:2537-2546.

Talwalkar, A., Miller, C. W., Kailasapathy, K. and Nguyen, M. H. 2004. Effect of packaging materials and dissolved oxygen on the survival of probiotics bacteria in yoghurt. International Journal of Food Science and Technology 39:605-611.

Tamime, A. Y. 2002. Fermented milks: A historical food with modern applications - a review. European Journal of Clinical Nutrition 56:S2-S15. 
Tamime, A. Y., Saarela, M., Sondergaard, A. K., Mistry, V. V. and Shah, N. P. 2005. Production and maintenance of viability of probiotic micro-organisms in dairy products. In: Probiotic Dairy Products. Tamime, A. Y. ed., Blackwell Publishing: Oxford. pp. 39-72.

Taranto, M. P., Medici, M., Perdigon, G., Holgado, A. P. R. and Valdez, G. F. 1998. Evidence for hypocholesterolemic effect of Lactobacillus reuteri in hypercholesterolemic mice. Journal of Dairy Science 81:2336-2340.

Teraguchi, S., Ono, J., Kiyosawa, I. and Okonogi, S. 1987. Oxygen uptake activity and aerobic metabolism of Streptococcus thermophilus STH450. Journal of Dairy Science 70: 514-523.

Tharmaraj, N. and Shah, N. P. 2003. Selective enumeration of Lactobacillus delbrueckii ssp. bulgaricus, Streptococcus thermophilus, Lactobacillus acidophilus, bifidobacteria, Lactobacillus casei, Lactobacillus rhamnosus, and propionibacteria. Journal of Dairy Science 86:2288-2296.

Van de Casteele, S., Vanheuverzwijn, T., Ruyssen, Assche, P. V., Swings, J. and Huys, G. 2006. Evaluation of culture media for selective enumeration of probiotic strains of lactobacilli and bifidobacteria in combination with yoghurt or cheese starters. International Dairy Journal 16:1470-1476.

Van de Guchte, M., Penaud, S., Grimaldi, C., Barbe, V., Bryson, K., Nicolas, P., Robert, C., Oztas, S., Mangenot, S., Couloux, A., Loux, V., Dervyn, R., Bossy, R., Bolotin, A., Batto, J.-M., Walunas, T., Gibrat, J.-F., Bessières, P., Weissenbach, J., Ehrlich, S. D. and Maguin, E. 2006. The complete genome sequence of Lactobacillus bulgaricus reveals extensive and ongoing reductive evolution. Proceedings of the National Academy of Sciences USA103:9274-9279.

Van de Guchte, M., Serror, P., Charvaux, C., Smokvina, T., Ehrlich, S. D. and Maguin, E. 2002. Stress responses in lactic acid bacteria. Antonie van Leeuwenhoek 82:187-216.

Varga, L., Szigeti, J. and Csengeri, É. 2003. Effect of oligofructose on the microflora of and ABT-type fermented milk during refrigerated storage. Milchwissenschaft 58:55-58.

Vaughan, E. E. and Mollet, B. 1999. Probiotics in the new millennium. Nahrung 43:148153.

Vasiljevic, T. and Shah, N. P. 2008 Probiotics - from Metchnikoff to bioactives. International Dairy Journal 18(7):714-728. 
Vedamuthu, E. R. 2006. Starter cultures for yogurt and fermented milks. In: Manufacturing yogurt and fermented milks. Chandan, R. C. ed., Blackwell Publishing: Oxford. pp. 89-115.

Villegas, E. and Gilliland, S. E. 1998. Hydrogen peroxide production by Lactobacillus delbrueckii ssp. lactis at $5^{\circ} \mathrm{C}$. Journal of Food Science 63:65-70.

Vinderola, C. G., Bailo, N. and Reinheimer, J. A. 2000. Survival of probiotic microflora in Argentinian yogurts during storage. Food Research International 33:97-102.

Vinderola, C. G., Mocchiutti, P. and Reinheimer, J. A. 2002. Interaction among lactic acid starter and probiotic bacteria used for fermented dairy products. Journal of Dairy Science 85:721-729.

Vinderola, C. G. and Reinheimer, J. A. 1999. Culture media for the enumeration of Bifidobacterium bifidum and Lactobacillus acidophilus in the presence of yogurt bacteria. International Dairy Journal 9:497-505.

Vorob'eva, L. I. 2004. Stressors, stress reactions, and survival of bacteria: A review. Applied Biochemistry and Microbiology 40:217-224.

Walker, N. 2002. A technique whose time has come. Science 296:557-558.

Walker, D. K. and Gilliland, S. E. 1993. Relationships among bile tolerance, bile salt deconjugation, and assimilation of cholesterol by Lactobacillus acidophilus. Journal of Dairy Science 76:956-961.

Wang, T. and Brown, M. J. 1999. mRNA quantification by real-time TaqMan polymerase chain reaction: Validation and comparison with RNase protection. Analytical Biochemistry 269:198-201.

Wang, Y-C, Yu, R-C. and Chou, C-C. 2002. Growth and survival of bifidobacteria and lactic acid bacteria during the fermentation and storage of cultured soymilk drinks. Food Microbiology 19:501-508.

Weese, J. S. 2002. Microbiological evaluation of commercial probiotics. Journal of the American Veterinary Medical Association 220(6):794-797.

Weis, J. H., Tan, S. S., Martin, B. K. and Wittwer, C. T. 1992. Detection of rare mRNAs via quantitative RT-PCR. Trends in Genetics 8:263-264.

Wetzel, K., Menzel, M. and Heller, K. J. 1999. Stress response in Lactococcus lactis and Streptococcus thermophilus induced by carbon starvation. Kieler Milchwirtschaftliche Forschungsberichte 51:319-332. 
Wintzingerode, F. V., Gobel, U. B. and Stackebrandt, E. 1997. Determination of microbial diversity in environmental samples: Pitfalls of PCR-based rRNA analysis. FEMS Microbiology Reviews 21:213-229.

Yeung,P. S. M., Sanders, M. E., Kitts, C. L., Cano, R. and Tong, P. S. 2002.SpeciesSpecific Identification of Commercial Probiotic Strains. Journal of Dairy Science 85:1039-1051.

Yura, T. and Nakahigashi, K. 1999. Regulation of the heat-shock response. Current Opinion in Microbiology 2:153-158.

Zamorano, P. L., Mahesh, V. B. and Brann, D. W. 1996. Quantitative RT-PCR for neuroendocrine studies - a minirevire. Neuroendocrinology 63:397-407.

Zink, R., Walker, C., Schmidt, G., Elli, M., Pridmore, D. and Reniero, R. 2000. Impact of multiply stress factors on the survival of dairy lactobacilli. Sciences des Aliments 20:119-126. 
APPENDIX A. Carbohydrate fermentation profile using API $50 \mathrm{CH}$ after 24 hours of incubation at $37^{\circ} \mathrm{C}$. Positive reaction is indicated by a color change from purple to yellow (purple to black for esculin), and negative reaction is assigned when the color remain purple. A score of 0 to 2 was given to purple to blue color, and 3 to 5 then was given to green to yellow color. Numerical scores were converted to positive or negative before speciation.

Legend:

\begin{tabular}{|c|c|}
\hline No. & Carbohydrate \\
\hline 0 & Control \\
\hline 1 & Glycerol \\
\hline 2 & Erythriol \\
\hline 3 & D-Arabinose \\
\hline 4 & L-Arabinose \\
\hline 5 & Ribose \\
\hline 6 & D-Xylose \\
\hline 7 & L-Xylose \\
\hline 8 & Adonitol \\
\hline 9 & $\beta$-Methyl-xyloside \\
\hline 10 & Galactose \\
\hline 11 & D-Glucose \\
\hline 12 & D-Fructose \\
\hline 13 & D-Mannose \\
\hline 14 & L-Sorbose \\
\hline 15 & Rhamnose \\
\hline 16 & Dulcitol \\
\hline 17 & Inositol \\
\hline 18 & Mannitol \\
\hline 19 & Sorbitol \\
\hline 20 & $\alpha$-Methyl-D-manniside \\
\hline 21 & $\alpha-$ Methyl-D-glucosamine \\
\hline 22 & N-Acetyl-glucosamine \\
\hline 23 & Amygdaline \\
\hline 24 & Arbutine \\
\hline \multicolumn{2}{|c}{} \\
\hline
\end{tabular}

\begin{tabular}{|c|c|}
\hline No. & Carbohydrate \\
\hline 25 & Esculine \\
\hline 26 & Salicine \\
\hline 27 & Cellobiose \\
\hline 28 & Maltose \\
\hline 29 & Lactose \\
\hline 30 & Melibiose \\
\hline 31 & Saccharose \\
\hline 32 & Trehalose \\
\hline 33 & Inuline \\
\hline 34 & Melezitose \\
\hline 35 & D-Raffinose \\
\hline 36 & Amidone \\
\hline 37 & Glycogene \\
\hline 38 & Xylitol \\
\hline 39 & $\beta$-Gentiobiose \\
\hline 40 & D-Turanose \\
\hline 41 & D-Lyxose \\
\hline 42 & D-Tagatose \\
\hline 43 & D-Fucose \\
\hline 44 & L-Fucose \\
\hline 45 & D-Arabitol \\
\hline 46 & L-Arabitol \\
\hline 47 & Gluconate \\
\hline 48 & 2-Ceto-gluconate \\
\hline 49 & 5-Ceto-gluconate \\
\hline
\end{tabular}




\begin{tabular}{|c|c|c|c|c|c|c|c|c|c|c|c|c|c|c|c|c|c|c|c|c|c|c|c|c|c|c|}
\hline \multirow{2}{*}{ Strain } & \multirow{2}{*}{$\#$} & \multicolumn{25}{|c|}{ Carbohydrate No. } \\
\hline & & 0 & 1 & 2 & 3 & 4 & 5 & 6 & 7 & 8 & 9 & 10 & 11 & 12 & 13 & 14 & 15 & 16 & 17 & 18 & 19 & 20 & 21 & 22 & 23 & 24 \\
\hline \multirow{3}{*}{$\begin{array}{l}\text { ATCC } \\
\text { 700396 }^{1}\end{array}$} & 1 & 0 & 0 & 0 & 0 & 7 & 0 & 0 & 0 & 0 & 0 & 5 & 5 & 5 & 0 & 0 & 0 & 0 & 0 & 0 & 0 & 0 & 0 & 5 & 4 & 0 \\
\hline & 2 & 0 & 0 & 0 & 0 & 0 & 0 & 0 & 0 & 0 & 0 & 5 & 5 & 5 & 0 & 0 & 0 & 0 & 0 & 0 & 0 & 0 & 0 & 5 & 4 & 0 \\
\hline & 3 & 0 & 0 & 0 & 0 & 0 & 0 & 0 & 0 & 0 & 0 & 5 & 5 & 5 & 3 & 0 & 0 & 0 & 0 & 0 & 0 & 0 & 0 & 5 & 3 & 0 \\
\hline \multirow[t]{2}{*}{ LA- $^{1}$} & 1 & 0 & 0 & 0 & 0 & 0 & 0 & 0 & 0 & 0 & 0 & 5 & 5 & 5 & 3 & 0 & 0 & 0 & 0 & 0 & 0 & 0 & 0 & 5 & 3 & 0 \\
\hline & 2 & 0 & 0 & 0 & 0 & 0 & 0 & 0 & 0 & 0 & 0 & 5 & 5 & 5 & 3 & 0 & 0 & 0 & 0 & 0 & 0 & 0 & 0 & 5 & 3 & 0 \\
\hline \multirow[t]{3}{*}{ NCFM $^{1}$} & 1 & 0 & 0 & 0 & 0 & 0 & 0 & 0 & 0 & 0 & 0 & 4 & 5 & 5 & 0 & 0 & 0 & 0 & 0 & 0 & 0 & 0 & 0 & 5 & 4 & 0 \\
\hline & 2 & 0 & 0 & 0 & 0 & 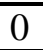 & 0 & 0 & 0 & 0 & 0 & 5 & 5 & 5 & 0 & 0 & 0 & 0 & 0 & 0 & 0 & 0 & 0 & 5 & 4 & 0 \\
\hline & 3 & 0 & 0 & 0 & 0 & 0 & 0 & 0 & 0 & 0 & 0 & 5 & 5 & 5 & 0 & 0 & 0 & 0 & 0 & 0 & 0 & 0 & 0 & 5 & 3 & 5 \\
\hline \multirow{3}{*}{$\begin{array}{l}\text { PIM } \\
7^{103^{1}}\end{array}$} & 1 & 0 & 0 & 0 & 0 & - & 0 & 0 & 0 & 0 & 0 & 0 & 5 & 5 & 5 & 0 & 0 & 0 & 0 & 0 & 0 & 0 & 0 & 5 & 5 & 0 \\
\hline & 2 & 0 & 0 & 0 & 0 & 0 & 0 & 0 & 0 & 0 & 0 & 0 & 5 & 5 & 5 & 0 & 0 & 0 & 0 & 0 & 0 & 0 & 0 & 5 & 4 & 0 \\
\hline & 3 & 0 & 0 & 0 & 0 & 7 & 0 & 0 & 0 & 0 & 0 & 0 & 5 & 5 & 5 & 0 & 0 & 0 & 0 & 0 & 0 & 0 & 0 & 5 & 5 & 0 \\
\hline \multirow{2}{*}{$\begin{array}{l}\text { SBT } \\
\text { 2062 }^{1}\end{array}$} & 1 & 0 & 0 & 0 & 0 & 0 & 0 & 0 & 0 & 0 & 0 & 5 & 5 & 5 & 5 & 0 & 0 & 0 & 0 & 0 & 0 & 0 & 0 & 5 & 0 & 0 \\
\hline & 2 & 0 & 0 & 0 & 0 & 0 & 0 & 0 & 0 & 0 & 0 & 5 & 5 & 3 & 5 & 0 & 0 & 0 & 0 & 0 & 0 & 0 & 0 & 0 & 0 & 0 \\
\hline \multirow[t]{2}{*}{$\mathbf{S T}^{2}$} & 1 & 0 & 0 & 0 & 0 & 0 & 0 & 0 & 0 & 0 & 0 & 0 & 0 & 0 & 0 & 0 & 0 & 0 & 0 & 0 & 0 & 0 & 0 & 0 & 0 & 0 \\
\hline & 2 & 0 & 0 & 0 & 0 & 0 & 0 & 0 & 0 & 0 & 0 & 0 & 0 & 0 & 0 & 0 & 0 & 0 & 0 & 0 & 0 & 0 & 0 & 0 & 0 & 0 \\
\hline \multirow[t]{2}{*}{$\mathbf{L B}^{3}$} & 1 & 0 & 0 & 0 & 0 & 0 & 0 & 0 & 0 & 0 & 0 & 0 & 0 & 0 & 0 & 0 & 0 & 0 & 0 & 0 & 0 & 0 & 0 & 0 & 0 & 0 \\
\hline & 2 & 0 & 0 & 0 & 0 & 0 & 0 & 0 & 0 & 0 & 0 & 0 & 0 & 0 & 0 & 0 & 0 & 0 & 0 & 0 & 0 & 0 & 0 & 0 & 0 & 0 \\
\hline
\end{tabular}

\begin{tabular}{|c|c|c|c|c|c|c|c|c|c|c|c|c|c|c|c|c|c|c|c|c|c|c|c|c|c|c|}
\hline \multirow{2}{*}{ Strain } & \multirow{2}{*}{$\#$} & \multicolumn{25}{|c|}{ Carbohydrate No. } \\
\hline & & 25 & 26 & 27 & 28 & 29 & 30 & 31 & 32 & 33 & 34 & 35 & 36 & 37 & 38 & 39 & 40 & 41 & 42 & 43 & 44 & 45 & 46 & 47 & 48 & 49 \\
\hline \multirow{3}{*}{$\begin{array}{l}\text { ATCC } \\
\text { 700396 }^{1}\end{array}$} & 1 & 5 & 5 & 4 & 5 & 4 & 0 & 5 & 5 & 0 & 0 & 5 & 0 & 0 & 0 & 4 & 0 & 0 & 0 & 0 & 0 & 0 & 0 & 0 & 0 & 0 \\
\hline & 2 & 5 & 5 & 5 & 5 & 5 & 0 & 5 & 5 & 0 & 0 & 5 & 0 & 0 & 0 & 5 & 0 & 0 & 0 & 0 & 0 & 0 & 0 & 0 & 0 & 0 \\
\hline & 3 & 5 & 5 & 5 & 5 & 5 & 0 & 5 & 5 & 0 & 0 & 5 & 0 & 0 & 0 & 3 & 0 & 0 & 0 & 0 & 0 & 0 & 0 & 0 & 0 & 0 \\
\hline \multirow[t]{2}{*}{ LA-5 $^{1}$} & 1 & 5 & 5 & 5 & 5 & 5 & 0 & 5 & 5 & 0 & 0 & 5 & 0 & 0 & 0 & 4 & 0 & 0 & 0 & 0 & 0 & 0 & 0 & 0 & 0 & 0 \\
\hline & 2 & 5 & 5 & 4 & 5 & 5 & 0 & 5 & 5 & 0 & 0 & 5 & 0 & 0 & 0 & 5 & 0 & 0 & 0 & 0 & 0 & 0 & 0 & 0 & 0 & 0 \\
\hline \multirow[t]{3}{*}{ NCFM $^{1}$} & 1 & 5 & 5 & 5 & 5 & 5 & 0 & 5 & 5 & 0 & 0 & 5 & 0 & 0 & 0 & 4 & 0 & 0 & 0 & 0 & 0 & 0 & 0 & 0 & 0 & 0 \\
\hline & 2 & 5 & 5 & 5 & 5 & 5 & 0 & 5 & 5 & 0 & 0 & 5 & 0 & 0 & 0 & 4 & 0 & 0 & 0 & 0 & 0 & 0 & 0 & 0 & 0 & 0 \\
\hline & 3 & 5 & 5 & 5 & 5 & 5 & 0 & 5 & 5 & 0 & 0 & 5 & 0 & 0 & 0 & 3 & 0 & 0 & 0 & 0 & 0 & 0 & 0 & 0 & 0 & 0 \\
\hline \multirow{3}{*}{$\begin{array}{l}\text { PIM } \\
7^{103^{1}}\end{array}$} & 1 & 5 & 5 & 5 & 4 & 5 & 0 & 5 & 5 & 0 & 0 & 0 & 0 & 0 & 0 & 5 & 0 & 0 & 0 & 0 & 0 & 0 & 0 & 0 & 0 & 0 \\
\hline & 2 & 5 & 5 & 5 & 4 & 5 & 0 & 5 & 5 & 0 & 0 & 0 & 0 & 0 & 0 & 5 & 0 & 0 & 0 & 0 & 0 & 0 & 0 & 0 & 0 & 0 \\
\hline & 3 & 5 & 5 & 5 & 3 & 5 & 0 & 5 & 5 & 0 & 0 & 0 & 0 & 0 & $\overline{0}$ & 5 & 0 & 0 & 0 & 0 & 0 & 0 & 0 & 0 & 0 & 0 \\
\hline \multirow{2}{*}{$\begin{array}{l}\text { SBT } \\
\text { 2062 }^{1}\end{array}$} & 1 & 5 & 5 & 3 & 5 & 5 & 0 & 5 & 5 & 0 & 0 & 5 & 0 & 0 & 0 & 0 & 0 & 0 & 0 & 0 & 0 & 0 & 0 & 0 & 0 & 0 \\
\hline & 2 & 5 & 5 & 3 & 5 & 5 & 0 & 5 & 5 & 0 & 0 & 5 & 0 & 0 & 0 & 0 & 0 & 0 & 0 & 0 & 0 & 0 & 0 & 0 & 0 & 0 \\
\hline \multirow[t]{2}{*}{$\overline{\text { ST }^{2}}$} & 1 & 0 & 0 & 0 & 0 & 5 & 0 & 5 & 0 & 0 & 0 & 0 & 0 & 0 & 0 & 0 & 0 & 0 & 0 & 0 & 0 & 0 & 0 & 0 & 0 & 0 \\
\hline & 2 & 0 & 0 & 0 & 0 & 5 & 0 & 5 & 0 & 0 & 0 & 0 & 0 & 0 & 0 & 0 & 0 & 0 & 0 & 0 & 0 & 0 & 0 & 0 & 0 & 0 \\
\hline \multirow[t]{2}{*}{$\mathbf{L B}^{3}$} & 1 & 0 & 0 & 0 & 0 & 4 & 0 & 0 & 0 & 0 & 0 & 0 & 0 & 0 & 0 & 0 & 0 & 0 & 0 & 0 & 0 & 0 & 0 & 0 & 0 & 0 \\
\hline & 2 & 0 & 0 & 0 & 0 & 4 & 0 & 0 & 0 & 0 & 0 & 0 & 0 & 0 & 0 & 0 & 0 & 0 & 0 & 0 & 0 & 0 & 0 & 0 & 0 & 0 \\
\hline
\end{tabular}

${ }^{2}$ Streptococcus thermophilus

${ }^{3}$ Lactobacillus delbrueckii ssp. bulgaricus 
APPENDIX B. Carbohydrate fermentation profile using API $50 \mathrm{CH}$ after 48 hours of incubation at $37^{\circ} \mathrm{C}$. Positive reaction is indicated by a color change from purple to yellow (purple to black for esculin), and negative reaction is assigned when the color remain purple. A score of 0 to 2 was given to purple to blue color, and 3 to 5 then was given to green to yellow color. Numerical scores were converted to positive or negative before speciation.

\begin{tabular}{|c|c|c|c|c|c|c|c|c|c|c|c|c|c|c|c|c|c|c|c|c|c|c|c|c|c|c|}
\hline \multirow{2}{*}{ Strain } & \multirow{2}{*}{ \# } & \multicolumn{25}{|c|}{ Carbohydrate No. } \\
\hline & & 0 & 1 & 2 & 3 & 4 & 5 & 6 & 7 & 8 & 9 & 10 & 11 & 12 & 13 & 14 & 15 & 16 & 17 & 18 & 19 & 20 & 21 & 22 & 23 & 24 \\
\hline \multirow{3}{*}{$\begin{array}{l}\text { ATCC } \\
7^{100396}{ }^{1}\end{array}$} & 1 & 0 & 0 & 0 & c & 0 & 0 & 0 & 0 & 0 & 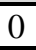 & 5 & 5 & 5 & 5 & 0 & 0 & 0 & 0 & 0 & 0 & 0 & 0 & 5 & 4 & 0 \\
\hline & 2 & 0 & 0 & 0 & 0 & 0 & 0 & 0 & 0 & 0 & 0 & 5 & 5 & 5 & 5 & 0 & 0 & 0 & 0 & 0 & 0 & 0 & 0 & 5 & 5 & 0 \\
\hline & 3 & $\overline{0}$ & 0 & 0 & 0 & 0 & 0 & 0 & 0 & $\overline{0}$ & 0 & 5 & 5 & 5 & 5 & 0 & 0 & 0 & 0 & 0 & 0 & 0 & 0 & 5 & 3 & 0 \\
\hline \multirow[t]{2}{*}{ LA- $^{1}$} & 1 & 0 & 0 & 0 & 0 & 0 & 0 & 0 & 0 & 0 & 0 & 5 & 5 & 5 & 5 & 0 & 0 & 0 & 0 & 0 & 0 & 0 & 0 & 5 & 5 & 0 \\
\hline & 2 & 0 & 0 & 0 & 0 & 0 & 0 & 0 & 0 & 0 & 0 & 5 & 5 & 5 & 5 & 0 & 0 & 0 & 0 & 0 & 0 & 0 & 0 & 5 & 5 & 0 \\
\hline \multirow[t]{3}{*}{ NCFM $^{1}$} & 1 & 0 & 0 & 0 & 0 & 0 & 0 & 0 & 0 & 0 & 0 & 4 & 5 & 5 & 5 & 0 & 0 & 0 & 0 & 0 & 0 & 0 & 0 & 5 & 4 & 0 \\
\hline & 2 & 0 & 0 & 0 & 0 & 0 & 0 & 0 & 0 & 0 & 0 & 5 & 5 & 5 & 5 & 0 & 0 & 0 & 0 & 0 & 0 & 0 & 0 & 5 & 3 & 0 \\
\hline & 3 & $\overline{0}$ & 0 & 0 & 0 & 0 & 0 & 0 & 0 & 0 & 0 & 5 & 5 & 5 & 5 & 0 & 0 & 0 & 0 & 0 & 0 & 0 & 0 & 5 & 3 & 0 \\
\hline \multirow{3}{*}{$\begin{array}{l}\text { PIM } \\
\mathbf{7 0 3}^{1}\end{array}$} & 1 & 0 & 0 & 0 & 0 & 0 & 0 & 0 & 0 & 0 & 0 & 0 & 5 & 5 & 5 & 0 & 0 & 0 & 0 & 0 & 0 & 0 & 0 & 5 & 5 & 0 \\
\hline & 2 & 0 & 0 & 0 & 0 & 0 & 0 & 0 & 0 & 0 & 0 & 0 & 5 & 5 & 5 & 0 & 0 & 0 & 0 & 0 & 0 & 0 & 0 & 5 & 5 & 0 \\
\hline & 3 & $\overline{0}$ & 0 & 0 & 0 & 0 & 0 & 0 & 0 & 0 & 0 & 0 & 5 & 5 & 5 & 0 & 0 & 0 & 0 & 0 & 0 & 0 & 0 & 5 & 5 & 0 \\
\hline \multirow{2}{*}{$\begin{array}{l}\text { SBT } \\
2062^{1}\end{array}$} & 1 & $\overline{0}$ & 0 & 0 & 0 & 0 & 0 & 0 & 0 & 0 & 0 & 5 & 5 & 5 & 5 & 0 & 0 & 0 & 0 & 0 & 0 & 0 & 0 & 5 & 0 & 0 \\
\hline & 2 & 0 & 0 & 0 & 0 & 0 & 0 & 0 & 0 & 0 & 0 & 5 & 5 & 5 & 5 & 0 & 0 & 0 & 0 & 0 & 0 & 0 & 0 & 5 & 0 & 0 \\
\hline \multirow[t]{2}{*}{$\overline{\mathrm{ST}^{2}}$} & 1 & 0 & 0 & 0 & 0 & 0 & 0 & 0 & 0 & 0 & 0 & 0 & 2 & 0 & 0 & 0 & 0 & 0 & 0 & 0 & 0 & 0 & 0 & 0 & 0 & 0 \\
\hline & 2 & 0 & 0 & 0 & 0 & 0 & 0 & 0 & 0 & 0 & 0 & 0 & 0 & 0 & 0 & 0 & 0 & 0 & 0 & 0 & 0 & 0 & 0 & 0 & 0 & 0 \\
\hline \multirow[t]{2}{*}{$\mathbf{L B}^{3}$} & 1 & 0 & 0 & 0 & 0 & 0 & 0 & 0 & 0 & 0 & 0 & 0 & 0 & 0 & 0 & 0 & 0 & 0 & 0 & 0 & 0 & 0 & 0 & 0 & 0 & 0 \\
\hline & 2 & 0 & 0 & 0 & 0 & 0 & 0 & 0 & 0 & 0 & 0 & 0 & 0 & 0 & 0 & 0 & 0 & 0 & 0 & 0 & 0 & 0 & 0 & 0 & 0 & 0 \\
\hline
\end{tabular}

\begin{tabular}{|c|c|c|c|c|c|c|c|c|c|c|c|c|c|c|c|c|c|c|c|c|c|c|c|c|c|c|}
\hline \multirow{2}{*}{ Strain } & \multirow{2}{*}{ \# } & \multicolumn{25}{|c|}{ Carbohydrate No. } \\
\hline & & 25 & 26 & 27 & 28 & 29 & 30 & 31 & 32 & 33 & 34 & 35 & 36 & 37 & 38 & 39 & 40 & 41 & 42 & 43 & 44 & 45 & 46 & 47 & 48 & 49 \\
\hline \multirow{3}{*}{$\begin{array}{l}\text { ATCC } \\
\text { 700396 }^{1}\end{array}$} & 1 & 5 & 5 & 5 & 5 & 5 & 0 & 5 & 5 & 0 & 0 & 5 & 0 & 0 & 0 & 5 & 0 & 0 & 0 & 0 & 0 & 0 & 0 & 0 & 0 & 0 \\
\hline & 2 & 5 & 5 & 5 & 5 & 5 & 0 & 5 & 5 & 0 & 0 & 5 & 0 & 0 & 0 & 5 & 0 & 0 & 0 & 0 & 0 & 0 & 0 & 0 & 0 & 0 \\
\hline & 3 & 5 & 5 & 5 & 5 & 5 & 0 & 5 & 5 & 0 & 0 & 5 & 0 & 0 & 0 & 5 & 0 & 0 & 0 & 0 & 0 & 0 & 0 & 0 & 0 & 0 \\
\hline \multirow[t]{2}{*}{ LA-5 $^{1}$} & 1 & 5 & 5 & 5 & 5 & 5 & 0 & 5 & 5 & 0 & 0 & 5 & 0 & 0 & 0 & 5 & 0 & 0 & 0 & 0 & 0 & 0 & 0 & 0 & 0 & 0 \\
\hline & 2 & 5 & 5 & 5 & 5 & 5 & 0 & 5 & 5 & 0 & 0 & 5 & 0 & 0 & 0 & 5 & 0 & 0 & 0 & 0 & 0 & 0 & 0 & 0 & 0 & 0 \\
\hline \multirow[t]{3}{*}{ NCFM $^{1}$} & 1 & 5 & 5 & 5 & 5 & 5 & 5 & 5 & 5 & 0 & 0 & 5 & 0 & 0 & 0 & 4 & 0 & 0 & 0 & 0 & 0 & 0 & 0 & 0 & 0 & 0 \\
\hline & 2 & 5 & 5 & 5 & 5 & 5 & 0 & 5 & 5 & 0 & 0 & 5 & 0 & 0 & 0 & 4 & 0 & 0 & 0 & 0 & 0 & 0 & 0 & 0 & 0 & 0 \\
\hline & 3 & 5 & 5 & 5 & 5 & 5 & 0 & 5 & 5 & 0 & 0 & 5 & 0 & 0 & 0 & 3 & 0 & 0 & 0 & 0 & 0 & 0 & 0 & 0 & 0 & 0 \\
\hline \multirow{3}{*}{$\begin{array}{l}\text { PIM } \\
7^{103}\end{array}$} & 1 & 5 & 5 & 5 & 5 & 5 & 0 & 5 & 5 & 0 & 0 & 0 & 0 & 0 & 0 & 5 & 0 & 0 & 0 & 0 & 0 & 0 & 0 & 0 & 0 & 0 \\
\hline & 2 & 5 & 5 & 5 & 5 & 5 & 0 & 5 & 5 & 0 & 0 & 0 & 0 & 0 & 0 & 5 & 0 & 0 & 0 & 0 & 0 & 0 & 0 & 0 & 0 & 0 \\
\hline & 3 & 5 & 5 & 5 & 5 & 5 & 0 & 5 & 5 & 0 & 0 & 0 & 0 & 0 & 0 & 5 & 0 & 0 & 0 & 0 & 0 & 0 & 0 & 0 & 0 & 0 \\
\hline \multirow{2}{*}{$\begin{array}{l}\text { SBT } \\
\text { 2062 }^{1}\end{array}$} & 1 & 5 & 5 & 5 & 5 & 5 & 0 & 5 & 5 & 0 & 0 & 5 & 0 & 0 & 0 & 0 & 0 & 0 & 0 & 0 & 0 & 0 & 0 & 0 & 0 & 0 \\
\hline & 2 & 5 & 5 & 5 & 5 & 5 & 0 & 5 & 5 & 0 & 0 & 5 & 0 & 0 & 0 & 0 & 0 & 0 & 0 & 0 & 0 & 0 & 0 & 0 & 0 & 0 \\
\hline \multirow[t]{2}{*}{$\mathrm{ST}^{2}$} & 1 & 0 & 0 & 0 & 0 & 5 & 0 & 5 & 0 & 0 & 0 & 0 & 0 & 0 & 0 & 0 & 0 & 0 & 0 & 0 & 0 & 0 & 0 & 0 & 0 & 0 \\
\hline & 2 & 0 & 0 & 0 & 0 & 5 & 0 & 5 & 0 & 0 & 0 & 0 & 0 & 0 & 0 & 0 & 0 & 0 & 0 & 0 & 0 & 0 & 0 & 0 & 0 & 0 \\
\hline \multirow[t]{2}{*}{$\mathbf{L B}^{3}$} & 1 & 0 & 0 & 0 & 0 & 5 & 0 & 0 & 0 & 0 & 0 & 0 & 0 & 0 & 0 & 0 & 0 & 0 & 0 & 0 & 0 & 0 & 0 & 0 & 0 & 0 \\
\hline & 2 & 0 & 0 & 0 & 0 & 5 & 0 & 0 & 0 & 0 & 0 & 0 & 0 & 0 & 0 & 0 & 0 & 0 & 0 & 0 & 0 & 0 & 0 & 0 & 0 & 0 \\
\hline
\end{tabular}


APPENDIX C. Carbohydrate fermentation profile using API $50 \mathrm{CH}$ after 72 hours of incubation at $37^{\circ} \mathrm{C}$. Positive reaction is indicated by a color change from purple to yellow (purple to black for esculin), and negative reaction is assigned when the color remain purple. A score of 0 to 2 was given to purple to blue color, and 3 to 5 then was given to green to yellow color. Numerical scores were converted to positive or negative before speciation.

\begin{tabular}{|c|c|c|c|c|c|c|c|c|c|c|c|c|c|c|c|c|c|c|c|c|c|c|c|c|c|c|}
\hline \multirow{2}{*}{ Strain } & \multirow{2}{*}{ \# } & \multicolumn{25}{|c|}{ Carbohydrate No. } \\
\hline & & $\mathbf{0}$ & 1 & 2 & 3 & 4 & 5 & 6 & 7 & 8 & 9 & 10 & 11 & 12 & 13 & 14 & 15 & 16 & 17 & \begin{tabular}{|l}
18 \\
\end{tabular} & 19 & 20 & 21 & 22 & 23 & 24 \\
\hline \multirow{3}{*}{$\begin{array}{l}\text { ATCC } \\
\text { 700396 }^{1}\end{array}$} & 1 & 0 & 0 & 0 & 0 & 0 & 0 & 0 & 0 & 0 & 0 & 5 & 5 & 5 & 5 & 0 & 0 & 0 & 0 & 0 & 0 & 0 & 0 & 5 & 4 & 0 \\
\hline & 2 & 0 & 0 & 0 & 0 & 0 & 0 & 0 & 0 & 0 & 0 & 5 & 5 & 5 & 5 & 0 & 0 & 0 & 0 & 0 & 0 & 0 & 0 & 5 & 5 & 0 \\
\hline & 3 & 0 & 0 & 0 & 0 & 0 & 0 & 0 & 0 & 0 & 0 & 5 & 5 & 5 & 5 & 0 & 0 & 0 & 0 & 0 & 0 & 0 & 0 & 5 & 5 & 0 \\
\hline \multirow[t]{2}{*}{ LA- $^{1}$} & 1 & 0 & 0 & 0 & 0 & 0 & 0 & 0 & 0 & 0 & 0 & 5 & 5 & 5 & 5 & 0 & 0 & 0 & 0 & 0 & 0 & 0 & 0 & 5 & 5 & 0 \\
\hline & 2 & 0 & 0 & 0 & 0 & 0 & 0 & 0 & 0 & 0 & 0 & 5 & 5 & 5 & 5 & 0 & 0 & 0 & 0 & 0 & 0 & 0 & 0 & 5 & 5 & 0 \\
\hline \multirow[t]{3}{*}{$\mathrm{NCFM}^{1}$} & 1 & 0 & 0 & 0 & 0 & 0 & 0 & 0 & 0 & 0 & 0 & 5 & 5 & 5 & 5 & 0 & 0 & 0 & 0 & 0 & 0 & 0 & 0 & 5 & 3 & 0 \\
\hline & 2 & 0 & 0 & 0 & 0 & 0 & 0 & 0 & 0 & 0 & 0 & 5 & 5 & 5 & 5 & 0 & 0 & 0 & 0 & 0 & 0 & 0 & 0 & 5 & 5 & 0 \\
\hline & 3 & 0 & 0 & 0 & 0 & 0 & 0 & 0 & 0 & 0 & 0 & 5 & 5 & 5 & 5 & 0 & 0 & 0 & 0 & 0 & 0 & 0 & 0 & 5 & 5 & 0 \\
\hline \multirow{3}{*}{$\begin{array}{l}\text { PIM } \\
703^{1}\end{array}$} & 1 & 0 & 0 & 0 & 0 & 0 & 0 & 0 & 0 & 0 & 0 & 5 & 5 & 5 & 5 & 0 & 0 & 0 & 0 & 0 & 0 & 0 & 0 & 5 & 5 & 0 \\
\hline & 2 & 0 & 0 & 0 & 0 & 0 & 0 & 0 & 0 & 0 & 0 & 3 & 5 & 5 & 5 & 0 & 0 & 0 & 0 & 0 & 0 & 0 & 0 & 5 & 5 & 0 \\
\hline & 3 & 0 & 0 & 0 & 0 & 0 & 0 & 0 & 0 & 0 & 0 & 0 & 5 & 5 & 5 & 0 & 0 & 0 & 0 & 0 & 0 & 0 & 0 & 5 & 5 & 0 \\
\hline \multirow{2}{*}{$\begin{array}{l}\text { SBT } \\
\text { 2062 }^{1}\end{array}$} & 1 & 0 & 0 & 0 & 0 & 0 & 0 & 0 & 0 & 0 & 0 & 5 & 5 & 5 & 5 & 0 & 0 & 0 & 0 & 0 & 0 & 0 & 0 & 5 & 0 & 0 \\
\hline & 2 & 0 & 0 & 0 & 0 & 0 & 0 & 0 & 0 & 0 & 0 & 5 & 5 & 5 & 5 & 0 & 0 & 0 & 0 & 0 & 0 & 0 & 0 & 5 & 0 & 0 \\
\hline \multirow[t]{2}{*}{$\mathrm{ST}^{2}$} & 1 & 0 & 0 & 0 & 0 & 0 & 0 & 0 & 0 & 0 & 0 & 0 & 2 & 0 & 0 & 0 & 0 & 0 & 0 & 0 & 0 & 0 & 0 & 0 & 0 & 0 \\
\hline & 2 & 0 & 0 & 0 & 0 & 0 & 0 & 0 & 0 & 0 & 0 & 0 & 0 & 0 & 0 & 0 & 0 & 0 & 0 & 0 & 0 & 0 & 0 & 0 & 0 & 0 \\
\hline \multirow[t]{2}{*}{$\mathbf{L B}^{3}$} & 1 & 0 & 0 & 0 & 0 & 0 & 0 & 0 & 0 & 0 & 0 & 0 & 0 & 0 & 0 & 0 & 0 & 0 & 0 & 0 & 0 & 0 & 0 & 0 & 0 & 0 \\
\hline & 2 & 0 & 0 & 0 & 0 & 0 & 0 & 0 & 0 & 0 & 0 & 0 & 0 & 0 & 0 & 0 & 0 & 0 & 0 & 0 & 0 & 0 & 0 & 0 & 0 & 0 \\
\hline
\end{tabular}

\begin{tabular}{|c|c|c|c|c|c|c|c|c|c|c|c|c|c|c|c|c|c|c|c|c|c|c|c|c|c|c|}
\hline \multirow{2}{*}{ Strain } & \multirow{2}{*}{ \# } & \multicolumn{25}{|c|}{ Carbohydrate No. } \\
\hline & & 25 & 26 & 27 & 28 & 29 & 30 & 31 & 32 & 33 & 34 & 35 & 36 & 37 & 38 & 39 & 40 & 41 & 42 & 43 & 44 & 45 & 46 & 47 & 48 & 49 \\
\hline \multirow{3}{*}{$\begin{array}{l}\text { ATCC } \\
\text { 700396 }^{1}\end{array}$} & 1 & 5 & 5 & 5 & 5 & 5 & 0 & 5 & 5 & 0 & 0 & 5 & 0 & 0 & 0 & 5 & 0 & 0 & 0 & 0 & 0 & 0 & 0 & 0 & 0 & 0 \\
\hline & 2 & 5 & 5 & 5 & 5 & 5 & 4 & 5 & 5 & 0 & 0 & 5 & 0 & 0 & 0 & 5 & 0 & 0 & 0 & 0 & 0 & 0 & 0 & 0 & 0 & 0 \\
\hline & 3 & 5 & 5 & 5 & 5 & 5 & 0 & 5 & 5 & 0 & 0 & 5 & 0 & 0 & 0 & 5 & 0 & 0 & 0 & 0 & 0 & 0 & 0 & 0 & 0 & 0 \\
\hline \multirow[t]{2}{*}{ LA-5 $^{1}$} & 1 & 5 & 5 & 5 & 5 & 5 & 0 & 5 & 5 & 0 & 0 & 5 & 0 & 0 & 0 & 5 & 0 & 0 & 0 & 0 & 0 & 0 & 0 & 0 & 0 & 0 \\
\hline & 2 & 5 & 5 & 5 & 5 & 5 & 0 & 5 & 5 & 0 & 0 & 5 & 0 & 0 & 0 & 5 & 0 & 0 & 0 & 0 & 0 & 0 & 0 & 0 & 0 & 0 \\
\hline \multirow[t]{3}{*}{$\mathrm{NCFM}^{1}$} & 1 & 5 & 5 & 5 & 5 & 5 & 4 & 5 & 5 & 0 & 0 & 5 & 0 & 0 & 0 & 4 & 0 & 0 & 0 & 0 & 0 & 0 & 0 & 0 & 0 & 0 \\
\hline & 2 & 5 & 5 & 5 & 5 & 5 & 0 & 5 & 5 & 0 & 0 & 5 & 0 & 0 & 0 & 5 & 0 & 0 & 0 & 0 & 0 & 0 & 0 & 0 & 0 & 0 \\
\hline & 3 & 5 & 5 & 5 & 5 & 5 & 0 & 5 & 5 & 0 & 0 & 5 & 0 & 0 & 0 & 3 & 0 & 0 & 0 & 0 & 0 & 0 & 0 & 0 & 0 & 0 \\
\hline \multirow{3}{*}{$\begin{array}{l}\text { PIM } \\
7^{1}{ }^{1}\end{array}$} & 1 & 5 & 5 & 5 & 5 & 5 & 0 & 5 & 5 & 0 & 0 & 4 & 0 & 0 & 0 & 5 & 0 & 0 & 0 & 0 & 0 & 0 & 0 & 0 & 0 & 0 \\
\hline & 2 & 5 & 5 & 5 & 5 & 5 & 0 & 5 & 5 & 0 & 0 & 4 & 0 & 0 & 0 & 5 & 0 & 0 & 0 & 0 & 0 & 0 & 0 & 0 & 0 & 0 \\
\hline & 3 & 5 & 5 & 5 & 5 & 5 & 0 & 5 & 5 & 0 & 0 & 0 & 0 & 0 & 0 & 5 & 0 & 0 & 0 & 0 & 0 & 0 & 0 & 0 & 0 & 0 \\
\hline \multirow{2}{*}{$\begin{array}{l}\text { SBT } \\
\text { 2062 }^{1}\end{array}$} & 1 & 5 & 5 & 5 & 5 & 5 & 0 & 5 & 5 & 0 & 0 & 5 & 0 & 0 & 0 & 0 & 0 & 0 & 0 & 0 & 0 & 0 & 0 & 0 & 0 & 0 \\
\hline & 2 & 5 & 5 & 5 & 5 & 5 & 0 & 5 & 5 & 0 & 0 & 5 & 0 & 0 & 0 & 0 & 0 & 0 & 0 & 0 & 0 & 0 & 0 & 0 & 0 & 0 \\
\hline \multirow[t]{2}{*}{$\overline{\text { ST }^{2}}$} & 1 & 0 & 0 & 0 & 0 & 5 & 0 & 5 & 0 & 0 & 0 & 0 & 0 & 0 & 0 & 0 & 0 & 0 & 0 & 0 & 0 & 0 & 0 & 0 & 0 & 0 \\
\hline & 2 & 0 & 0 & 0 & 0 & 5 & 0 & 5 & 0 & 0 & 0 & 0 & 0 & 0 & 0 & 0 & 0 & 0 & 0 & 0 & 0 & 0 & 0 & 0 & 0 & 0 \\
\hline \multirow[t]{2}{*}{$\mathbf{L B}^{3}$} & 1 & $\overline{0}$ & 0 & 0 & 0 & 5 & 0 & 0 & 0 & 0 & 0 & 0 & 0 & 0 & 0 & 0 & 0 & 0 & 0 & 0 & 0 & 0 & 0 & 0 & 0 & 0 \\
\hline & 2 & 0 & 0 & \begin{tabular}{|l|}
0 \\
\end{tabular} & 0 & 5 & 0 & 0 & 0 & 0 & 0 & 0 & 0 & 0 & 0 & 0 & 0 & 0 & 0 & \begin{tabular}{|l|}
0 \\
\end{tabular} & 0 & 0 & 0 & 0 & \begin{tabular}{|l|}
0 \\
\end{tabular} & 0 \\
\hline
\end{tabular}

${ }^{3}$ Lactobacillus delbrueckii ssp. bulgaricus 
APPENDIX D. Statistical results of survival of L. acidophilus using Minitab software version 15.1

\title{
1. Effect of Yogurt Starter Cultures on Day 28 (General Linear Model: log prop [log survival] versus Block, Yogurt type, Bacteria)
}

\author{
Factor Type Levels Values \\ Block random $31,2,3$ \\ Yogurt type fixed 2 GDL, STLB \\ Bacteria fixed 5 ATCC700396, LA5, NCFM, PIM703, SBT2062
}

Analysis of Variance for log prop, using Adjusted SS for Tests

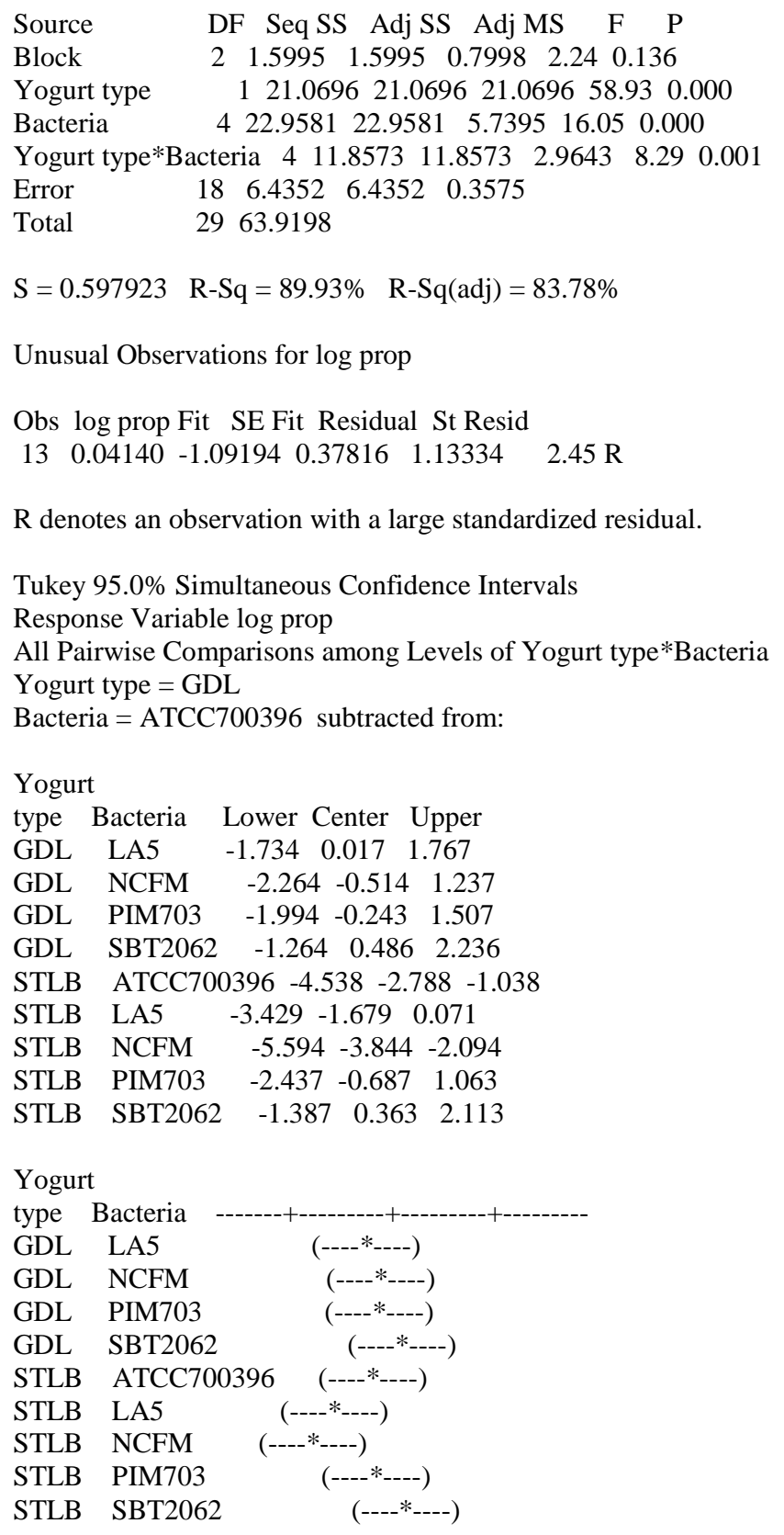


Yogurt type $=$ GDL

Bacteria = LA5 subtracted from:

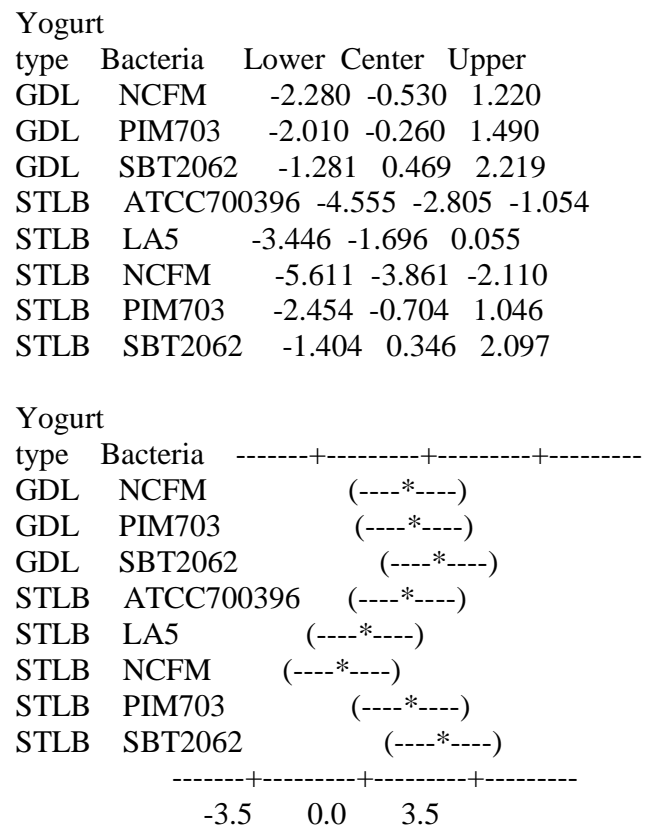

Yogurt type $=$ GDL

Bacteria = NCFM subtracted from:

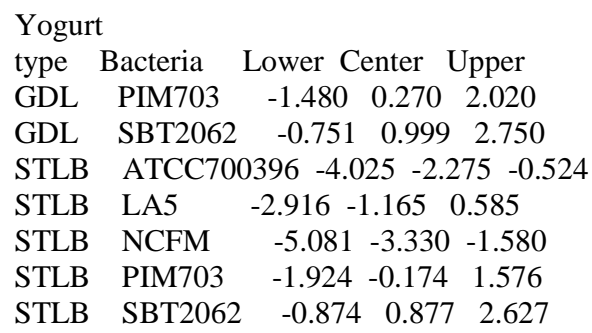

Yogurt

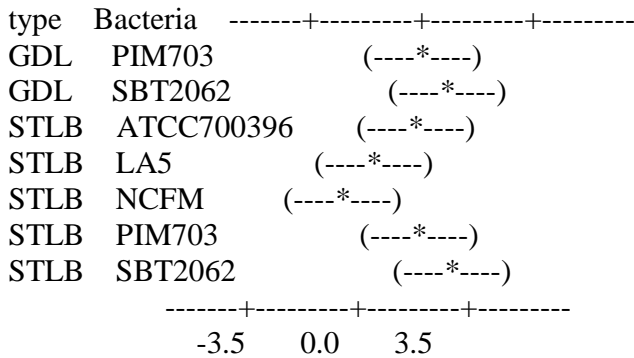

Yogurt type $=$ GDL

Bacteria = PIM703 subtracted from:

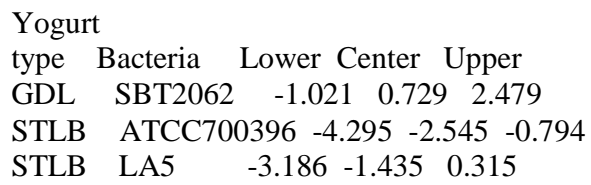




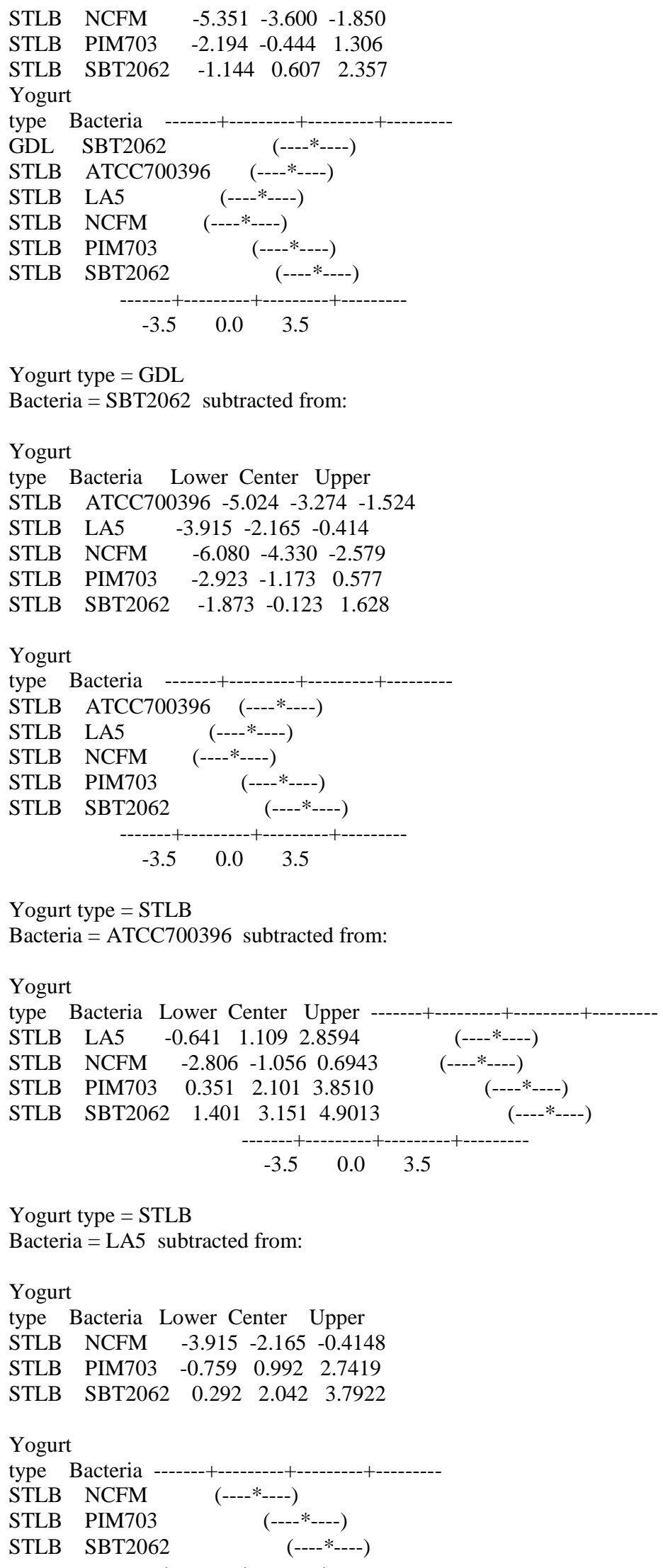


Yogurt type $=$ STLB

Bacteria $=$ NCFM subtracted from:

Yogurt

STLB PIM703 $1.406 \quad 3.1574 .907 \quad$ (----*----)

STLB SBT2062 2.457 4.207 $5.957 \quad$ (----*---)

$-3.5 \quad 0.0 \quad 3.5$

Yogurt type $=$ STLB

Bacteria = PIM703 subtracted from:

Yogurt

type Bacteria Lower Center Upper -------+----------+---------+----------

STLB SBT2062 -0.6999 $1.0502 .801 \quad$ (----*---)

$-3.5 \quad 0.0 \quad 3.5$

Tukey Simultaneous Tests

Response Variable log prop

All Pairwise Comparisons among Levels of Yogurt type*Bacteria

Yogurt type $=$ GDL

Bacteria = ATCC700396 subtracted from:

\begin{tabular}{lllllll}
\multicolumn{2}{l}{$\begin{array}{c}\text { Yogurt } \\
\text { type }\end{array}$} & Bacteria & Difference & \multicolumn{2}{c}{ SE of } & \multicolumn{4}{c}{ Adjusted } \\
of Means & Difference & T-Value & P-Value \\
GDL & LA5 & 0.017 & 0.4882 & 0.034 & 1.0000 \\
GDL & NCFM & -0.514 & 0.4882 & -1.052 & 0.9838 \\
GDL & PIM703 & -0.243 & 0.4882 & -0.499 & 0.9999 \\
GDL & SBT2062 & 0.486 & 0.4882 & 0.995 & 0.9888 \\
STLB & ATCC700396 & -2.788 & 0.4882 & -5.711 & 0.0007 \\
STLB & LA5 & -1.679 & 0.4882 & -3.439 & 0.0663 \\
STLB & NCFM & -3.844 & 0.4882 & -7.874 & 0.0000 \\
STLB & PIM703 & -0.687 & 0.4882 & -1.408 & 0.9095 \\
STLB & SBT2062 & 0.363 & 0.4882 & 0.744 & 0.9986
\end{tabular}

Yogurt type $=$ GDL

Bacteria = LA5 subtracted from:

\begin{tabular}{lllllll}
\multicolumn{1}{l}{$\begin{array}{c}\text { Yogurt } \\
\text { type }\end{array}$} & Bacteria & Difference & \multicolumn{2}{c}{ SE of } & \multicolumn{3}{c}{ Adjusted } \\
of Means & Difference & T-Value & P-Value \\
GDL & NCFM & -0.530 & 0.4882 & -1.086 & 0.9801 \\
GDL & PIM703 & -0.260 & 0.4882 & -0.533 & 0.9999 \\
GDL & SBT2062 & 0.469 & 0.4882 & 0.961 & 0.9912 \\
STLB & ATCC700396 & -2.805 & 0.4882 & -5.745 & 0.0006 \\
STLB & LA5 & -1.696 & 0.4882 & -3.473 & 0.0622 \\
STLB & NCFM & -3.861 & 0.4882 & -7.908 & 0.0000 \\
STLB & PIM703 & -0.704 & 0.4882 & -1.442 & 0.8977 \\
STLB & SBT2062 & 0.346 & 0.4882 & 0.710 & 0.9991
\end{tabular}

Yogurt type $=$ GDL

Bacteria $=$ NCFM subtracted from:

Yogurt Difference SE of Adjusted

type Bacteria of Means Difference T-Value P-Value

$\begin{array}{llllll}\text { GDL } & \text { PIM703 } & 0.270 & 0.4882 & 0.553 & 0.9999\end{array}$

$\begin{array}{llllll}\text { GDL } & \text { SBT2062 } & 0.999 & 0.4882 & 2.047 & 0.5810\end{array}$

$\begin{array}{llllll}\text { STLB } & \text { ATCC700396 } & -2.275 & 0.4882 & -4.659 & 0.0057\end{array}$ 


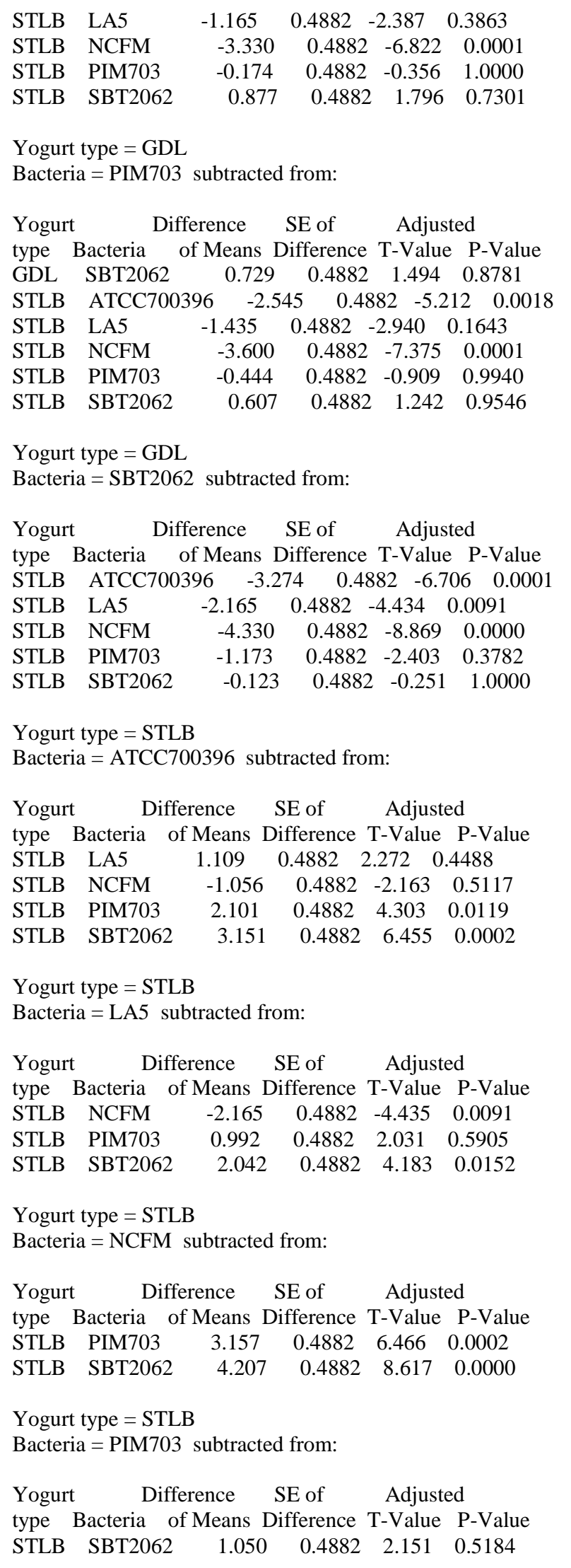



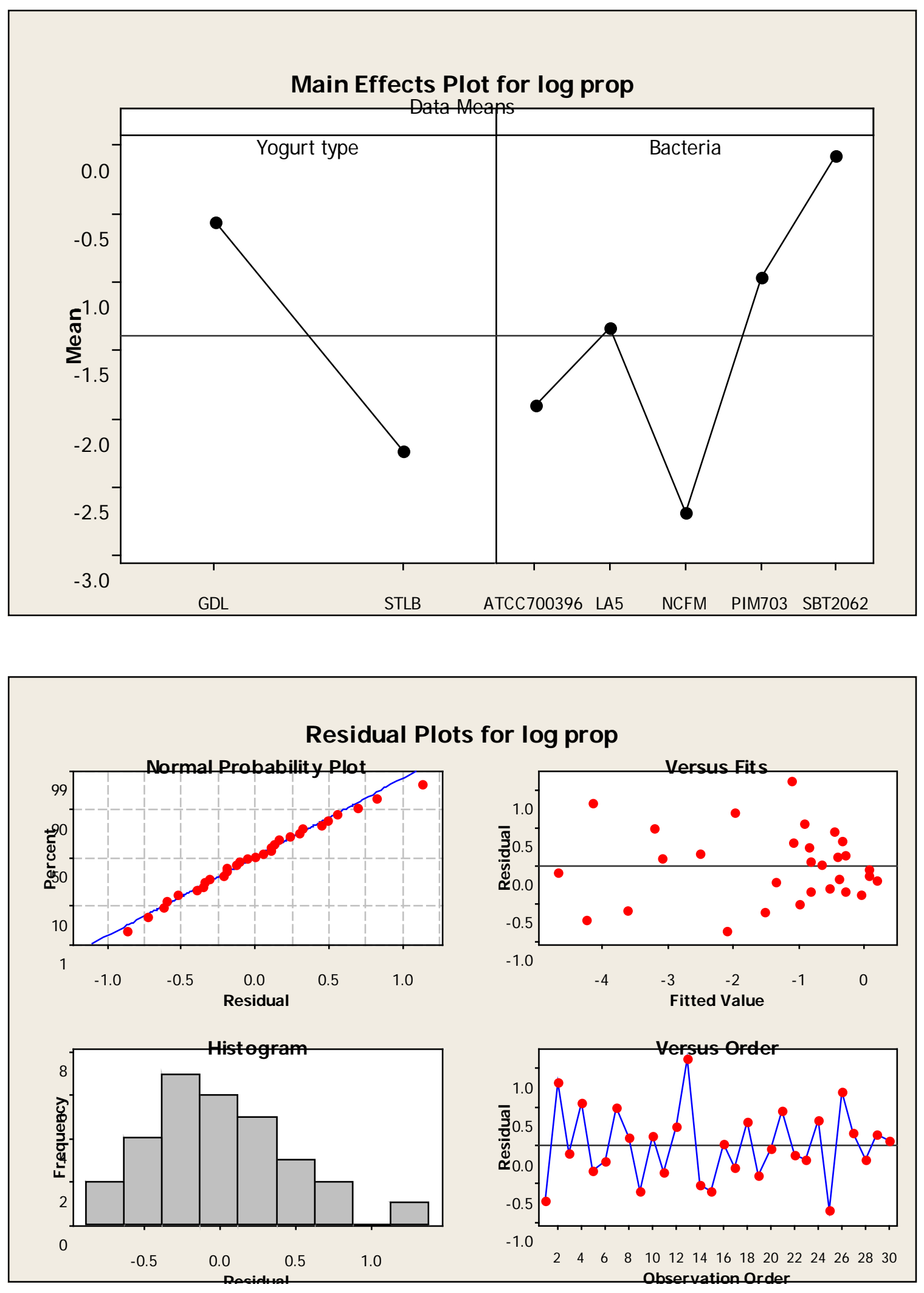


\section{Effect of Individual Starter Culture Species on Day 28 (General Linear Model: log prop [log survival] versus Block, Sample)}

Factor Type Levels Values

Block random $31,2,3$

Sample fixed 4 NCFM-LB, NCFM-ST, SBT2062-LB, SBT2062-ST

Analysis of Variance for log prop, using Adjusted SS for Tests

Source DF Seq SS Adj SS Adj MS F P

$\begin{array}{llllllll}\text { Block } 2 & 1.764 & 1.764 & 0.882 & 0.65 & 0.556\end{array}$

Sample $3 \quad 18.627 \quad 18.627 \quad 6.209 \quad 4.57 \quad 0.054$

$\begin{array}{lllll}\text { Error } & 6 & 8.155 & 8.155 & 1.359\end{array}$

Total 1128.545

$\mathrm{S}=1.16580 \quad \mathrm{R}-\mathrm{Sq}=71.43 \% \quad \mathrm{R}-\mathrm{Sq}(\mathrm{adj})=47.63 \%$

Tukey 95.0\% Simultaneous Confidence Intervals

Response Variable log prop

All Pairwise Comparisons among Levels of Sample

Sample $=$ NCFM-LB subtracted from:

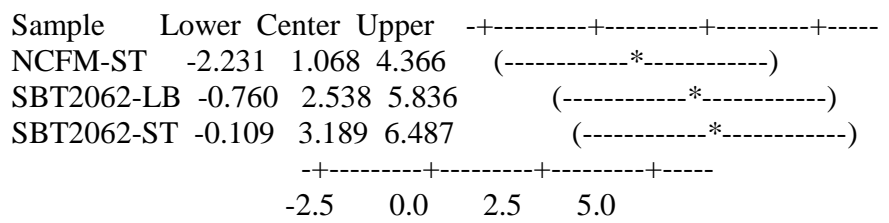

Sample $=$ NCFM-ST subtracted from:

Sample Lower Center Upper -+

SBT2062-LB -1.827 1.4714 .769

SBT2062-ST -1.177 $2.121 \quad 5.419$

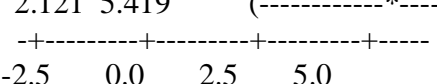

$\begin{array}{llll}-2.5 & 0.0 & 2.5 & 5.0\end{array}$

Sample $=$ SBT2062-LB subtracted from:

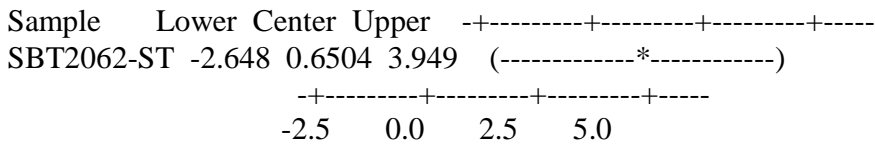

Tukey Simultaneous Tests

Response Variable log prop

All Pairwise Comparisons among Levels of Sample

Sample $=$ NCFM-LB subtracted from:

\begin{tabular}{lccccc}
\multicolumn{2}{c}{ Difference } & \multicolumn{2}{c}{ SE of } & \multicolumn{2}{c}{ Adjusted } \\
Sample of Means & Difference & T-Value & P-Value \\
NCFM-ST & 1.068 & 0.9519 & 1.121 & 0.6911 \\
SBT2062-LB & 2.538 & 0.9519 & 2.667 & 0.1285 \\
SBT2062-ST & 3.189 & 0.9519 & 3.350 & 0.0569
\end{tabular}

Sample $=$ NCFM-ST subtracted from:

Difference SE of Adjusted

Sample of Means Difference T-Value P-Value

$\begin{array}{lllll}\text { SBT2062-LB } & 1.471 & 0.9519 & 1.545 & 0.4700\end{array}$ 
Sample $=$ SBT2062-LB subtracted from:

\begin{tabular}{ccccc} 
Difference & SE of & \multicolumn{2}{c}{ Adjusted } \\
Sample of Means Difference & T-Value & P-Value \\
SBT2062-ST & 0.6504 & 0.9519 & 0.6833 & 0.8998
\end{tabular}

$\begin{array}{lllll}\text { SBT2062-ST } & 0.6504 & 0.9519 & 0.6833 & 0.8998\end{array}$

\section{Residual Plots for log prop}
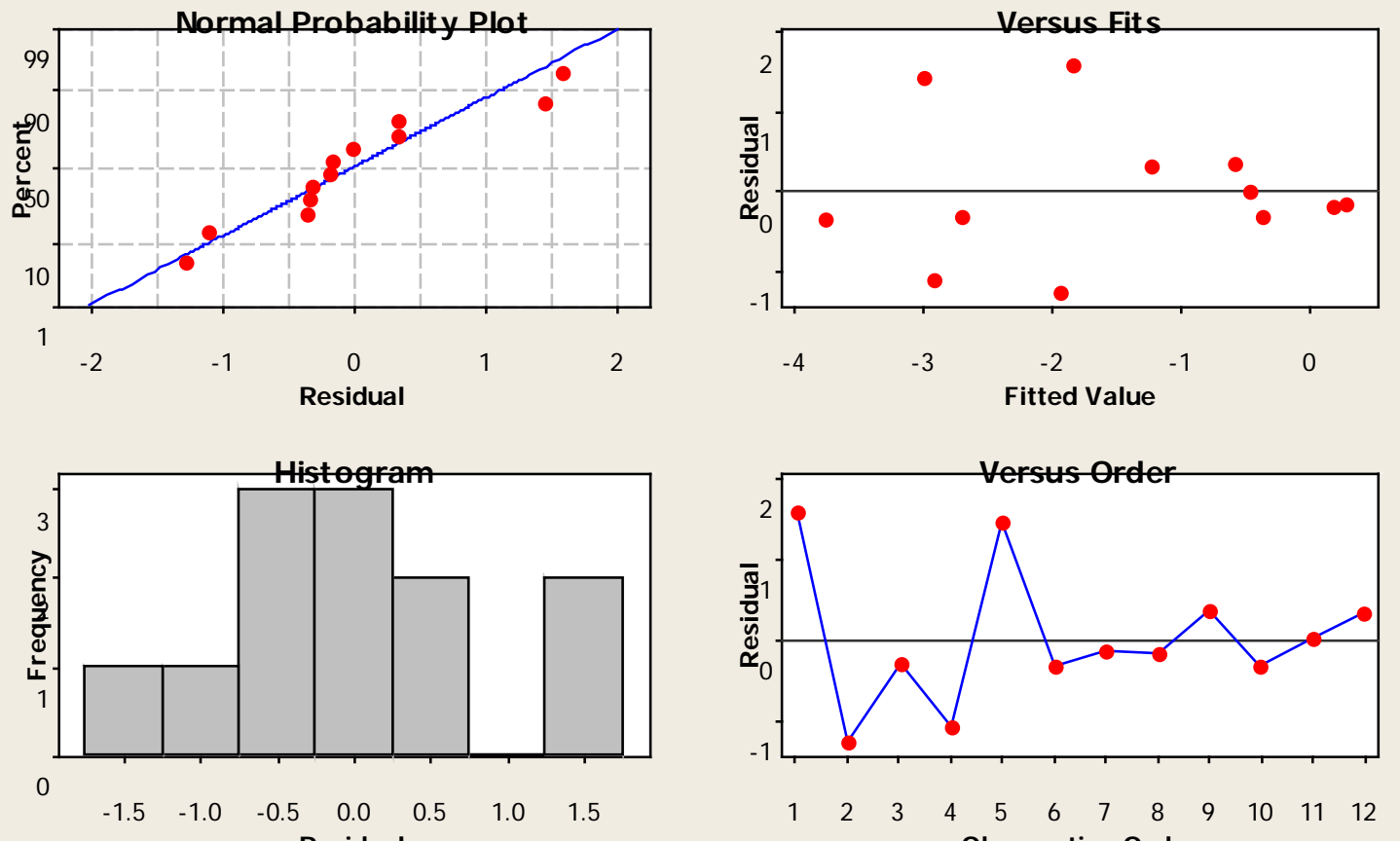

\section{Effect of Yogurt Filtrate on Day 28 (General Linear Model: log prop [log survival] versus Block, Sample)}

Factor Type Levels Values

Block random 21,2

Sample fixed 7 10G, 10S, 1S9G, 2S8G, 5S5G, 8S2G, 9S1G

Analysis of Variance for log prop, using Adjusted SS for Tests

Source DF Seq SS Adj SS Adj MS F P

$\begin{array}{llllllllll}\text { Block } & 1 & 0.00457 & 0.00457 & 0.00457 & 0.07 & 0.805\end{array}$

Sample $\begin{array}{llllll}6 & 0.84334 & 0.84334 & 0.14056 & 2.06 & 0.200\end{array}$

Error $6 \quad 0.40952 \quad 0.40952 \quad 0.06825$

Total 131.25743

$S=0.261254 \quad R-S q=67.43 \% \quad R-S q(\operatorname{adj})=29.44 \%$

Tukey 95.0\% Simultaneous Confidence Intervals Response Variable log prop

All Pairwise Comparisons among Levels of Sample 


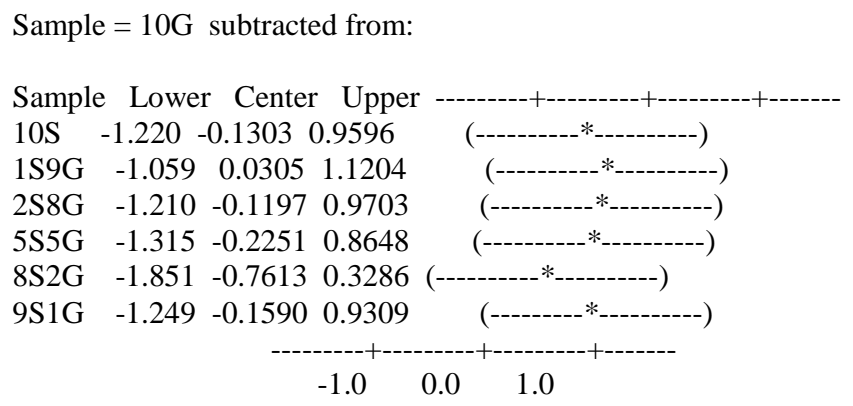

Sample $=10 \mathrm{~S}$ subtracted from:

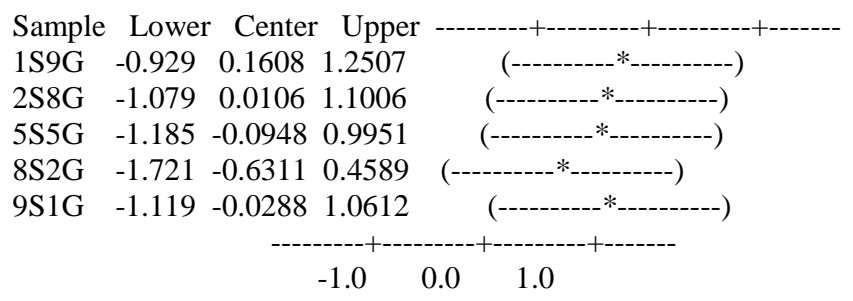

Sample $=1$ S9G subtracted from:

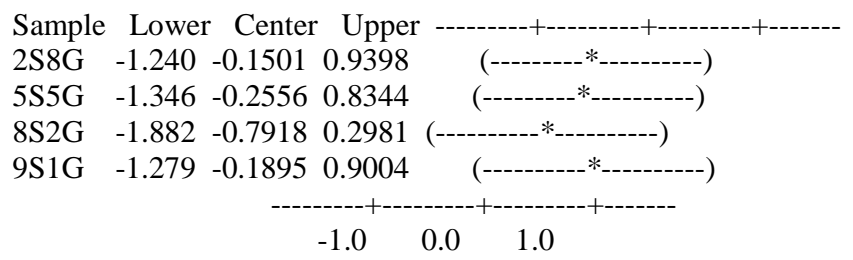

Sample $=$ 2S8G subtracted from:

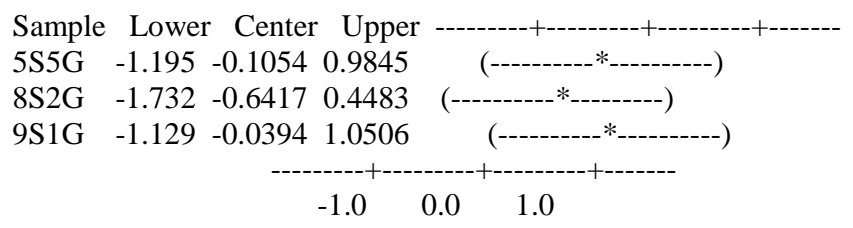

Sample $=5$ S5G subtracted from:

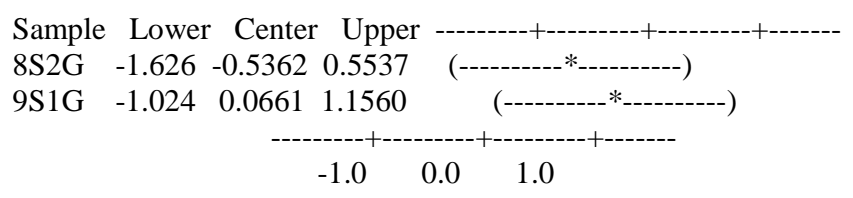

Sample $=8$ S2G subtracted from:

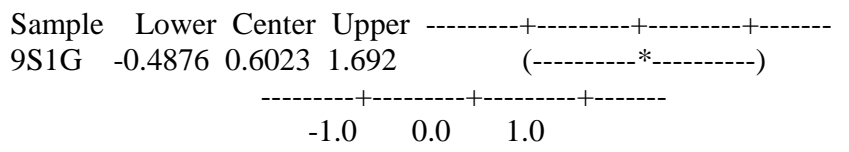

Tukey Simultaneous Tests

Response Variable log prop 
All Pairwise Comparisons among Levels of Sample Sample $=10 \mathrm{G}$ subtracted from:

Difference SE of Adjusted

Sample of Means Difference T-Value P-Value

$\begin{array}{lllll}10 \mathrm{~S} & -0.1303 & 0.2613 & -0.499 & 0.9979\end{array}$

$\begin{array}{lllll}1 S 9 G & 0.0305 & 0.2613 & 0.117 & 1.0000\end{array}$

2S8G $\quad-0.1197 \quad 0.2613 \quad-0.458 \quad 0.9987$

$\begin{array}{lllll}5 \mathrm{~S} 5 \mathrm{G} & -0.2251 & 0.2613 & -0.862 & 0.9666\end{array}$

8S2G $\quad-0.7613 \quad 0.2613 \quad-2.914 \quad 0.1915$

$\begin{array}{lllll}9 S 1 G & -0.1590 & 0.2613 & -0.609 & 0.9938\end{array}$

Sample $=10 \mathrm{~S}$ subtracted from:

Difference SE of Adjusted

Sample of Means Difference T-Value P-Value

$\begin{array}{lllll}\text { 1S9G } & 0.1608 & 0.2613 & 0.615 & 0.9935\end{array}$

2S8G $\quad 0.0106 \quad 0.2613 \quad 0.041 \quad 1.0000$

5S5G $\quad-0.0948 \quad 0.2613 \quad-0.363 \quad 0.9996$

8S2G $\quad-0.6311 \quad 0.2613 \quad-2.415 \quad 0.3269$

$\begin{array}{lllll}9 S 1 G & -0.0288 & 0.2613 & -0.110 & 1.0000\end{array}$

Sample $=1$ S9G subtracted from:

Difference SE of Adjusted

Sample of Means Difference T-Value P-Value

2S8G $\quad-0.1501 \quad 0.2613 \quad-0.575 \quad 0.9954$

5S5G $\quad-0.2556 \quad 0.2613 \quad-0.978 \quad 0.9421$

$\begin{array}{lllll}8 S 2 G & -0.7918 & 0.2613 & -3.031 & 0.1686\end{array}$

$\begin{array}{lllll}9 S 1 G & -0.1895 & 0.2613 & -0.725 & 0.9851\end{array}$

Sample $=$ 2S8G subtracted from:

Difference SE of Adjusted

Sample of Means Difference T-Value P-Value

5S5G $\quad-0.1054 \quad 0.2613 \quad-0.404 \quad 0.9993$

$\begin{array}{lllll}8 S 2 G & -0.6417 & 0.2613 & -2.456 & 0.3133\end{array}$

$\begin{array}{lllll}9 \mathrm{~S} 1 \mathrm{G} & -0.0394 & 0.2613 & -0.151 & 1.0000\end{array}$

Sample $=5$ S5G subtracted from:

Difference SE of Adjusted

Sample of Means Difference T-Value P-Value

$\begin{array}{lllll}8 S 2 G & -0.5362 & 0.2613 & -2.053 & 0.4698\end{array}$

$\begin{array}{lllll}\text { 9S1G } & 0.0661 & 0.2613 & 0.253 & 1.0000\end{array}$

Sample $=8$ S2G subtracted from:

Difference SE of Adjusted Sample of Means Difference T-Value P-Value $\begin{array}{lllll}9 S 1 G & 0.6023 & 0.2613 & 2.305 & 0.3661\end{array}$ 


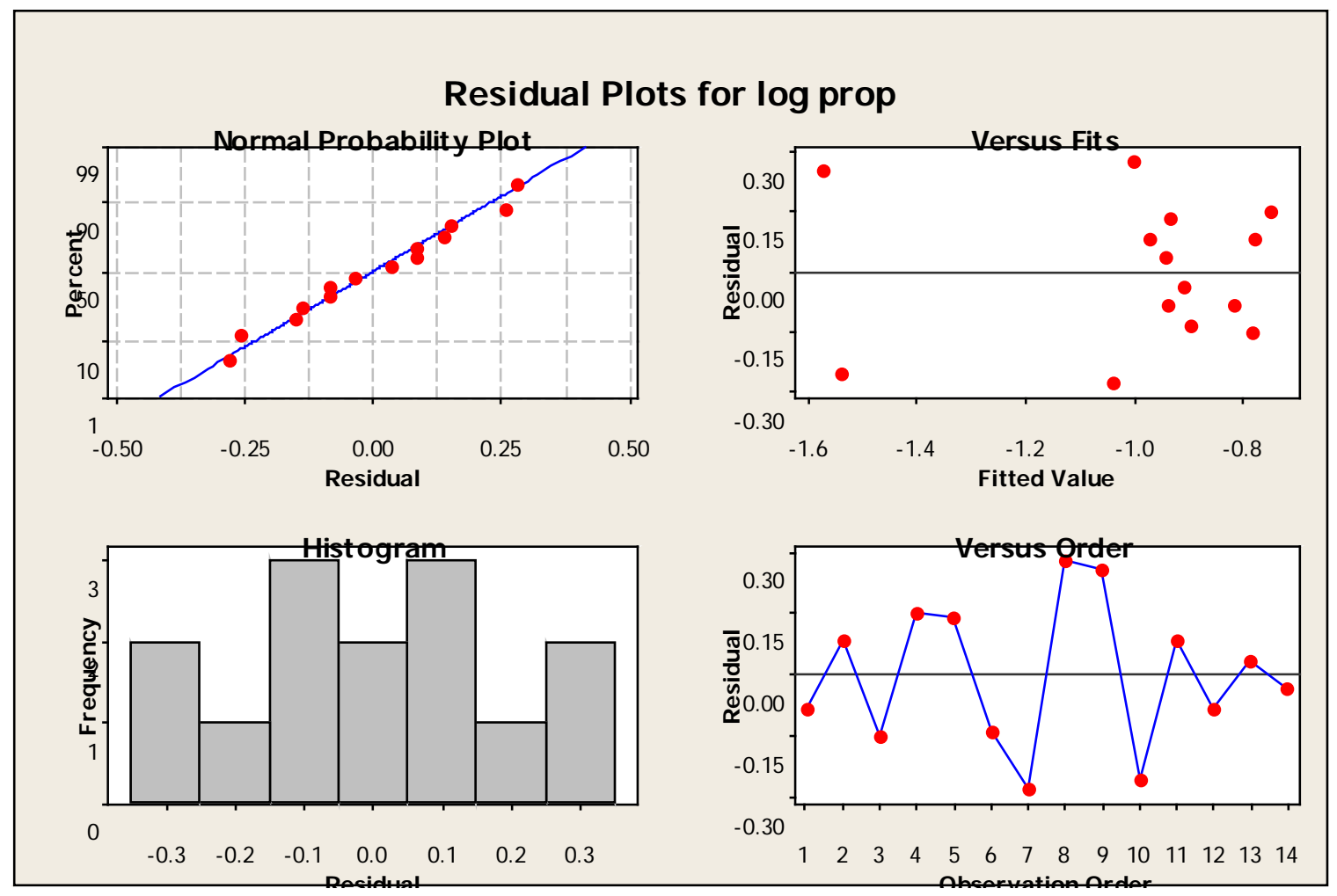

